Cochrane Database of Systematic Reviews

\title{
Intravesical electromotive drug administration for non-muscle invasive bladder cancer (Review)
}

Jung JH, Gudeloglu A, Kiziloz H, Kuntz GM, Miller A, Konety BR, Dahm P

Jung JH, Gudeloglu A, Kiziloz H, Kuntz GM, Miller A, Konety BR, Dahm P.

Intravesical electromotive drug administration for non-muscle invasive bladder cancer.

Cochrane Database of Systematic Reviews 2017, Issue 9. Art. No.: CD011864.

DOI: 10.1002/14651858.CD011864.pub2.

www.cochranelibrary.com 
TABLE OF CONTENTS

PLAIN LANGUAGE SUMMARY

SUMMARY OF FINDINGS

BACKGROUND

OBJECTIVES

METHODS

RESULTS

Figure 1.

Figure 2.

Figure 3.

DISCUSSION

AUTHORS' CONCLUSIONS

ACKNOWLEDGEMENTS

REFERENCES

CHARACTERISTICS OF STUDIES

DATA AND ANALYSES

Analysis 1.1. Comparison 1 Postoperative MMC-EMDA induction versus postoperative BCG induction (short term), Outcome 1

Time to recurrence.

Analysis 1.2. Comparison 1 Postoperative MMC-EMDA induction versus postoperative BCG induction (short term), Outcome 2 Time to progression.

Analysis 1.3. Comparison 1 Postoperative MMC-EMDA induction versus postoperative BCG induction (short term), Outcome 3 Serious adverse events.

Analysis 1.4. Comparison 1 Postoperative MMC-EMDA induction versus postoperative BCG induction (short term), Outcome 4 Disease-specific survival.

Analysis 1.5. Comparison 1 Postoperative MMC-EMDA induction versus postoperative BCG induction (short term), Outcome 5 Time to death.

Analysis 2.1. Comparison 2 Postoperative MMC-EMDA induction versus MMC-PD induction (short term), Outcome 1 Time to recurrence.

Analysis 2.2. Comparison 2 Postoperative MMC-EMDA induction versus MMC-PD induction (short term), Outcome 2 Time to progression.

Analysis 2.3. Comparison 2 Postoperative MMC-EMDA induction versus MMC-PD induction (short term), Outcome 3 Serious adverse events.

Analysis 2.4. Comparison 2 Postoperative MMC-EMDA induction versus MMC-PD induction (short term), Outcome 4 Diseasespecific survival.

Analysis 2.5. Comparison 2 Postoperative MMC-EMDA induction versus MMC-PD induction (short term), Outcome 5 Time to death.

Analysis 3.1. Comparison 3 Postoperative MMC-EMDA with sequential BCG induction and maintenance versus postoperative BCG induction and maintenance (long term), Outcome 1 Time to recurrence.

Analysis 3.2. Comparison 3 Postoperative MMC-EMDA with sequential BCG induction and maintenance versus postoperative BCG induction and maintenance (long term), Outcome 2 Time to progression.

Analysis 3.3. Comparison 3 Postoperative MMC-EMDA with sequential BCG induction and maintenance versus postoperative BCG induction and maintenance (long term), Outcome 3 Serious adverse events.

Analysis 3.4. Comparison 3 Postoperative MMC-EMDA with sequential BCG induction and maintenance versus postoperative BCG induction and maintenance (long term), Outcome 4 Disease-specific survival.

Analysis 3.5. Comparison 3 Postoperative MMC-EMDA with sequential BCG induction and maintenance versus postoperative BCG induction and maintenance (long term), Outcome 5 Time to death.

Analysis 4.1. Comparison 4 Single-dose, preoperative MMC-EMDA versus single-dose, postoperative MMC-PD (long term), Outcome 1 Time to recurrence.

Analysis 4.2. Comparison 4 Single-dose, preoperative MMC-EMDA versus single-dose, postoperative MMC-PD (long term), Outcome 2 Time to progression.

Analysis 4.3. Comparison 4 Single-dose, preoperative MMC-EMDA versus single-dose, postoperative MMC-PD (long term), Outcome 3 Serious adverse events.

Analysis 4.4. Comparison 4 Single-dose, preoperative MMC-EMDA versus single-dose, postoperative MMC-PD (long term), Outcome 4 Disease-specific survival. 
Analysis 4.5. Comparison 4 Single-dose, preoperative MMC-EMDA versus single-dose, postoperative MMC-PD (long term), Outcome 5 Time to death.

Analysis 4.6. Comparison 4 Single-dose, preoperative MMC-EMDA versus single-dose, postoperative MMC-PD (long term), Outcome 6 Minor adverse events.

Analysis 5.1. Comparison 5 Single-dose, preoperative MMC-EMDA versus TURBT alone (long term), Outcome 1 Time to recurrence.

Analysis 5.2. Comparison 5 Single-dose, preoperative MMC-EMDA versus TURBT alone (long term), Outcome 2 Time to progression.

Analysis 5.3. Comparison 5 Single-dose, preoperative MMC-EMDA versus TURBT alone (long term), Outcome 3 Serious adverse events.

Analysis 5.4. Comparison 5 Single-dose, preoperative MMC-EMDA versus TURBT alone (long term), Outcome 4 Disease-specific survival.

Analysis 5.5. Comparison 5 Single-dose, preoperative MMC-EMDA versus TURBT alone (long term), Outcome 5 Time to death. . Analysis 5.6. Comparison 5 Single-dose, preoperative MMC-EMDA versus TURBT alone (long term), Outcome 6 Minor adverse events.

ADDITIONAL TABLES 
[Intervention Review]

\section{Intravesical electromotive drug administration for non-muscle invasive bladder cancer}

Jae Hung Jung1,2,3, Ahmet Gudeloglu4, Halil Kiziloz ${ }^{4}$, Gretchen M Kuntz5, Alea Miller ${ }^{6}$, Badrinath R Konety ${ }^{7}$, Philipp Dahm,7

1Department of Urology, Yonsei University Wonju College of Medicine, Wonju, Korea, South. 2Department of Urology, University of Minnesota, Minneapolis, Minnesota, USA. 3Urology Section, Minneapolis VA Health Care System, Minneapolis, Minnesota, USA. ${ }^{4}$ Department of Urology, Hacettepe University, Ankara, Turkey. ${ }^{5}$ Borland Health Sciences Library, University of Florida-Jacksonville, Jacksonville, Florida, USA. 6Urology Section, Minneapolis VA Health Care System, Minneapolis, Minnesota, USA. ${ }^{7}$ Department of Urology, University of Minnesota, Minneapolis, Minnesota, USA

Contact: Jae Hung Jung, Department of Urology, Yonsei University Wonju College of Medicine, 20 Ilsan-ro, Wonju, Gangwon, 26426, Korea, South.geneuro95@yonsei.ac.kr.

Editorial group: Cochrane Urology Group.

Publication status and date: New, published in Issue 9, 2017.

Citation: Jung JH, Gudeloglu A, Kiziloz H, Kuntz GM, Miller A, Konety BR, Dahm P. Intravesical electromotive drug administration for non-muscle invasive bladder cancer. Cochrane Database of Systematic Reviews 2017, Issue 9. Art. No.: CD011864. DOI: 10.1002/14651858.CD011864.pub2.

Copyright ( 2017 The Cochrane Collaboration. Published by John Wiley \& Sons, Ltd.

\section{A B S T R A C T}

\section{Background}

Electromotive drug administration (EMDA) is the use of electrical current to improve the delivery of intravesical agents to reduce the risk of recurrence in people with non-muscle invasive bladder cancer (NMIBC). It is unclear how effective this is in comparison to other forms of intravesical therapy.

\section{Objectives}

To assess the effects of intravesical EMDA for the treatment of NMIBC.

\section{Search methods}

We performed a comprehensive search using multiple databases (CENTRAL, MEDLINE, EMBASE), two clinical trial registries and a grey literature repository. We searched reference lists of relevant publications and abstract proceedings. We applied no language restrictions. The last search was February 2017.

\section{Selection criteria}

We searched for randomised studies comparing EMDA of any intravesical agent used to reduce bladder cancer recurrence in conjunction with transurethral resection of bladder tumour (TURBT).

\section{Data collection and analysis}

Two review authors independently screened the literature, extracted data, assessed risk of bias and rated quality of evidence (QoE) according to GRADE on a per outcome basis.

\section{Main results}

We included three trials with 672 participants that described five distinct comparisons. The same principal investigator conducted all three trials. All studies used mitomycin C (MMC) as the chemotherapeutic agent for EMDA. 
1. Postoperative MMC-EMDA induction versus postoperative Bacillus Calmette-Guérin (BCG) induction: based on one study with 72 participants with carcinoma in situ (CIS) and concurrent pT1 urothelial carcinoma, we are uncertain (very low QoE) about the effect of MMCEMDA on time to recurrence (risk ratio (RR) 1.06, 95\% confidence interval (CI) 0.64 to 1.76; corresponding to 30 more per 1000 participants, 95\% Cl 180 fewer to 380 more). There was no disease progression in either treatment arm at three months' follow-up. We are uncertain (very low QoE) about serious adverse events (RR 0.75, 95\% $\mathrm{Cl} 0.18$ to 3.11 ).

2. Postoperative MMC-EMDA induction versus MMC-passive diffusion (PD) induction: based on one study with 72 participants with CIS and concurrent pT1 urothelial carcinoma, postoperative MMC-EMDA may (low QoE) reduce disease recurrence (RR $0.65,95 \% \mathrm{Cl} 0.44$ to 0.98; corresponding to 147 fewer per 1000 participants, $95 \% \mathrm{Cl} 235$ fewer to 8 fewer). There was no disease progression in either treatment arm at three months' follow-up. We are uncertain (very low QoE) about the effect of MMC-EMDA on serious adverse events (RR $1.50,95 \%$ $\mathrm{Cl} 0.27$ to 8.45$)$.

3. Postoperative MMC-EMDA with sequential BCG induction and maintenance versus postoperative BCG induction and maintenance: based on one study with 212 participants with pT 1 urothelial carcinoma of the bladder with or without CIS, postoperative MMC-EMDA with sequential BCG may result (low QoE) in a longer time to recurrence (hazard ratio (HR) $0.51,95 \% \mathrm{Cl} 0.34$ to 0.77 ; corresponding to 181 fewer per 1000 participants, $95 \% \mathrm{Cl} 256$ fewer to 79 fewer) and time to progression (HR 0.36, $95 \% \mathrm{Cl} 0.17$ to 0.75 ; corresponding to 63 fewer per 1000 participants, $95 \% \mathrm{Cl} 82$ fewer to 24 fewer). We are uncertain (very low QoE) about the effect of MMC-EMDA on serious adverse events (RR $1.02,95 \% \mathrm{Cl} 0.21$ to 4.94 ).

4. Single-dose, preoperative MMC-EMDA versus single-dose, postoperative MMC-PD: based on one study with 236 participants with primary pTa and pT1 urothelial carcinoma, preoperative MMC-EMDA likely (moderate QoE) results in a longer time to recurrence (HR 0.47 , $95 \%$ Cl 0.32 to 0.69 ; corresponding to 247 fewer per 1000 participants, $95 \% \mathrm{Cl} 341$ fewer to 130 fewer) for a median follow-up of 86 months. We are uncertain (very low QoE) about the effect of MMC-EMDA on time to progression (HR $0.81,95 \% \mathrm{Cl} 0.00$ to 259.93 ; corresponding to 34 fewer per 1000 participants, $95 \% \mathrm{Cl} 193$ fewer to 807 more) and serious adverse events ( $\mathrm{RR} 0.79,95 \% \mathrm{Cl} 0.30$ to 2.05 ).

5. Single-dose, preoperative MMC-EMDA versus TURBT alone: based on one study with 233 participants with primary pTa and pT1 urothelial carcinoma, preoperative MMC-EMDA likely (moderate QoE) results in a longer time to recurrence $(\mathrm{HR} 0.40,95 \% \mathrm{Cl} 0.28$ to 0.57 ; corresponding to 304 fewer per 1000 participants, $95 \% \mathrm{Cl} 390$ fewer to 198 fewer) for a median follow-up of 86 months. We are uncertain (very low QoE) about the effect of MMC-EMDA on time to progression (HR 0.74, 95\% $\mathrm{Cl} 0.00$ to 247.93; corresponding to 49 fewer per 1000 participants, $95 \% \mathrm{Cl} 207$ fewer to 793 more) or serious adverse events (HR 1.74, 95\% Cl 0.52 to 5.77).

\section{Authors' conclusions}

While the use of EMDA to administer intravesical MMC may result in a delay in time to recurrence in select patient populations, we are uncertain about its impact on serious adverse events in all settings. Common reasons for downgrading the QoE were study limitations and imprecision. A potential role for EMDA-based administration of MMC may lie in settings where more established agents (such as BCG) are not available. In the setting of low or very low QoE for most comparisons, our confidence in the effect estimates is limited and the true effect sizes may be substantially different from those reported here.

\section{PLAIN LANGUAGE SUMMARY}

\section{Drug delivery technique using electrical current for the treatment of non-muscle invasive bladder cancer}

\section{Review question}

In people with non-muscle invasive bladder cancer (NMIBC), how do methods using electrical current to deliver a medicine compare to methods without electrical current?

\section{Background}

NMIBC is a cancer (tumour) of the inner lining of the bladder that can be removed from the inside using small instruments and a light source, so-called endoscopic surgery. These tumours can come back over time and spread into the deeper layers of the bladder wall. We know that different types of medicines that we can put into the bladder help prevent this. Investigators have looked at the use of an electrical current to make medicines work better. In this review, we wanted to discover whether using an electrical current was better or worse than not using an electrical current.

\section{Study characteristics}

The evidence is current to 7 February 2017. We found three studies that were conducted between 1994 and 2003 with 672 participants that compared five different ways of giving this treatment. Mitomycin (MMC) was the only medicine used together with electrical current. All three studies came from the same research team.

\section{Key results}


We are very unsure whether the use of an electrical current to give a course of $\mathrm{MMC}$ after endoscopic surgery is better or worse compared to giving a course of Bacillus Calmette-Guérin (BCG; vaccine usually used in tuberculosis) or MMC without electrical current. MMC given with electrical current together with BCG given over a long period of time may be better than BCG alone in delaying the tumour from coming back and from spreading into the deeper layer of the bladder wall. Giving one dose of MMC with electrical current before endoscopic surgery may be better than one dose of MMC without electric current after surgery or surgery alone without further treatment. We are uncertain whether people are more or less likely to have bad reactions from these treatments.

\section{Quality of the evidence}

The quality of evidence was low or very low for most of the treatments we compared, meaning that we were often uncertain about whether the findings were true. Further research will likely change these findings. 


\begin{tabular}{|c|c|c|c|c|c|c|}
\hline 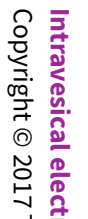 & $\begin{array}{l}\text { S U M M A R Y O F F I N } \\
\text { Summary of findings for } \\
\text { invasive bladder cancer }\end{array}$ & mparison. Post & perative MMC-EML & induction vers & ostoperative B & duction therapy for non-muscle \\
\hline 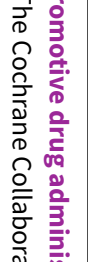 & $\begin{array}{l}\text { Participants: people with } \\
\text { Setting: multicentre study } \\
\text { Intervention: initial } 6 \mathrm{MMC} \\
\text { Control: initial } 6 \mathrm{BCG} \text { intrav }\end{array}$ & $\begin{array}{l}\text { invasive bladder canc } \\
\text { omparisons in the re } \\
\text { vesical instillations a } \\
\text { lations at weekly inte }\end{array}$ & $\begin{array}{l}\text { r (multifocal carcino } \\
\text { ew stemmed from sa } \\
\text { Neekly interval about } \\
\text { al about } 3 \text { weeks aft }\end{array}$ & $\begin{array}{l}\text { in situ or concur } \\
\text { e study group) } \\
\text { weeks after TURE } \\
\text { TURBT }\end{array}$ & TT1, or both) & \\
\hline 苛. & Outcomes & No of participants & Quality of the evi- & Relative effect & Anticipated ab & effects ${ }^{\star}(95 \% \mathrm{Cl})$ \\
\hline  & & & (GRADE) & & Risk with BCG & $\begin{array}{l}\text { Risk difference with postoperative } \\
\text { MMC-EMDA }\end{array}$ \\
\hline$\frac{5}{5}$ & Time to recurrence & & $\oplus \odot \odot \odot$ & RR 1.06 & Study populati & \\
\hline  & Follow-up: mean 3 months & & & & 444 per 1000 & $\begin{array}{l}27 \text { more per } 1000 \\
\text { (160 fewer to } 338 \text { more) }\end{array}$ \\
\hline$\frac{\pi}{2}$ & & & & & Moderate & \\
\hline 产 & & & & & 500 per $1000^{3}$ & $\begin{array}{l}30 \text { more per } 1000 \\
\text { (180 fewer to } 380 \text { more) }\end{array}$ \\
\hline 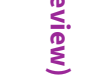 & Time to progression & $\begin{array}{l}72 \\
(1 \mathrm{RCT})\end{array}$ & $\oplus \oplus \odot \ominus$ & Not estimable & Study populati & \\
\hline & Follow-up: mean 3 months & & & & - & - \\
\hline & Serious adverse events & $\begin{array}{l}72 \\
(1 \mathrm{RCT})\end{array}$ & $\begin{array}{l}\oplus \ominus \odot \ominus \\
\text { Verv low } 1,2\end{array}$ & $\begin{array}{l}\text { RR } 0.75 \\
\text { (0.18 to } 3.11)\end{array}$ & Study populati & \\
\hline & Follow-up: mean 3 months & & & & 111 per 1000 & $\begin{array}{l}28 \text { fewer per } 1000 \\
\text { (91 fewer to } 234 \text { more) }\end{array}$ \\
\hline & & & & & High & \\
\hline & & & & & 60 per 10005 & $\begin{array}{l}15 \text { fewer per } 1000 \\
\text { (49 fewer to } 127 \text { more) }\end{array}$ \\
\hline & $\begin{array}{l}\text { Disease-specific survival } \\
\text { Follow-up: mean } 3 \text { months }\end{array}$ & $\begin{array}{l}72 \\
(1 \mathrm{RCT})\end{array}$ & $\begin{array}{l}\oplus \oplus \Theta \Theta \\
\text { Low } 1,4\end{array}$ & Not estimable & Study populati & \\
\hline
\end{tabular}




\begin{tabular}{|c|c|c|c|c|c|}
\hline & & & & & (404 fewer to 14 fewer) \\
\hline & & & & Moderate & \\
\hline & & & & 420 per $1000^{3}$ & $\begin{array}{l}147 \text { fewer per } 1000 \\
\text { ( } 235 \text { fewer to } 8 \text { fewer) }\end{array}$ \\
\hline Time to progression & 72 & $\oplus \oplus \odot \odot$ & Not estimable & Study population & \\
\hline Follow-up: mean 3 months & & & & - & - \\
\hline Serious adverse events & & $\oplus \ominus \ominus \ominus$ & RR 1.50 & Study population & \\
\hline Follow-up: mean 3 months & & & & 56 per 1000 & $\begin{array}{l}28 \text { more per } 1000 \\
\text { ( } 41 \text { fewer to } 414 \text { more) }\end{array}$ \\
\hline & & & & High & \\
\hline & & & & 30 per $1000^{3}$ & $\begin{array}{l}15 \text { more per } 1000 \\
\text { ( } 22 \text { fewer to } 223 \text { more) }\end{array}$ \\
\hline Disease-specific survival & 72 & $\oplus \oplus \odot \odot$ & Not estimable & Study population & \\
\hline Follow-up: mean 3 months & & & & - & - \\
\hline $\begin{array}{l}\text { Disease-specific quality of life - } \\
\text { not reported }\end{array}$ & - & - & - & - & - \\
\hline
\end{tabular}

${ }^{*}$ The risk in the intervention group (and its $95 \%$ confidence interval) is based on the assumed risk in the comparison group and the relative effect of the intervention (and its $95 \% \mathrm{Cl}$ ).

Cl: confidence interval; MMC-EMDA: electromotive drug administration of mitomycin C; MMC-PD: passive diffusion of mitomycin C; RCT: randomised controlled trial; RR: risk ratio; TURBT: transurethral resection of bladder tumour.

\section{GRADE Working Group grades of evidence}

High quality: We are very confident that the true effect lies close to that of the estimate of the effect.

Moderate quality: We are moderately confident in the effect estimate: The true effect is likely to be close to the estimate of the effect, but there is a possibility that it is substantially different.

Low quality: Our confidence in the effect estimate is limited: The true effect may be substantially different from the estimate of the effect.

Very low quality: We have very little confidence in the effect estimate: The true effect is likely to be substantially different from the estimate of effect.

1 Downgraded by one level for study limitations: unclear risk of selection bias, high risk of performance, detection and other bias.

2 Downgraded by one level for imprecision: confidence interval crossed assumed clinically meaningful threshold. 


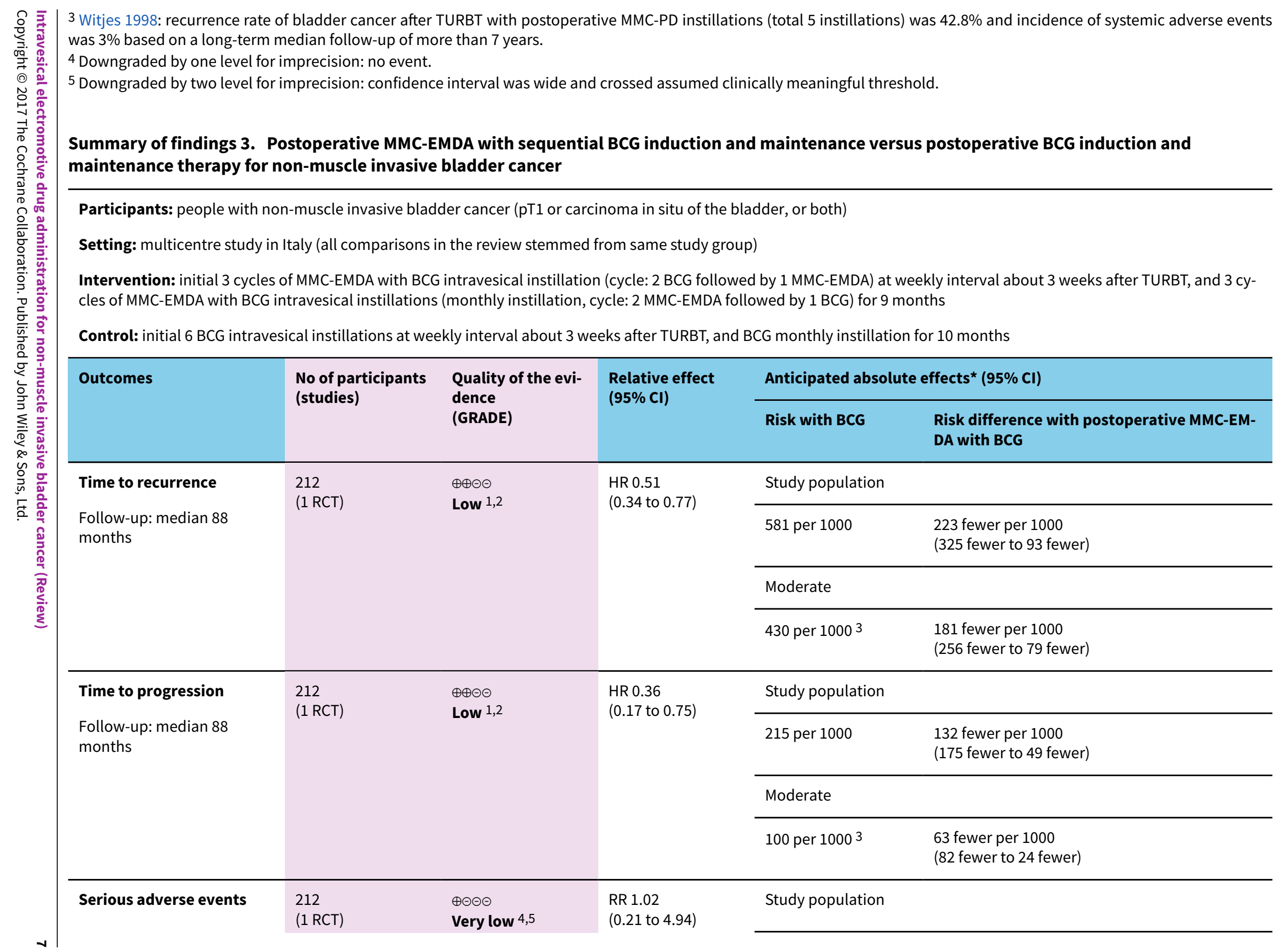




$\begin{array}{ll}70 \text { per } 1000^{3} & 1 \text { more per } 1000 \\ & \text { (55 fewer to } 276 \text { more) }\end{array}$

\begin{tabular}{|c|c|c|c|c|c|}
\hline Disease-specific survival & 212 & $\oplus \oplus \ominus \ominus$ & HR 0.31 & Study population & \\
\hline $\begin{array}{l}\text { Follow-up: median } 88 \\
\text { months }\end{array}$ & & & 10.22 & 159 per 1000 & $\begin{array}{l}107 \text { fewer per } 1000 \\
\text { (138 fewer to } 30 \text { fewer) }\end{array}$ \\
\hline
\end{tabular}

\section{Disease-specific quality of}

life - not reported

${ }^{\star}$ The risk in the intervention group (and its $95 \%$ confidence interval) is based on the assumed risk in the comparison group and the relative effect of the intervention (and its $95 \% \mathrm{Cl})$.

BCG: Bacillus Calmette-Guérin; CI: confidence interval; HR: hazard ratio; MMC-EMDA: electromotive drug administration of mitomycin C; RCT: randomised controlled trial; RR: risk ratio; TURBT: transurethral resection of bladder tumour.

\section{GRADE Working Group grades of evidence}

High quality: We are very confident that the true effect lies close to that of the estimate of the effect.

Moderate quality: We are moderately confident in the effect estimate: The true effect is likely to be close to the estimate of the effect, but there is a possibility that it is substantially different.

Low quality: Our confidence in the effect estimate is limited: The true effect may be substantially different from the estimate of the effect.

Very low quality: We have very little confidence in the effect estimate: The true effect is likely to be substantially different from the estimate of effect.

1 Downgrade by one level for study limitations: unclear risk of selection and attrition bias and high risk of performance and detection bias.

2 Downgrade by one level for imprecision: confidence interval crossed assumed clinically meaningful threshold.

3 Oddens 2013: disease recurrence, progression and disease-specific death after TURBT with BCG maintenance therapy (once a week for 6 weeks, followed by three weekly instillations at months 3, 6 and 12 ) were $42.8 \%, 9.1 \%$ and $5.9 \%$, respectively and stopped treatment due to local or systemic adverse events was $7 \%$ based on a long-term median follow-up of more than 7.1 years.

4 Downgrade by one level for study limitations: unclear risk of selection bias and high risk of performance and detection bias.

5 Downgraded by two level for imprecision: confidence interval was wide and crossed assumed clinically meaningful threshold. 


\begin{tabular}{|c|c|c|c|c|c|}
\hline \multicolumn{6}{|c|}{$\begin{array}{l}\text { Participants: people with non-muscle invasive bladder cancer (primary pTa and pT1 urothelial carcinoma) } \\
\text { Setting: multicentre study in Italy (all comparisons in the review stemmed from same study group) } \\
\text { Intervention: single MMC-EMDA intravesical instillation about } 30 \text { minutes before spinal or general anaesthesia for TURBT } \\
\text { Control: single MMC-PD intravesical instillation immediately after TURBT }\end{array}$} \\
\hline \multirow[t]{2}{*}{ Outcomes } & \multirow{2}{*}{$\begin{array}{l}\text { No of participants } \\
\text { (studies) }\end{array}$} & \multirow{2}{*}{$\begin{array}{l}\text { Quality of the evi- } \\
\text { dence } \\
\text { (GRADE) }\end{array}$} & \multirow{2}{*}{$\begin{array}{l}\text { Relative effect } \\
(95 \% \mathrm{CI})\end{array}$} & \multicolumn{2}{|c|}{ Anticipated absolute effects ${ }^{\star}(95 \% \mathrm{Cl})$} \\
\hline & & & & Risk with MMC-PD & Risk difference with preoperative MMC-EMDA \\
\hline \multirow{6}{*}{$\begin{array}{l}\text { Time to recurrence } \\
\text { Follow-up: median } 86 \\
\text { months }\end{array}$} & \multirow{6}{*}{$\begin{array}{l}236 \\
(1 \mathrm{RCT})\end{array}$} & \multirow{6}{*}{$\begin{array}{l}\oplus \oplus \oplus \ominus \\
\text { Moderate } 1\end{array}$} & \multirow{6}{*}{$\begin{array}{l}\text { HR } 0.47 \\
(0.32 \text { to } 0.69)\end{array}$} & \multicolumn{2}{|l|}{ Study population } \\
\hline & & & & 588 per 1000 & $\begin{array}{l}247 \text { fewer per } 1000 \\
\text { (341 fewer to } 130 \text { fewer) }\end{array}$ \\
\hline & & & & \multicolumn{2}{|l|}{ Low 2} \\
\hline & & & & 100 per 1000 & $\begin{array}{l}52 \text { fewer per } 1000 \\
\text { (67 fewer to } 30 \text { fewer) }\end{array}$ \\
\hline & & & & \multicolumn{2}{|l|}{ High 2} \\
\hline & & & & 500 per 1000 & $\begin{array}{l}222 \text { fewer per } 1000 \\
\text { (301 fewer to } 120 \text { fewer) }\end{array}$ \\
\hline \multirow{6}{*}{$\begin{array}{l}\text { Time to progression } \\
\text { Follow-up: median } 86 \\
\text { months }\end{array}$} & \multirow[t]{6}{*}{$\begin{array}{l}236 \\
(1 \mathrm{RCT})\end{array}$} & \multirow[t]{6}{*}{$\begin{array}{l}\oplus \odot \odot \odot \\
\text { Very low 1,3 }\end{array}$} & \multirow[t]{6}{*}{$\begin{array}{l}\text { HR } 0.81 \\
\text { (0.00 to 259.93) }\end{array}$} & \multicolumn{2}{|l|}{ Study population } \\
\hline & & & & 193 per 1000 & $\begin{array}{l}34 \text { fewer per } 1000 \\
\text { (193 fewer to } 807 \text { more) }\end{array}$ \\
\hline & & & & \multicolumn{2}{|l|}{ Low 2} \\
\hline & & & & 20 per 1000 & $\begin{array}{l}4 \text { fewer per } 1000 \\
\text { (20 fewer to } 975 \text { more) }\end{array}$ \\
\hline & & & & \multicolumn{2}{|l|}{ High 2} \\
\hline & & & & 100 per 1000 & $\begin{array}{l}18 \text { fewer per } 1000 \\
\text { (100 fewer to } 900 \text { more) }\end{array}$ \\
\hline
\end{tabular}




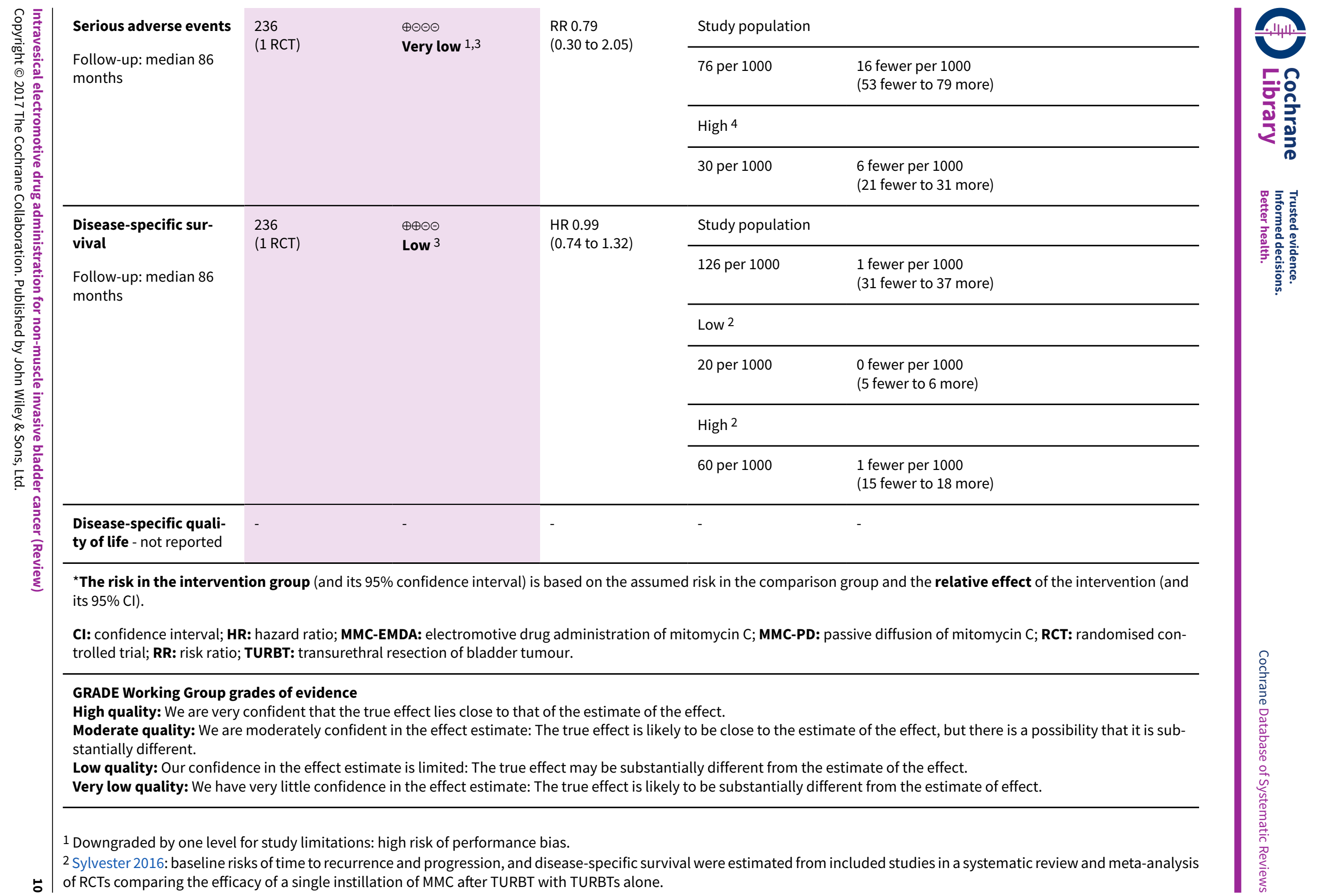




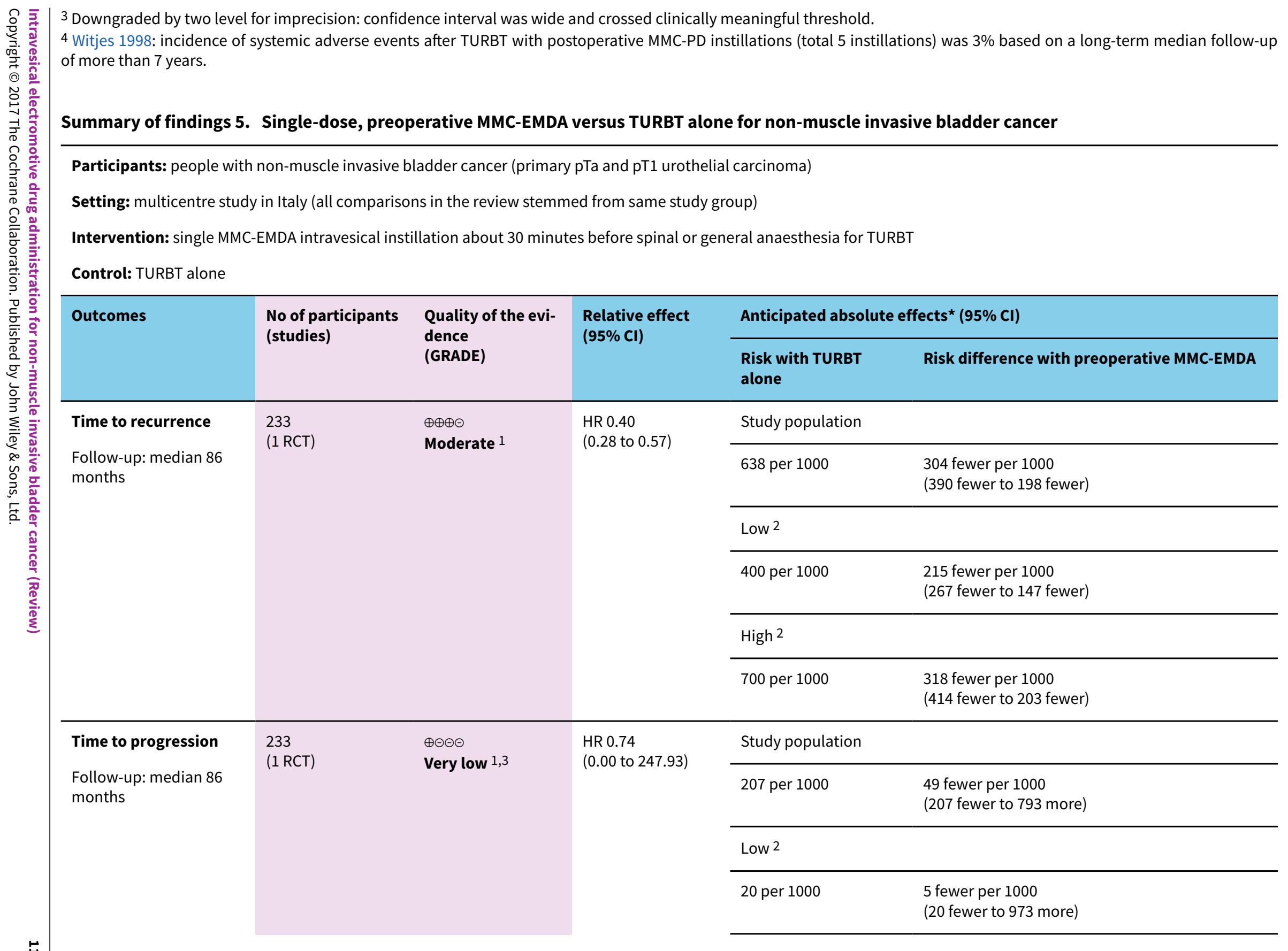




\begin{tabular}{|c|c|c|c|c|c|}
\hline \multirow[b]{2}{*}{$\frac{\bar{D}}{\frac{D}{0}}$} & & & & \multicolumn{2}{|l|}{ High 2} \\
\hline & & & & 100 per 1000 & $\begin{array}{l}25 \text { fewer per } 1000 \\
(100 \text { fewer to } 900 \text { more) }\end{array}$ \\
\hline \multirow{4}{*}{$\begin{array}{l}\text { Serious adverse events } \\
\text { Follow-up: median } 86 \\
\text { months }\end{array}$} & \multirow{4}{*}{$\begin{array}{l}233 \\
(1 \mathrm{RCT})\end{array}$} & \multirow{4}{*}{$\begin{array}{l}\oplus \ominus \ominus \ominus \\
\text { Very low } 1,3\end{array}$} & \multirow{4}{*}{$\begin{array}{l}\text { RR } 1.74 \\
(0.52 \text { to } 5.77)\end{array}$} & \multicolumn{2}{|l|}{ Study population } \\
\hline & & & & 34 per 1000 & $\begin{array}{l}26 \text { more per } 1000 \\
\text { (17 fewer to } 164 \text { more) }\end{array}$ \\
\hline & & & & \multicolumn{2}{|l|}{ Moderate 4} \\
\hline & & & & 30 per 1000 & $\begin{array}{l}22 \text { more per } 1000 \\
\text { (14 fewer to } 143 \text { more) }\end{array}$ \\
\hline \multirow{6}{*}{$\begin{array}{l}\text { Disease-specific sur- } \\
\text { vival } \\
\text { Follow-up: median } 86 \\
\text { months }\end{array}$} & \multirow{6}{*}{$\begin{array}{l}233 \\
(1 \mathrm{RCT})\end{array}$} & \multirow{6}{*}{$\begin{array}{l}\oplus \oplus \oplus \ominus \\
\text { Moderate } 5\end{array}$} & \multirow{6}{*}{$\begin{array}{l}\text { HR } 1.06 \\
(0.80 \text { to } 1.40)\end{array}$} & \multicolumn{2}{|l|}{ Study population } \\
\hline & & & & 129 per 1000 & $\begin{array}{l}7 \text { more per } 1000 \\
\text { (24 fewer to } 47 \text { more) }\end{array}$ \\
\hline & & & & \multicolumn{2}{|l|}{ Low 2} \\
\hline & & & & 20 per 1000 & $\begin{array}{l}1 \text { more per } 1000 \\
\text { (4 fewer to } 8 \text { more) }\end{array}$ \\
\hline & & & & \multicolumn{2}{|l|}{ High 2} \\
\hline & & & & 100 per 1000 & $\begin{array}{l}6 \text { more per } 1000 \\
\text { (19 fewer to } 37 \text { more) }\end{array}$ \\
\hline $\begin{array}{l}\text { Disease-specific quali- } \\
\text { ty of life - not reported }\end{array}$ & - & - & - & - & - \\
\hline \multicolumn{6}{|c|}{$\begin{array}{l}{ }^{*} \text { The risk in the intervention group (and its } 95 \% \text { confidence interval) is based on the assumed risk in the comparison group and the relative effect of the intervention (and } \\
\text { its } 95 \% \mathrm{Cl} \text { ). }\end{array}$} \\
\hline \multicolumn{6}{|c|}{$\begin{array}{l}\text { CI: confidence interval; HR: hazard ratio; MMC-EMDA: electromotive drug administration of mitomycin C; RCT: randomised controlled trial; RR: risk ratio; TURBT: } \\
\text { transurethral resection of bladder tumour. }\end{array}$} \\
\hline
\end{tabular}

\section{GRADE Working Group grades of evidence}

High quality: We are very confident that the true effect lies close to that of the estimate of the effect.

Moderate quality: We are moderately confident in the effect estimate: The true effect is likely to be close to the estimate of the effect, but there is a possibility that it is substantially different.

Low quality: Our confidence in the effect estimate is limited: The true effect may be substantially different from the estimate of the effect. 
Very low quality: We have very little confidence in the effect estimate: The true effect is likely to be substantially different from the estimate of effect.

1 Downgraded by one level for study limitations: high risk of performance bias.

2 Sylvester 2016: baseline risks of time to recurrence and progression, and disease-specific survival were estimated from included studies in a systematic review and meta-analysis of RCTs comparing the efficacy of a single instillation of MMC after TURBT with TURBT alone.

3 Downgraded by two level for imprecision: confidence interval was wide and crossed assumed clinically meaningful threshold.

Matulewicz 2015: rates of death and overall adverse events rate after TURBT were $2.8 \%$ and $5.8 \%$

5 Downgraded by one level for imprecision: confidence interval crossed assumed clinically meaningful threshold. 


\section{B A C K G R O U N D}

\section{Description of the condition}

Urothelial carcinoma of the bladder is the sixth most common cancer in men and the 19th most common cancer in women (Ferlay 2013). It is estimated that the age-standardised incidence rate is 5.3 per 100,000 and mortality rate is 1.9 per 100,000 for both sexes (Ferlay 2013). Based on their prognostic risk, people with urothelial bladder cancer can be broadly categorised into those with non-muscle invasive bladder cancer (NMIBC) and those with muscle invasive bladder cancer (MIBC). People with NMIBC are at risk for recurrence of the tumour as well as progression to MIBC, which is associated with the risk of lymphatic and vascular metastatic spread and portends a markedly worse prognosis. Approximately $75 \%$ of people with bladder cancer have NMIBC at the time of diagnosis (Babjuk 2017). NMIBC can be localised either to the mucosa (Ta or carcinoma in situ; CIS) or to the submucosa (T1). Important risk factors for NMIBC are incorporated in the European Organisation for Research and Treatment of Cancer (EORTC) scoring system, which includes six clinical and pathological factors (i.e. number of tumours, tumour size, prior recurrence rate, $\mathrm{T}$ category, presence of concurrent $\mathrm{CIS}$ and tumour grade) to predict short- and long-term probabilities of recurrence and progression (Sylvester 2006). Based on these parameters, people with NMIBC can be stratified into three risk groups (i.e. low risk, intermediate risk and high risk) using EORTC recurrence and progression parameters (Babjuk 2017; Brausi 2011). CIS is a flat and non-invasive urothelial carcinoma; however, people with CIS are at high risk of progression (Sylvester 2005). Approximately 54\% of these people progress to MIBC when no treatment is given (Lamm 1992).

Standard treatment for NMIBC is complete transurethral resection of bladder tumour (TURBT), followed by close cystoscopic surveillance and intermittent upper tract imaging. After TURBT alone, five-year-recurrence risk varies from $31 \%$ (for Ta, low-grade tumours) to $78 \%$ (for T1, high-grade tumours), while progression risk varies from $0.8 \%$ to $45 \%$ (Sylvester 2006). In addition, it is recommended that select patients at high risk for recurrence, progression, or both, undergo adjuvant intravesical treatment (Babjuk 2017; Chang 2016).

Two approaches to intravesical treatment are routinely used. First, intravesical chemotherapy instillation immediately after TURBT is recommended to destroy exfoliated tumour cells and residual tumour cells at the resection site (Babjuk 2017). One systematic review by Sylvester et al. demonstrated that a single intravesical chemotherapy instillation after TURBT reduced the recurrence rate when compared to TURBT alone $(48.4 \%$ versus $36.7 \%, \mathrm{P}<0.0001)$ (Sylvester 2004).

Second, intravesical agents can be used in delayed, adjuvant settings to reduce the risk of recurrence (Shelley 2000). Of these, intravesical immunotherapy with Bacillus Calmette-Guérin (BCG), given by induction and maintenance regimens, has been shown to be more effective than intravesical chemotherapy with agents such as mitomycin or epirubicin (Shang 2011; Shelley 2003). Despite adjuvant BCG treatment, the risk of recurrence (39\%) and progression (10\%) remains high (Böhle 2003; Sylvester 2002). Moreover, cystitis symptoms are very common (Brausi 2014; Shang 2011). Despite some studies that have demonstrated improved compliance rates, treatment discontinuation due to adverse effects remains an issue (Brausi 2014; Lamm 2000; Saint 2001).

Because of the limited effectiveness and side effect profiles of these agents, there is considerable interest in alternative agents and delivery forms. An innovative approach to adjuvant therapy is electromotive drug administration (EMDA). Similar to EMDA, hyperthermia may also potentiate the cytotoxic effect of chemotherapeutic agents. There are promising, improved outcomes with thermochemotherapy modalities in other types of cancer, as well as bladder cancer (Maffezzini 2014; Van Driel 2015).

\section{Description of the intervention}

EMDA represents a novel intravesical drug administration modality for people with bladder cancer. It is defined as the intravesical instillation of a drug, accompanied by electrical current, designed to promote drug uptake. EMDA can be used for immediate (before or after TURBT) induction or maintenance treatment for NMIBC (Di Stasi 2003; Di Stasi 2006; Di Stasi 2011).

\section{How the intervention might work}

One ex-vivo study suggested that EMDA of mitomycin increased the mitomycin tissue concentration in urothelium, lamina propria and superficial muscle layers in fresh human bladder tissue when compared with the passive diffusion of mitomycin C (MMC-PD; Di Stasi 1999). Additionally, previous reports showed a significant increase in peak plasma mitomycin levels in electromotive mitomycin administration when compared with MMC-PD (Di Stasi 1999). The combined effects are thought to be the basis for a potentially increased therapeutic effect of EMDA compared with PD.

\section{Why it is important to do this review}

While EMDA has the potential to improve the outcomes of people with NMIBC (Brausi 1998; Di Stasi 1999), there has been no systematic review to critically appraise the current best evidence on the therapeutic effectiveness and adverse effects of EMDA. We performed this review to provide a methodologically rigorous systematic review that included a comprehensive literature search, a focus on patient-important outcomes and rating of the quality of the evidence (QoE) using GRADE. We expect this review to be helpful to guide clinicians', guideline developers' and policymakers' decision-making about the use and implementation of EMDA technology in NMIBC.

\section{O B JECT IVES}

To assess the effects of the intravesical EMDA treatment modality for NMIBC.

\section{METHODS}

\section{Criteria for considering studies for this review}

\section{Types of studies}

We searched for randomised and quasi-randomised studies, which we included regardless of their publication status or language of publication.

\section{Types of participants}

We included studies of participants with NMIBC (Ta, T1 or CIS), as determined by pathological evaluation of the TURBT, with no 
lymph node involvement and no metastases (clinically N0, M0). We considered studies of participants with both primary and recurrent disease. We excluded trials that included participants with known MIBC, non-urothelial type bladder cancer or upper urinary tract urothelial carcinoma at the time of presentation.

According to our published protocol (Gudeloglu 2015), we planned to classify participants who had NMIBC as using low-, intermediate- or high-risk categories in accordance with the European Association of Urology (EAU) classification system (Babjuk 2017).

\section{Types of interventions}

We planned to investigate the following comparisons of experimental intervention versus comparator intervention. Concomitant interventions had to be the same in the experimental and comparator groups to establish fair comparisons.

\section{Experimental interventions}

- EMDA of any intravesical chemotherapeutic agent (e.g. mitomycin, epirubicin, gemcitabine or other).

We excluded studies of other types of drug delivery methods such as chemohyperthermia, which is based on a different mechanism of action than EMDA.

\section{Comparator interventions}

- Placebo.

- Passive instillation of any chemotherapeutic agent.

- BCG instillation.

- TURBT without intravesical instillation.

\section{Comparisons}

- EMDA of any intravesical chemotherapeutic agent versus placebo.

- EMDA of any intravesical chemotherapeutic agent versus passive instillation of any chemotherapeutic agent.

- EMDA of any intravesical chemotherapeutic agent versus BCG instillation.

- EMDA of any intravesical chemotherapeutic agent versus TURBT without intravesical instillation.

We distinguished and separately analysed the use of EMDA in the preoperative setting and postoperative, adjuvant setting. We expected to find multiple distinct comparisons between EMDA with each chemotherapeutic agent and passive instillation of any chemotherapeutic agent, placebo, BCG, or TURBT alone. These comparisons were separately performed and analysed for both the preoperative and postoperative settings.

There were no eligibility criteria related to delivery, dosing, duration, and intensity of experimental and comparator interventions.

If a study included more than two intervention arms, we included only those experimental and comparator intervention groups that met the eligibility criteria of the review.

\section{Types of outcome measures}

We did not use the measurement of the outcomes included in this review as an eligibility criterion.

\section{Primary outcomes}

- Time to recurrence.

- Time to progression.

- Serious adverse events.

\section{Secondary outcomes}

- Disease-specific survival.

- Time to death due to any cause.

- Minor adverse events.

- Disease-specific quality of life.

\section{Method and timing of outcome measurement}

- Time to recurrence: measured from the date of randomisation to the date of biopsy or resection, with confirmation of tumour of any grade or stage.

- Time to progression: measured from the date of randomisation to the date of biopsy or resection, with confirmation of MIBC (development of muscle invasive disease).

- Serious adverse events: determined the Common Toxicity Criteria Grade 3 or higher complications as serious (e.g. intraperitoneal bladder injury and need to surgically repair, sepsis). If the authors did not use Common Toxicity Criteria, we graded the adverse events as described in the respective studies.

- Disease-specific survival: measured from the date of randomisation to the date of death from bladder cancer.

- Time to death due to any cause: measured from the date of randomisation to date of death from any cause.

- Minor adverse events: determined the Common Toxicity Criteria Grade 1 or 2 complications as minor (e.g. haematuria, dysuria). If the authors did not use Common Toxicity Criteria, we graded the adverse events as described in the respective studies.

- Disease-specific quality of life: mean change assessed with validated questionnaire such as EORTC core quality of life questionnaire version 3.0 (QLQ C-30).

We used previously reported minimally clinical important difference (MCID) for the review outcomes to rate overall QoE in 'Summary of finding' tables (Jaeschke 1989; Johnston 2013). When the mean difference (MD), risk ratio (RR), or hazard ratio (HR) was equal to or larger than the MCID, we considered that many participants may have gained detectable benefits from treatment (Johnston 2013). We considered MCIDs of EORTC QLQ C-30 based on the previous literature (Bedard 2014). In settings where we could not find established thresholds for MCID in the literature, we used a relative risk reduction of at least $25 \%$ based on guidance by Guyatt 2011a.

We planned to assess the outcomes as short-term, mid-term and long-term outcomes.

- Short-term: up to six months after randomisation.

- Mid-term: later than six months up to 24 months.

- Long-term: later than 24 months. 
When there were insufficient data to analyse time-to-event outcomes, we assessed event rate for dichotomised outcomes (e.g. recurrence, mortality) at the time points of completion of the primary intervention. To allow meaningful interpretation, we truncated data analysis at three months for Di Stasi 2003 at the time point when treatment deviated from the standard of care (further course of intravesical therapy instead of TURBT) and subsequent cross-over at six months.

\section{Main outcomes for 'Summary of findings' table}

- Time to recurrence.

- Time to progression.

- Serious adverse events.

- Disease-specific survival.

- Disease-specific quality of life.

\section{Search methods for identification of studies}

We employed a combination of electronic and manual searches. No language restrictions were imposed.

\section{Electronic searches}

We initially searched the following sources from inception of each database to 1 June 2016. We re-ran the searches in all relevant databases on 7 February 2017, and incorporated any identified relevant studies into the review.

- Cochrane Central Register of Controlled Trials (CENTRAL) (part of the Cochrane Library; 2017, Issue 1 Appendix 1).

- MEDLINE (from 1950 to 2017; Appendix 2).

- EMBASE (from 1980 to 2017; Appendix 3).

We searched CENTRAL via the Wiley Online Library, MEDLINE via PubMed and EMBASE via Ovid, with the assistance of a dedicated information specialist (GMK).

We searched the following trials registers on 1 June 2016 and again on 7 February 2017.

- ClinicalTrials.gov (clinicaltrials.gov/; Appendix 4).

- World Health Organization International Clinical Trials Registry Platform (WHO ICTRP; www.who.int/ictrp/en/; Appendix 5).

- The grey literature repository from the current Grey Literature Report (www.greylit.org/).

\section{Searching other resources}

We also searched three major urological society abstract proceedings for 2015 to 2017 before publication, namely the American Urological Association, EAU, and American Society of Clinical Oncology. We contacted the authors of existing studies, experts in the field and the companies making the EMDA device to request information about additional trials. We further searched the reference lists of existing reviews on the same topic.

\section{Data collection and analysis}

\section{Selection of studies}

We used reference management software to identify and remove potential duplicate records (EndNote 2016). Two review authors (AG, HK or JHJ) independently assessed the titles, abstract, or both, of records identified in the search against the predefined inclusion criteria to determine which studies should be assessed further using Covidence. Two review authors (JHJ, AM) investigated all potentially relevant records as full text, mapped records to studies, and classified studies as included studies, excluded studies, studies awaiting classification or ongoing studies in accordance with the criteria for each provided in the Cochrane Handbook for Systematic Reviews of Interventions (Higgins 2011a). We resolved any discrepancies through discussion or arbitration by a third review author (PD). If resolution of a disagreement was not possible, we planned to designate the study as 'awaiting classification' and contact study authors for clarification. We documented reasons for exclusion of studies that may have reasonably been expected to be included in the review in the Characteristics of excluded studies table. We presented an adapted PRISMA flow diagram showing the process of study selection (Liberati 2009).

\section{Data extraction and management}

Two review authors (AG, JHJ) independently extracted data using a piloted data extraction form and compared their extracted data. A third review author $(P D)$ resolved differences in the extracted data. The extracted data included the following.

- Record citation (e.g. authors' names, article title).

- Details of methods: study design, dates when the study was conducted.

- Details of participants: inclusion and exclusion criteria; setting; country; age; sex; number of included participants; participants' risk factors for recurrence, progression, or both (number of tumours, tumour size, prior recurrence rate, T category, presence of concurrent CIS, tumour grade); and number of participants in each risk group.

- Details of interventions: drug, dosage and dilution details, duration of instillation, number of participants randomly assigned to each intervention group; for EMDA, we recorded the current used, number of administrations, and duration of administration.

- Details of outcomes: outcomes included in this review that were assessed in each study, including how measured and the times at which they were measured.

- Study funding sources.

- Declarations of interest among the primary study authors.

- Study characteristics relevant to risk of bias assessment (e.g. randomisation method, allocation concealment method, blinding methods, completeness of follow-up, intention-to-treat and selective reporting).

We extracted outcome data relevant to this review. For time-toevent outcomes, we obtained log HRs with standard errors and HR with $95 \%$ confidence intervals (Cls). For dichotomous outcomes, we obtained numbers of events and totals for population of a $2 \times 2$ table, as well as summary statistics with corresponding measures of variance. For continuous outcomes, we planned to obtain means and standard deviations or data necessary to calculate this information.

We provided information about potentially relevant ongoing studies, including the trial identifier, in the Characteristics of ongoing studies table. We attempted to contact authors of included studies to obtain key missing data as needed. 


\section{Dealing with duplicate and companion publications}

In the event of duplicate publications, companion documents or multiple reports of a primary study, we maximised yield of information by mapping all publications to unique studies and collating all available data. We used the most complete data-set aggregated across all known publications. In case of doubt, we gave priority to the publication reporting the longest follow-up associated with our primary or secondary outcomes.

\section{Assessment of risk of bias in included studies}

Two review authors (JHJ, AM) independently assessed the risk of bias of each included study. We resolved disagreements by consensus, or by consultation with a third review author (PD).

We assessed risk of bias using Cochrane's 'Risk of bias' assessment tool for the following domains (Higgins 2011b).

- Random sequence generation (selection bias).

- Allocation concealment (selection bias).

- Blinding of participants and personnel (performance bias).

- Blinding of outcome assessment (detection bias).

- Incomplete outcome data (attrition bias).

- Selective reporting (reporting bias).

- Other sources of bias.

We judged risk of bias domains as 'low risk,' 'high risk' or 'unclear risk' and evaluated individual bias items as described in the Cochrane Handbook for Systematic Reviews of Interventions (Higgins 2011b). We presented a 'Risk of bias' summary figure to illustrate these findings.

For selection bias (random sequence generation and allocation concealment) and reporting bias (selective reporting), we evaluated risk of bias at a trial level.

For performance bias (blinding of participants and personnel), we evaluated the risk of bias separately for each outcome.

We defined the following outcomes susceptible to performance bias:

- time to recurrence;

- time to progression;

- serious and minor adverse events;

- disease-specific quality of life.

We defined the following outcomes non-susceptible to performance bias:

- disease-specific survival;

- time to death.

For detection bias (blinding of outcome assessment), we grouped outcomes as susceptible to detection bias (subjective) or not susceptible to detection bias (objective) outcomes.

We defined the following outcomes as subjective outcomes:

- time to recurrence;

- time to progression;

- disease-specific survival;
- serious and minor adverse events;

- disease-specific quality of life.

We defined the following outcome as objective outcomes:

- time to death.

We assessed attrition bias (incomplete outcome data) on a per outcome basis but sought to create groups of outcomes based on similar reporting characteristics.

We further summarised the risk of bias across domains for each outcome in each included study, as well as across studies and domains for each outcome, in accordance with the approach for summary assessments of the risk of bias presented in the Cochrane Handbook for Systematic Reviews of Interventions (Higgins 2011b).

\section{Measures of treatment effect}

For time-to-event outcomes, we calculated HRs and corresponding $95 \% \mathrm{Cls}$ to assess the intervention effect. For dichotomous data, we calculated the RRs with $95 \% \mathrm{Cls}$. We planned to express continuous data as MDs with $95 \% \mathrm{Cls}$ unless different studies used different measures to assess the same outcome, in which case we expressed data as standardised mean differences with $95 \% \mathrm{Cls}$. We analysed the data using Review Manager 5 software (RevMan 2014).

\section{Unit of analysis issues}

The unit of analysis was the individual participant. When we identified cross-over trials, cluster-randomised trials or trials with more than two intervention groups for inclusion in the review, we handled these in accordance with guidance provided in the Cochrane Handbook for Systematic Reviews of Interventions (Higgins 2011c).

\section{Dealing with missing data}

We obtained missing data from study authors and performed intention-to-treat analyses if data were available; otherwise we performed available case analyses. We investigated attrition rates, (e.g. dropouts, losses to follow-up and withdrawals), and critically appraised issues of missing data. We did not impute missing data.

\section{Assessment of heterogeneity}

We had planned to identify heterogeneity (inconsistency) through visual inspection of forest plots to assess the amount of overlap of $\mathrm{Cls}$, and the 12 statistic, which quantifies inconsistency across studies to assess the impact of heterogeneity in the meta-analysis (Higgins 2002; Higgins 2003); we had planned to interpret the 12 statistic as follows (Deeks 2011).

- $0 \%$ to $40 \%$ : may not be important.

- $30 \%$ to $60 \%$ : may indicate moderate heterogeneity.

- $50 \%$ to $90 \%$ : may indicate substantial heterogeneity.

- $75 \%$ to $100 \%$ : considerable heterogeneity.

When we found heterogeneity, we attempted to determine possible reasons for it by examining individual study and subgroup characteristics. 


\section{Assessment of reporting biases}

We attempted to obtain study protocols to assess for selective outcome reporting. We could not produce funnel plots for the visual detection of publication bias since there were fewer than 10 studies included in each meta-analysis.

\section{Data synthesis}

If a meta-analysis was appropriate to calculate the estimate of effect, we used a random-effects model to combine data from the included studies. For dichotomous outcomes, we planned to use the Mantel-Haenszel method; for continuous outcomes, we planned to use the inverse variance method; and for time-to-event outcomes, we planned to use the generic inverse variance method. Analyses were carried out using Review Manager 5 software (RevMan 2014). If meta-analysis was not appropriate, or if sufficient data were unavailable, we provided a narrative synthesis of the data and planned to perform meta-analysis in a future update of this review.

\section{Subgroup analysis and investigation of heterogeneity}

For the case that we had sufficient data, we planned to perform a predefined subgroup analysis for low-, intermediate- and highrisk participants, according to the EAU risk classification system (Babjuk 2017). We planned that should we be unable to stratify the analysis based on the EAU risk categories, we would use its main components, namely the number of tumours (one versus more than one), tumour size (less than $3 \mathrm{~cm}$ versus $3 \mathrm{~cm}$ or greater), tumour stage (Ta versus T1), presence of CIS (absent versus present), tumour grade (Grade 1 versus Grades 2 and 3 ) and primary versus recurrent disease.

The rationale for the planned EAU risk classification subgroup analysis was that people in different risk groups have different recurrence and progression rates, and may be managed differently (i.e. cystoscopic follow-up only versus adjuvant intravesical therapy); therefore, their outcomes are of great interest to clinicians. We planned to investigate heterogeneity for the results of subgroups by inspecting the overlap of $\mathrm{Cls}$ and using the test for subgroup differences in Review Manager 5 (RevMan 2014). In the presence of a suspected subgroup effect, we planned to perform statistical tests for interaction. If applicable, we would have also assessed methodological quality as a source of heterogeneity, comparing studies at low, high and unclear risk of bias. However, too few studies were identified for this to be meaningful.

\section{Sensitivity analysis}

If the number of included studies had permitted, we would have performed sensitivity analyses based on the risk of bias, by excluding studies that we judged to have high or unclear risk of bias for the particular outcome. However, too few studies were available for this to be meaningful.

\section{'Summary of findings' tables}

We presented the overall QoE for each outcome according to the GRADE approach, which takes into account five criteria related to internal validity (risk of bias, inconsistency, imprecision and publication bias), and external validity (directness of results) (Guyatt 2008). For each comparison, two review authors (JHJ, AM) independently rated the QoE for each outcome as 'high,' 'moderate,' 'low' or 'very low' using GRADEpro GDT. We resolved any discrepancies by consensus, or, if needed, by arbitration by a third review author (PD). For each comparison, we presented a summary of the evidence for the main outcomes in a 'Summary of findings' table, which provides key information about the best estimate of the magnitude of the effect in relative terms and absolute differences for each relevant comparison of alternative management strategies; numbers of participants and studies addressing each important outcome; and the rating of the overall confidence in effect estimates for each outcome (Guyatt 2011b; Schünemann 2011). If meta-analysis was not possible, we planned to present results in a narrative 'Summary of findings' table.

\section{RE S U L T S}

\section{Description of studies}

\section{Results of the search}

We identified 538 records through our electronic database search including one record from a trial registry. We found no additional record in the grey literature repository. We found no additional records through handsearching of abstract proceedings. After removal of 75 duplicates, we screened the titles and abstracts of 463 records, and excluded references. We screened 19 full-text articles and ultimately included three studies (reported in 16 references) in this review (Figure 1). The updated search in 7 February 2017 yielded three citations but did not reveal any further relevant studies for full-text review. 
Figure 1. Study flow diagram.

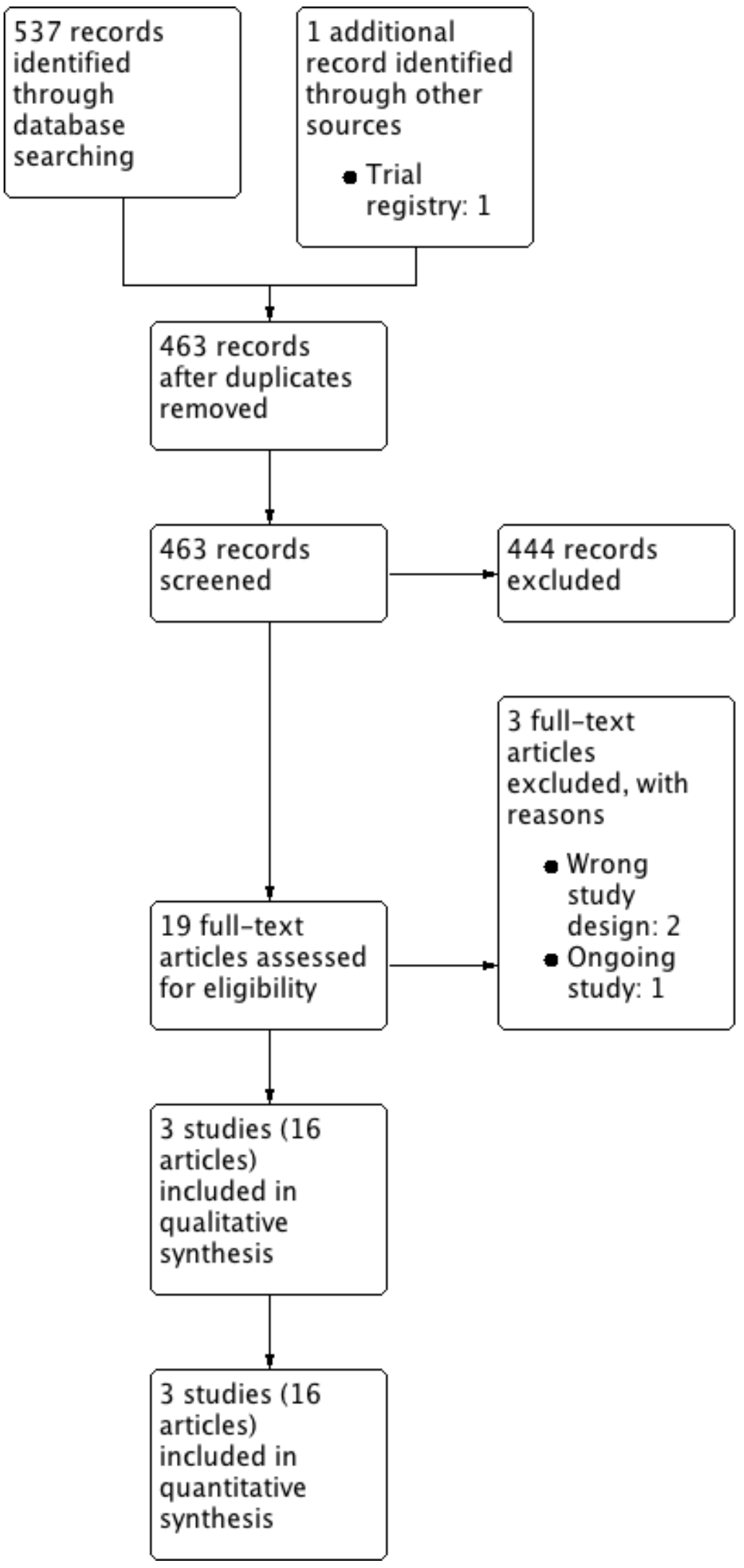




\section{Included studies}

Three randomised controlled trials (RCTs) investigating intravesical EMDA treatment met the inclusion criteria for this review (Di Stasi 2003; Di Stasi 2006; Di Stasi 2011). We required more information for all of the included trials and were able to contact the author by email (Di Stasi 2003; Di Stasi 2006; Di Stasi 2011). See Characteristics of included studies; Table 1; and Table 2 for details.

\section{Study design}

Two included studies were parallel and multicentre RCTs ( $D i$ Stasi 2006; Di Stasi 2011), and one study was a randomised controlled, parallel group trial which permitted additional sessions of intravesical therapy at three months and cross-over at six months (Di Stasi 2003). All included studies were conducted by the same study group in Italy.

\section{Participants}

We evaluated 672 participants (528 males, 144 females) with NMIBC (Di Stasi 2003; Di Stasi 2006: CIS or concurrent T1 (or both); Di Stasi 2011: Ta or T1), as determined by pathological evaluation of TURBT. Mean age of included studies ranged from 64.5 to 68.5 years. Two studies enrolled people with primary disease (Di Stasi 2003; Di Stasi 2011), and one study enrolled the people with both primary and recurrent disease (Di Stasi 2006).

\section{Interventions and comparisons}

MMC was the only intravesical agent used in all trials. Two studies used EMDA in the postoperative setting (Di Stasi 2003; Di Stasi 2006). Di Stasi 2011 used EMDA in the preoperative setting.

Di Stasi 2003 compared MMC-EMDA with BCG and MMC PD. Participants received an initial six intravesical instillations according to their assigned intervention at weekly intervals starting about three weeks after TURBT. If cancer persisted at three months, participants received an additional six-week course. If disease persisted at six months, there was cross-over to a six-week additional course of BCG for people who underwent the MMC-EMDA or MMC-PD instillation. The participants in the BCG group were crossed over to a six-week MMC-EMDA course.

Di Stasi 2006 compared MMC-EMDA with sequential BCG with BCG alone. MMC-EMDA with sequential BCG instillations consisted of an initial three cycles of MMC-EMDA with BCG intravesical instillation. One cycle consisted of two BCG installations followed by one MMC-EMDA installation at weekly intervals about three weeks after TURBT. Subsequently, participants received three cycles of MMCEMDA with BCG intravesical instillation. One subsequent cycle consisted of two MMC-EMDA installations followed by one BCG installation at monthly intervals for nine months. In comparison, an initial six BCG intravesical instillations were performed at weekly intervals about three weeks after TURBT and BCG monthly instillations for 10 months.

Di Stasi 2011 compared a single MMC-EMDA intravesical instillation about 30 minutes before spinal or general anaesthesia for TURBT with a single MMC-EMDA intravesical instillation immediately after TURBT and TURBT without immediate intravesical instillation. Participants received adjuvant intravesical therapy if indicated based on EAU guidelines (Babjuk 2017).

\section{Outcomes}

All included studies reported time to recurrence, time to progression, disease-specific survival, time to death and serious adverse events. Two studies reported minor adverse events as count data (Di Stasi 2003; Di Stasi 2006). None of the studies reported disease-specific quality of life.

Median follow-up of included studies ranged from 43 to 88 months. However, as Di Stasi 2003 was designed to allow cross-over, we used data up to three months after intervention only (before additional session of intravesical therapy and cross-over) in our data analysis. For further descriptive information about the studies, refer to the Characteristics of included studies table.

\section{Funding sources and conflicts of interests}

Two studies specified funding sources (Di Stasi 2003: Tor Vergata University of Rome and Physion Srl, Medolla, Italy, Di Stasi 2011: none). Di Stasi 2006 did not report the funding sources. Two studies reported no conflicts of interests (Di Stasi 2006; Di Stasi 2011), and Di Stasi 2003 reported financial interest or other relationships with Physion Srl (or both).

\section{Excluded studies}

We excluded two publications because they had the wrong study design (non-RCT: Brausi 1998, commentary: Grossman 2006). See Characteristics of excluded studies table.

\section{Study awaiting classification}

We found one study waiting classification (NCT01920269). We contacted the author but did not receive a reply. See Characteristics of studies awaiting classification.

\section{Risk of bias in included studies}

We did not assess risk of bias for quality of life due to the lack of data. Detailed results of the 'Risk of bias' assessment are provided in Figure 2, Figure 3 and judgement of individual domains are in the Characteristics of included studies table. 
Figure 2. Risk of bias graph: review authors' judgements about each risk of bias item presented as percentages across all included studies.

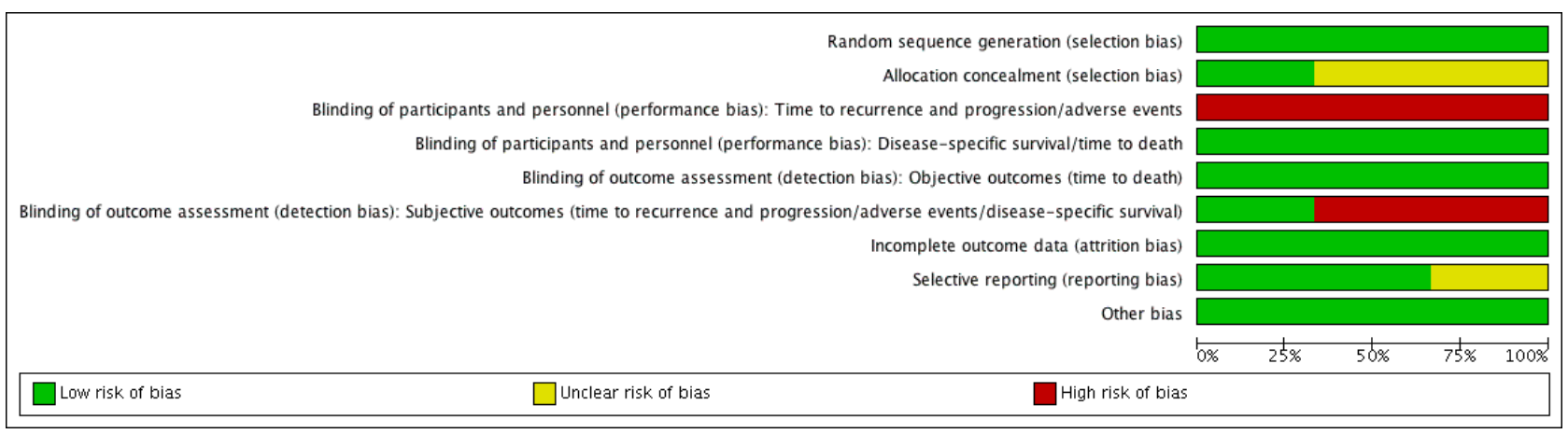


Figure 3. Risk of bias summary: review authors' judgements about each risk of bias item for each included study.

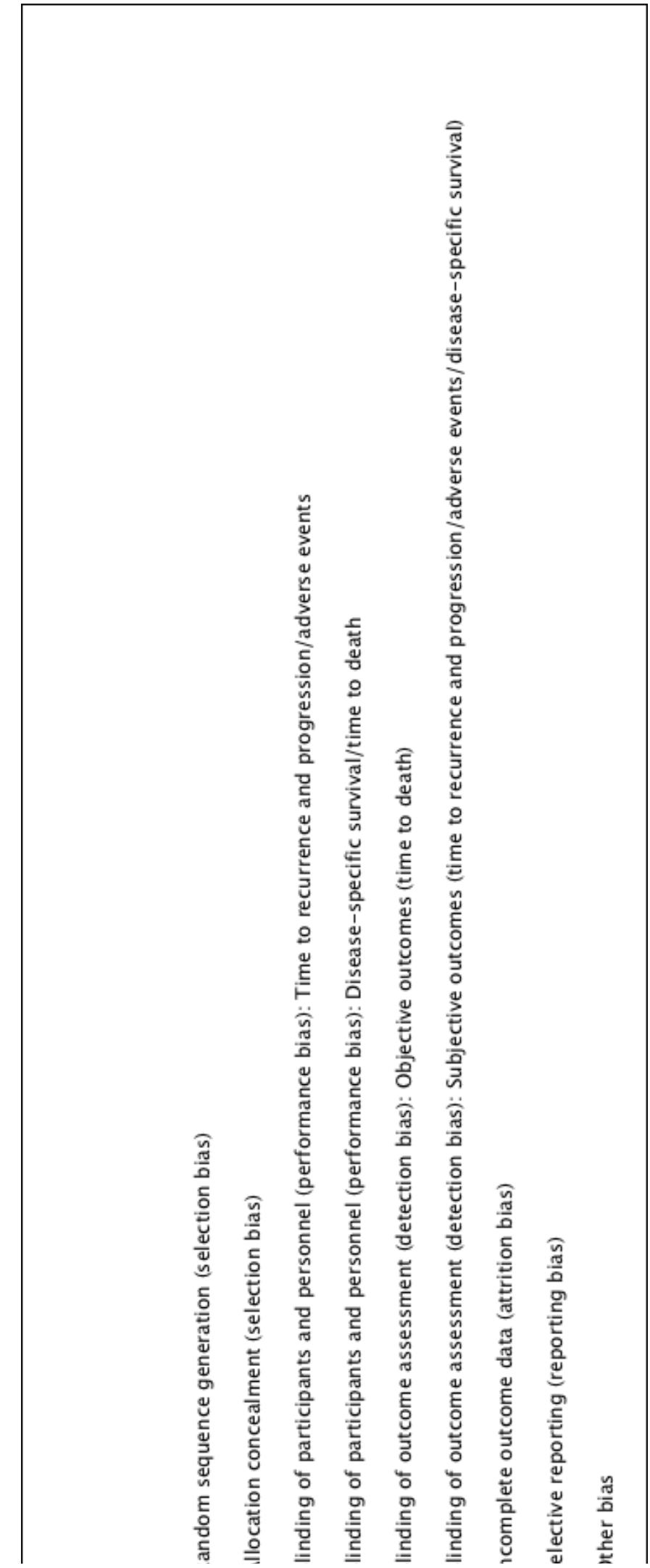


Figure 3. (Continued)

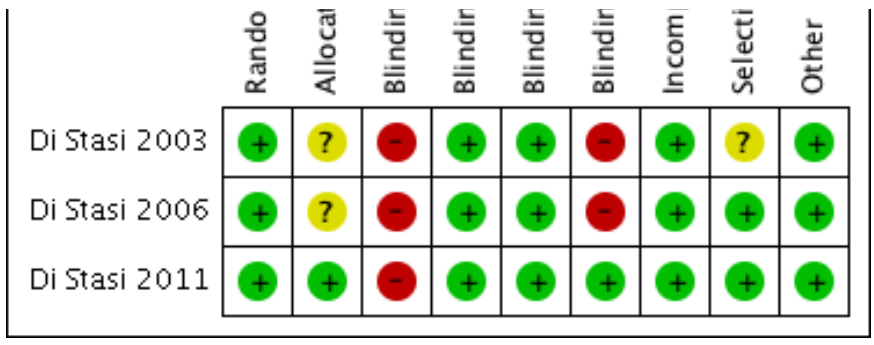

\section{Allocation}

\section{Random sequence generation}

All included studies used stratified blocked randomisation. We judged the risk of bias to be low for random sequence generation for all three studies (Di Stasi 2003; Di Stasi 2006; Di Stasi 2011).

\section{Allocation concealment}

We considered allocation concealment to be at low risk of bias in one trial (Di Stasi 2011). Two trials did not describe an adequate method of allocation concealment and was at unclear risk of bias in this domain (Di Stasi 2003; Di Stasi 2006).

\section{Blinding}

\section{Blinding of participants and personnel}

According to our protocol, we grouped the outcomes with an expected similar risk of bias together.

- Blinding of time to recurrence and progression, serious and minor adverse events: all trials had inadequate blinding for these outcomes and were at high risk of bias (Di Stasi 2003; Di Stasi 2006; Di Stasi 2011).

- Blinding of disease-specific survival and time to death: we rated all trials at low risk of bias given that lack of blinding was unlikely to have affected these outcomes (Di Stasi 2003; Di Stasi 2006; Di Stasi 2011).

\section{Blinding of outcome assessment}

- Blinding of subjective outcomes (time to recurrence and progression, serious and minor adverse event, disease-specific survival): Di Stasi 2011 had an adequate method of blinding for these outcomes so we judged the risk of bias as low. Other trials did not use blinding and were at high risk (Di Stasi 2003; Di Stasi 2006).

- Blinding of objective outcomes (time to death): we rated all three trials at low risk due to the objective nature of the outcomes (Di Stasi 2003; Di Stasi 2006; Di Stasi 2011).

\section{Incomplete outcome data}

- Time to recurrence and progression: we judged all studies to be at low risk of bias (Di Stasi 2003; Di Stasi 2006; Di Stasi 2011). Attrition and exclusion were clearly described and the vast majority of randomised participants were included in the analysis.

\section{Selective reporting}

Two trials reported all outcomes intended to be investigated by published protocol and we judged both trials at low risk of bias ( $\mathrm{Di}$
Stasi 2006; Di Stasi 2011). One study rated unclear risk of bias due to absence of published protocol (Di Stasi 2003).

\section{Other potential sources of bias}

All trials appeared to be free from other sources of bias (low risk of bias).

\section{Effects of interventions}

See: Summary of findings for the main comparison Postoperative MMC-EMDA induction versus postoperative BCG induction therapy for non-muscle invasive bladder cancer; Summary of findings 2 Postoperative MMC-EMDA induction versus MMC-PD induction therapy for non-muscle invasive bladder cancer; Summary of findings 3 Postoperative MMC-EMDA with sequential BCG induction and maintenance versus postoperative BCG induction and maintenance therapy for non-muscle invasive bladder cancer; Summary of findings 4 Single-dose, preoperative MMC-EMDA versus single-dose, postoperative MMC-PD for non-muscle invasive bladder cancer; Summary of findings 5 Single-dose, preoperative MMC-EMDA versus TURBT alone for non-muscle invasive bladder cancer

We included three unique studies with 672 participants analysed (694 randomised) across five comparisons. See Summary of findings for the main comparison; Summary of findings 2; Summary of findings 3; Summary of findings 4; Summary of findings 5.

We used previous data from EORTC trials, the American College of Surgeons National Surgical Quality Improvement Program and systematic reviews to assume baseline risk of main outcomes for the 'Summary of findings' tables (Bouffioux 1995; Gontero 2016; Matulewicz 2015; Oddens 2013; Sylvester 2016).

\section{Postoperative MMC-EMDA induction versus postoperative BCG induction therapy (short term)}

We included one study with 72 participants (intervention 36, control 36) with $\mathrm{CIS}$ and concurrent pT1 urothelial carcinoma, which compared MMC-EMDA intravesical instillation with BCG about three weeks after TURBT (Di Stasi 2003). While the median follow-up period was 43 months, we used the data at three months after intervention (before second session of additional intravesical therapy and cross-over).

\subsection{Time to recurrence}

We are uncertain about the effect of MMC-EMDA on time to recurrence ( $\mathrm{RR} 1.06,95 \% \mathrm{Cl} 0.64$ to 1.76 ). We rated the QoE as very low according to GRADE, downgrading for study limitations and imprecision. 
1.2. Time to progression, disease-specific survival and time to death due to any cause

There was no disease progression, disease-specific death, and death due to any cause in either intervention group.

\subsection{Serious adverse events}

We are uncertain about the effect of MMC-EMDA on serious adverse events (RR $0.75,95 \% \mathrm{Cl} 0.18$ to 3.11). We rated the QoE as very low according to GRADE, downgrading for study limitations and imprecision.

\subsection{Minor adverse events}

We were unable to use data related to minor adverse events due to unit of analysis errors/likely double-counting of participants.

\subsection{Disease-specific quality of life}

We found no data related to disease-specific quality of life.

\section{Subgroup and sensitivity analysis}

We could not perform a subgroup analysis or sensitivity analysis due to lack of relevant data.

\section{Postoperative MMC-EMDA induction versus MMC-PD induction therapy (short term)}

We included one study with 72 participants (intervention 36, control 36) with CIS and concurrent pT1 urothelial carcinoma, which compared MMC-EMDA intravesical instillation with MMC-PD about three weeks after TURBT (Di Stasi 2003). Median followup period was 43 months. We used the data at three months after intervention (before second session of additional intravesical therapy and cross-over).

\subsection{Time to recurrence}

Postoperative MMC-EMDA intravesical instillation may reduce disease recurrence but may not represent a clinically important difference (RR $0.65,95 \% \mathrm{Cl} 0.44$ to 0.98 ). We rated the QoE as low according to GRADE, downgrading for study limitations and imprecision. Assuming a baseline risk of recurrence of $42.0 \%$ (Witjes 1998), postoperative EMDA would result in 147 fewer recurrences per 1000 participants ( $95 \% \mathrm{Cl} 235$ fewer to 8 fewer).

\subsection{Time to progression, disease-specific survival and time to death due to any cause}

There was no disease progression, disease-specific death, and death due to any cause in either intervention group (RR 1.00, 95\% $\mathrm{Cl}$ not estimable).

\subsection{Serious adverse events}

We are uncertain about the effect of postoperative MMC-EMDA intravesical instillation on serious adverse events (RR 1.50, 95\% Cl 0.27 to 8.45 ). We rated the QoE as very low according to GRADE, downgrading for study limitations and imprecision.

\subsection{Minor adverse events}

We were unable to use data related to minor adverse events due to unit of analysis error.

\subsection{Disease-specific quality of life}

We found no data related to disease-specific quality of life.

\section{Subgroup and sensitivity analysis}

We could not perform a subgroup analysis or sensitivity analysis due to no relevant data.

\section{Postoperative MMC-EMDA with sequential BCG induction and maintenance versus postoperative BCG induction and maintenance therapy (long term)}

We included only one study with 212 participants (intervention 107, control 105) with pT1 urothelial carcinoma of the bladder with or without concomitant CIS (Di Stasi 2006). The study compared MMCEMDA with sequential BCG with BCG about three weeks after TURBT. Median follow-up period was 88 months.

\subsection{Time to recurrence}

Postoperative MMC-EMDA intravesical instillation with sequential BCG may result in a longer time to recurrence but may not represent a clinically important difference (HR $0.51,95 \% \mathrm{Cl} 0.34$ to 0.77 ). We rated the QoE as low according to GRADE, downgrading for study limitations and imprecision. Assuming a baseline risk of recurrence of $43.0 \%$ (Oddens 2013), postoperative EMDA with sequential BCG would result in 181 fewer recurrences per 1000 participants $(95 \% \mathrm{Cl}$ 256 fewer to 79 fewer).

\subsection{Time to progression}

Postoperative MMC-EMDA intravesical instillation with sequential BCG may result in a longer time to progression but may not represent a clinically important difference (HR $0.36,95 \% \mathrm{Cl} 0.17$ to $0.75)$. We rated the QoE as low according to GRADE, downgrading for study limitations and imprecision. Assuming a baseline risk of progression of $10.0 \%$ (Oddens 2013), postoperative EMDA with sequential BCG instillation would result in 63 fewer progressions per 1000 participants ( $95 \% \mathrm{Cl} 82$ fewer to 24 fewer).

\subsection{Serious adverse events}

We are uncertain about the effect of MMC-EMDA in serious adverse events (RR $1.02,95 \% \mathrm{Cl} 0.21$ to 4.94). We rated the $\mathrm{QoE}$ as very low according to GRADE, downgrading for study limitations and imprecision.

\subsection{Disease-specific survival}

Postoperative MMC-EMDA with sequential BCG intravesical instillation may improve disease-specific survival but may not represent a clinically important difference (HR $0.31,95 \% \mathrm{Cl} 0.12$ to 0.80 ). We rated the QoE as low according to GRADE, with downgrading for study limitations and imprecision. Assuming a baseline risk of disease-specific death of $6.0 \%$ (Oddens 2013), postoperative EMDA with sequential BCG instillation would result in 41 fewer deaths per 1000 participants ( $95 \% \mathrm{Cl} 53$ fewer to 12 fewer).

\subsection{Time to death due to any cause}

Postoperative MMC-EMDA with sequential BCG intravesical instillation may result in little or no difference in time to death (HR $0.59,95 \% \mathrm{Cl} 0.35$ to 1.00 ). We rated the QoE as low according to GRADE, downgrading for study limitations and imprecision. 


\subsection{Minor adverse events}

We found no data related to minor adverse events.

\subsection{Disease-specific quality of life}

We found no data related to disease-specific quality of life.

\section{Subgroup and sensitivity analysis}

We did not perform a subgroup analysis or sensitivity analysis due to no relevant data.

\section{Single-dose, preoperative MMC-EMDA versus single-dose, postoperative MMC-PD (long term)}

We included only one study with 236 participants (intervention 117 , control 119) with primary pTa and pT1 urothelial carcinoma (people with concomitant CIS were excluded), which compared MMC-EMDA before TURBT with MMC-PD immediately after TURBT (Di Stasi 2011). Median follow-up period was 86 months.

\subsection{Time to recurrence}

Preoperative MMC-EMDA intravesical instillation likely results in a longer time to recurrence ( $\mathrm{HR} 0.47,95 \% \mathrm{Cl} 0.32$ to 0.69 ). We rated the QoE as moderate according to GRADE, downgrading for study limitations. Assuming a baseline risk of recurrence of $10 \%$ (low risk; Sylvester 2016) or 50\% (high risk; Sylvester 2016), preoperative MMC-EMDA would result in 52 fewer recurrences per 1000 participants (95\% Cl 67 fewer to 30 fewer) (low risk) or 222 fewer recurrences per 1000 participants $(95 \% \mathrm{Cl} 301$ fewer to 120 fewer) (high risk).

\subsection{Time to progression}

We are uncertain about the effect of preoperative MMC-EMDA in time to progression (HR $0.81,95 \% \mathrm{Cl} 0.00$ to 259.93). We rated the QoE as very low according to GRADE, downgrading for study limitations and imprecision.

\subsection{Serious adverse events}

We are uncertain about the effect of preoperative MMC-EMDA in serious adverse events (RR $0.79,95 \% \mathrm{Cl} 0.30$ to 2.05). We rated the QoE as very low according to GRADE, downgrading for study limitations and imprecision.

\subsection{Disease-specific survival}

Preoperative MMC-EMDA intravesical instillation may result in little to no difference in disease-specific survival ( $\mathrm{HR} 0.99,95 \% \mathrm{Cl} 0.74$ to 1.32). We rated the QoE as low according to GRADE, downgrading for imprecision.

\subsection{Time to death due to any cause}

Preoperative MMC-EMDA intravesical instillation may result in little to no difference in time to death ( $\mathrm{HR} 0.89,95 \% \mathrm{Cl} 0.62$ to 1.28 ). We rated the QoE as low according to GRADE, downgrading for imprecision.

\subsection{Minor adverse events}

Preoperative MMC-EMDA intravesical instillation likely reduces minor adverse events (HR $0.55,95 \% \mathrm{Cl} 0.42$ to 0.72 ). We rated the QoE as moderate according to GRADE, downgrading for study limitations. Assuming a baseline risk of minor adverse events of
10.0\% (low risk; Bouffioux 1995) and 40.0\% (high risk; Witjes 1998), preoperative MMC-EMDA would result in 45 fewer minor adverse events per 1000 participants ( $95 \% \mathrm{Cl} 58$ fewer to 28 fewer) (low risk) and 180 fewer minor adverse events per 1000 participants $(95 \% \mathrm{Cl}$ 232 fewer to 112 fewer) (high risk).

\subsection{Disease-specific quality of life}

We found no data related to disease-specific quality of life.

\section{Subgroup and sensitivity analysis}

We did not perform a subgroup analysis or sensitivity analysis due to no relevant data.

\section{Single-dose, preoperative MMC-EMDA versus TURBT alone (long term)}

We included only one study with 233 participants (intervention 117 , control 116) with primary pTa and pT1 urothelial carcinoma (participants with concomitant CIS were excluded), which compared MMC-EMDA before TURBT with TURBT without intravesical instillation (Di Stasi 2011). Median follow-up period was 86 months.

\subsection{Time to recurrence}

Preoperative MMC-EMDA intravesical instillation likely results in a longer time to recurrence ( $\mathrm{HR} 0.40,95 \% \mathrm{Cl} 0.28$ to 0.57 ). We rated the QoE as moderate according to GRADE, downgrading for study limitations. Assuming a baseline risk of recurrence of 40\% (low risk; Sylvester 2016) and 70\% (high risk; Sylvester 2016), preoperative MMC-EMDA would result in 215 fewer recurrences per 1000 participants ( $95 \% \mathrm{Cl} 267$ fewer to 147 fewer) (low risk) and 318 fewer recurrences per 1000 participants $(95 \% \mathrm{Cl} 414$ fewer to 203 fewer) (high risk).

\subsection{Time to progression}

We are uncertain about the effect of preoperative MMC-EMDA intravesical instillation in time to progression (HR $0.74,95 \% \mathrm{Cl}$ 0.00 to 247.93 ). We rated the QoE as very low according to GRADE, downgrading for study limitations and imprecision.

\subsection{Serious adverse events}

We are uncertain about the effect of preoperative MMC-EMDA intravesical instillation in serious adverse events (HR $1.74,95 \% \mathrm{Cl}$ 0.52 to 5.77 ). We rated the QoE as very low according to GRADE, downgrading for study limitations and imprecision.

\subsection{Disease-specific survival}

Preoperative MMC-EMDA intravesical instillation likely results in little to no difference in disease-specific survival (HR 1.06, 95\% CI 0.80 to 1.40 ). We rated the QoE as moderate according to GRADE, downgrading for imprecision.

\subsection{Time to death due to any cause}

Preoperative MMC-EMDA intravesical instillation may result in little to no difference in time to death (HR $1.07,95 \% \mathrm{Cl} 0.73$ to 1.57 ). We rated the QoE as low according to GRADE, downgrading for imprecision. 


\subsection{Minor adverse events}

Preoperative MMC-EMDA intravesical instillation may increase minor adverse events (HR 1.68, 95\% $\mathrm{Cl} 1.11$ to 2.53). We rated the QoE as low according to GRADE, downgrading for study limitations and imprecision. Assuming a baseline risk of recurrence of $4 \%$ (low risk; Matulewicz 2015) or 11\% (high risk; Matulewicz 2015), preoperative MMC-EMDA would result in 27 more minor adverse events per 1000 participants ( $95 \% \mathrm{Cl} 4$ more to 61 more) (low risk) or 75 more minor adverse events per 1000 participants ( $95 \% \mathrm{Cl} 12$ more to 168 more) (high risk).

\subsection{Disease-specific quality of life}

We found no data related to disease-specific quality of life.

\section{Subgroup and sensitivity analysis}

We did not perform a subgroup analysis or sensitivity analysis due to the lack of relevant data.

\section{DISCUSSION}

\section{Summary of main results}

We identified only three RCTs which informed five separate comparisons (Di Stasi 2003; Di Stasi 2006; Di Stasi 2011). We evaluated 672 participants with NMIBC (Di Stasi 2003; Di Stasi 2006: CIS or concurrent T1 (or both), Di Stasi 2011: Ta or T1). The mean age of included participants ranged from 64.5 to 68.5 years. Two studies enrolled people with primary disease (Di Stasi 2003; Di Stasi 2011), and one study enrolled the people with both primary and recurrent disease (Di Stasi 2006). Median follow-up of included studies ranged from 43 to 88 months. We were able to use the data at three months after intervention in data analysis due to cross-over study design (Di Stasi 2003).

1. Postoperative MMC-EMDA induction versus postoperative BCG induction (short term): we are uncertain about the effect on time to disease recurrence and serious adverse events (very low QoE). There were no events of disease progression at three months to analyse; follow-up was likely too short to assess this outcome.

2. Postoperative MMC-EMDA induction versus MMC-PD induction (short term): based on low QoE, postoperative MMCEMDA may reduce disease recurrence. We are uncertain about the effect on serious adverse events (very low QoE). There were no events of disease progression at three months to analyse; followup was likely too short to assess this outcome.

3. Postoperative MMC-EMDA with sequential BCG induction and maintenance versus postoperative BCG induction and maintenance (long term): based on low QoE, postoperative MMCEMDA with sequential BCG may result in a longer time to recurrence and time to progression. We are uncertain about the effect on serious adverse events (very low QoE).

4. Single-dose, preoperative MMC-EMDA versus single-dose, postoperative MMC-PD (long term): based on moderate QoE, preoperative MMC-EMDA resulted in a longer time to recurrence. We are uncertain about its effect on time to progression and serious adverse events (very low QoE).

5. Single-dose, preoperative MMC-EMDA versus TURBT alone (long term): based on moderate QoE, preoperative MMC-EMDA resulted in a longer time to recurrence. We are uncertain about its effect on time to progression and serious adverse events (very low QoE).

\section{Overall completeness and applicability of evidence}

In this review, we found three trials of five treatment comparisons. These trials were conducted by the same study group based in Italy which has pioneered this technology; however, none of the study findings have been independently replicated by other centres. Similar studies performed by other investigators in other countries would be valuable in validating these findings.

The five comparisons described in this review are of varying degree of clinical interest. For example, the comparison of preoperative MMC-EMDA intravesical instillation versus TURBT alone is not very informative since TURBT alone is not the standard of practice for this patient population. Similarly, in Di Stasi 2003, people with recurrent tumours received an additional six-week course of the same agent after an initial course of induction therapy, whereas repeat TURBT would be the standard of care. Therefore, we only used data up to three months of follow-up, which is of limited value.

Based on current evidence-based guidelines (Babjuk 2017; Chang 2016), after TURBT, people should undergo immediate postoperative installation of MMC followed by an induction course of MMC or BCG, with or without maintenance therapy based on their risk of recurrence. None of the trials we identified used this comparison, which is considered the standard of care and therefore the most appropriate comparison. These issues limit clinical applicability. Future studies should compare EMDA to established standards of care. In addition, a number of other clinical factors may impact the effectiveness of intravesical therapy in the intervention and control arms; these include fluid status, drug concentration and BCG strain; assessing their impact was beyond the scope of this review.

All included studies in this review used MMC as the EMDA agent. We found no studies using other chemotherapeutic agents (Porten 2015; Veeratterapillay 2016). It is unknown whether EMDA has utility in conjunction with other intravesical agents.

We were unable to analyse data for minor adverse events from the studies due to the way the information was reported. Using the presented data would have resulted in double- and triple counting of participants with more than one adverse event resulting in a unit of analysis issue (Di Stasi 2003; Di Stasi 2006). We were unable to obtain additional data to address this issue from the study investigators. We did not find information on disease-specific quality of life.

The use of EMDA requires additional equipment which may be costly. Although an economic analysis was outside the scope of this review, this may represent a barrier to its uptake in clinical practice.

\section{Quality of the evidence}

We consistently downgraded the QoE for all five comparisons. The QoE was most commonly rated as very low to low; in select cases, we found moderate QoE. Issues that lowered our confidence in the estimates of effect were study limitations, specifically unclear allocation concealment (selection bias) and the lack of blinding (performance and detection bias). We also frequently downgraded for imprecision due to relatively low event rates that resulted in 
wide Cls. Due to the paucity of studies, we were unable to formally assess the possibility of publication bias.

\section{Potential biases in the review process}

Although we conducted this systematic review with a comprehensive search strategy identical with current standards of Cochrane, we found only three RCTs. There is a possibility that despite our best efforts, which included contacting the principal investigator of the existing studies as well as inquiring with experts in the field, we may have missed additional studies. This may be because they were published in languages other than English (although we applied no language restrictions), were published in non-indexed journals or were unpublished.

We contacted the study authors on several occasions and they provided feedback to several of our queries. However, we did not obtain data for minor adverse events in studies that used MMCEMDA postoperatively. This may represent a source of bias with potential under-reporting of the true treatment burden.

\section{Agreements and disagreements with other studies or reviews}

We identified one rapid review performed by the Canadian Agency for Drugs and Technologies in Health (CADTH 2014). They included one trial (Di Stasi 2011), which was also included in our review. Their review was based on a limited search (English language documents published between January 2009 and August 2014) and concluded that there was little evidence on the efficacy and safety of EMDA to treat NMIBC (CADTH 2014).

Narrative reviews suggested that EMDA appears to improve response rates that might be equivalent to $B C G$ in the short term but long-term efficacy data are lacking in cases of high-grade NMIBC (Porten 2015; Veeratterapillay 2016). These narrative reviews also included the same RCTs that were included in the present review (Di Stasi 2003; Di Stasi 2006; Di Stasi 2011), but lacked a formal assessment of the QoE.

\section{AUTHORS' CONCLUSIONS}

\section{Implications for practice}

While the use of electromotive drug administration (EMDA) to administer intravesical mitomycin C (MMC) may result in a delay in time to recurrence in select patient populations, we are uncertain about its impact on serious adverse events. A potential role for EMDA-based administration of MMC may lie in settings where more established agents (such as Bacillus Calmette-Guérin (BCG)) are not available.

\section{Implications for research}

The findings of this review that included five comparisons was informed by only three trials by one research team. These studies have important limitations that future studies should avoid. Future efforts should be directed towards:

- blinding of participants and personnel to guard against performance bias (which may require the use of a sham procedure) and blinding of outcome assessors;

- adequate sample size to allow stratification by prognostic risk groups to provide sufficiently precise results for each stratum;

- the use of accepted standards of care as comparators for EMDAbased interventions;

- investigation of other agents beyond MMC together with EMDA technology;

- inclusion of participant-reported outcomes such as validated quality-of-life measures;

- transparent reporting of results to allow independent confirmation of all analyses.

\section{ACKNOWLEDGEMENTS}

We acknowledge the work of Molly M. Neuberger as former Managing Editor of Cochrane Urology in the preparation of the protocol. We are very grateful to Maximilian Burger, Sam Chang and Robert Siemens for their critical appraisal of this review as part of the peer review process. We thank Cochrane Urology and its current Managing Editor Alea Miller for supporting this title. 


\section{REFERE N CES}

\section{References to studies included in this review}

\section{Di Stasi 2003 \{published data only\}}

Di Stasi SM, Giannantoni A, Stephen RL, Capelli G, Navarra P, Massoud $R$, et al. Intravesical electromotive mitomycin $C$ versus passive transport mitomycin $\mathrm{C}$ for high risk superficial bladder cancer: a prospective randomized study. Journal of Urology 2003;170(3):777-82. [DOI: 10.1097/01.ju.0000080568.91703.18]

\section{Di Stasi 2006 \{published data only\}}

* Di Stasi SM, Giannantoni A, Giurioli A, Valenti M, Zampa G, Storti $L$, et al. Sequential BCG and electromotive mitomycin versus BCG alone for high-risk superficial bladder cancer: a randomised controlled trial. Lancet Oncology 2006;7(1):43-51. [DOI: 10.1016/S1470-2045(05)70472-1]

Di Stasi SM, Riedl C, Giannantoni A, Verri C, Celestino F, De Carlo F, et al. Is intravesical BCG alone still the only truly effective intravesical therapy for non-muscle invasive bladder cancer?. Journal of Urology 2015;193(4):e381. [DOI: 10.1016/ j.juro.2015.02.659]

Di Stasi SM, Riedl C, Verri C, Celestino F, De Carlo F, Giannantoni A, et al. Is intravesical BCG alone still the only truly effective intravesical therapy for high risk non muscle invasive bladder cancer?. European Urology Supplements 2015;2(14):e945. [DOI: 10.1016/S1569-9056(15)60933-2]

Di Stasi SM, Verr C, Liberati E, Zampa G, Masedu F, Valenti M. Intravesical sequential BCG and electromotive mitomycin versus $B C G$ alone in high risk non-muscle invasive bladder cancer. Journal of Clinical Oncology 2012;30(15 Suppl):4572.

Di Stasi SM, Verri C, Liberati E, Masedu F, Topazio L, Valenti M. Intravesical sequential Bacillus Calmette-Guerin and electromotive mitomycin versus Bacillus Calmette-Guerin alone for stage pT1 urothelial bladder cancer. Journal of Urology 2012;187(4):e674. [DOI: 10.1016/j.juro.2012.02.1528]

Di Stasi SM, Verri C, Liberati E, Masedu F, Valenti M. Intravesical sequential BCG and electromotive mitomycin versus BCG alone for stage pT1 urothelial bladder cancer. European Urology Supplements 2013;1(12):e698-9. [DOI: 10.1016/ S1569-9056(13)61180-X]

Liberati E, Verri C, Topazio L, Valenti M, Di Stasi SM. Intravesical sequential BCG and electromotive mitomycin-C versus BCG alone for stage PT1 urothelial bladder cancer. Anticancer Research 2012;32(5):1861-2.

\section{Di Stasi 2011 \{published data only\}}

* Di Stasi SM, Valenti M, Verri C, Liberati E, Giurioli A, Leprini G, et al. Electromotive instillation of mitomycin immediately before transurethral resection for patients with primary urothelial non-muscle invasive bladder cancer: a randomised controlled trial. Lancet Oncology 2011;12(9):871-9. [DOI: 10.1016/S1470-2045\%2811\%2970190-5]

Di Stasi SM, Verri C, Capelli G, Brausi M, Leprini G, Casilio M, et al. Single preoperative intravesical instillation of electromotive mitomycin-C for primary non-muscle-invasive bladder cancer: a prospective randomized trial. Journal of Clinical Oncology 2010;28(15s):4543.

Di Stasi SM, Verri C, Capelli G, Brausi M, Leprini G, Zampa G, et al. Sigle immediate preoperative intravesical instillation of electromotive mitomycin-C for primary non-muscle invasive bladder cancer: a randomized prospective trial. European Urology Supplements 2010;9(2):93. [DOI: 10.1016/ S1569-9056\%2810\%2960199-6]

Di Stasi SM, Verri C, Capelli G, Brausi M, Leprini G, Zampa G, et al. Sigle preoperative intravesical instillation of electromotive mitomycin-C for primary non-muscle invasive bladder cancer: a randomized trial. Journal of Urology 2010;183(4):e520. [DOI: 10.1016/j.juro.2010.02.973]

Di Stasi SM, Verri C, Liberati E, Micali F, Masedu F, Valenti M. Intravesical adjuvant electromotive mitomycin- $C$ in patients with intermediate-risk non-muscle invasive bladder cancer: a randomized controlled trial. Journal of Urology 2012;187(4):e674. [DOI: 10.1016/j.juro.2012.02.1527]

Di Stasi SM, Verri C, Liberati E, Micali F, Masedu F, Zampa G, et al. Intravesical adjuvant electromotive drug administration (EMDA) of mitomycin-C in patients with intermediate-risk nonmuscle invasive bladder cancer: a randomized controlled trial. European Urology Supplements 2012;11(1):e1045-e1045a. [DOI: 10.1016/S1569-9056(12)61041-0]

Liberati E, Verri C, Casilio M, Brausi M, Leprini G, Zampa G, et al. Single preoperative intravesical instillation of electromotive mitomycin-C for primary non-muscle invasive bladder cancer: a prospective randomized trial. Anticancer Research 2010;30(4):1424.

Verri C, Liberati E, Topazio L, Valenti M, Di Stasi S. Intravesical adjuvant electromotive mitomycin-C in patients with primary intermediate-risk non-muscle invasive bladder cancer: a randomized controlled trial. Anticancer Research 2012;32:1860-1.

\section{References to studies excluded from this review}

Brausi 1998 \{published data only\}

Brausi M, Campo B, Pizzocaro G, Rigatti P, Parma A, Mazza G, et al. Intravesical electromotive administration of drugs for treatment of superficial bladder cancer: a comparative Phase II study. Urology 1998; Vol. 51, issue 3:506-9.

\section{Grossman 2006 \{published data only\}}

Grossman HB. Sequential BCG and electromotive mitomycin versus BCG alone for high-risk superficial bladder cancer: a randomised controlled trial. Urologic Oncology: Seminars and Original Investigations 2006;24(3):271-2. [DOI: 10.1016/ j.urolonc.2006.02.007] 


\section{References to studies awaiting assessment}

NCT01920269 \{published data only\}

NCT01920269. Intravesical Adjuvant Electromotive Mitomycin-C (EMDA/MMC). https://clinicaltrials.gov/ct2/show/NCT01920269? term=NCT01920269\&rank=1 (accessed 31 August 2017).

\section{Additional references}

\section{Babjuk 2017}

Babjuk M, Böhle A, Burger M, Capoun O, Cohen D, Compérat EM, et al. EAU guidelines on non-muscle-invasive urothelial carcinoma of the bladder: update 2016. European Urology 2017;71(3):447-61.

\section{Bedard 2014}

Bedard G, Zeng L, Zhang L, Lauzon N, Holden L, Tsao M, et al. Minimal important differences in the EORTC QLQ-C30 in patients with advanced cancer. Asia Pacific Journal of Clinical Oncology 2014;10(2):109-17.

\section{Bouffioux 1995}

Bouffioux C, Kurth KH, Bono A, Oosterlinck W, Kruger CB, De Pauw M, et al. Intravesical adjuvant chemotherapy for superficial transitional cell bladder carcinoma: results of 2 European Organization for Research and Treatment of Cancer randomized trials with mitomycin $\mathrm{C}$ and doxorubicin comparing early versus delayed instillations and short-term versus longterm treatment. Journal of Urology 1995;153(3 Pt 2):934-41.

\section{Brausi 2011}

Brausi M, Witjes JA, Lamm D, Persad R, Palou J, Colombel M, et al. A review of current guidelines and best practice recommendations for the management of nonmuscle invasive bladder cancer by the International Bladder Cancer Group. Journal of Urology 2011;186(6):2158-67. [PUBMED: 22014799]

\section{Brausi 2014}

Brausi M, Oddens J, Sylvester R, Bono A, van de Beek C, van Andel G, et al. Side effects of Bacillus Calmette-Guerin (BCG) in the treatment of intermediate- and high-risk Ta, T1 papillary carcinoma of the bladder: results of the EORTC genito-urinary cancers group randomised phase 3 study comparing one-third dose with full dose and 1 year with 3 years of maintenance BCG. European Urology 2014;65(1):69-76. [PUBMED: 23910233]

\section{Böhle 2003}

Böhle A, Jocham D, Bock PR. Intravesical Bacillus CalmetteGuerin versus mitomycin $C$ for superficial bladder cancer: a formal meta-analysis of comparative studies on recurrence and toxicity. Journal of Urology 2003;169(1):90-5. [PUBMED: $12478111]$

\section{CADTH 2014}

Canadian Agency for Drugs and Technologies in Health. The use of the electromotive drug administration system in patients with superficial bladder cancer: a review of the clinical effectiveness, safety, and cost-effectiveness. Canadian Agency for Drugs and Technologies in Health Rapid Response Report, 2014. www.ncbi.nlm.nih.gov/pubmedhealth/PMH0069840/ (accessed prior to 25 August 2017). [PUBMED: 25392897 ]

\section{Chang 2016}

Chang SS, Boorjian SA, Chou R, Clark PE, Daneshmand S, Konety BR, et al. Diagnosis and treatment of non-muscle invasive bladder cancer: AUA/SUO guideline. Journal of Urology 2016;196(4):1021-9.

\section{Covidence [Computer program]}

Veritas Health Innovation. Covidence systematic review software. Melbourne, Australia: Veritas Health Innovation, 2013. Available at www.covidence.org.

\section{Deeks 2011}

Deeks JJ, Higgins JP, Altman DG. Chapter 9: Analysing data and undertaking meta-analyses. Higgins JP, Green S, editor(s). Cochrane Handbook for Systematic Reviews of Interventions Version 5.1.0 (updated March 2011). The Cochrane Collaboration, 2011 Available from handbook.cochrane.org.

\section{Di Stasi 1999}

Di Stasi SM, Giannantoni A, Massoud R, Dolci S, Navarra P, Vespasiani $\mathrm{G}$, et al. Electromotive versus passive diffusion of mitomycin $C$ into human bladder wall: concentration-depth profiles studies. Cancer Research 1999;59(19):4912-8. [PUBMED: 10519404]

\section{EndNote 2016 [Computer program]}

Clarivate Analytics. EndNote Version 7.5. Clarivate Analytics, 2016.

\section{Ferlay 2013}

Ferlay J, Soerjomataram I, Ervik M, Dikshit R, Eser S, Mathers C, et al. GLOBOCAN 2012 v1.0, cancer incidence and mortality worldwide: IARC CancerBase No. 11. Lyon, France: International Agency for Research on Cancer; 2013. globocan.iarc.fr (accessed 28 July 2014).

\section{Gontero 2016}

Gontero P, Sylvester R, Pisano F, Joniau S, Oderda M, Serretta V, et al. The impact of re-transurethral resection on clinical outcomes in a large multicentre cohort of patients with T1 highgrade/grade 3 bladder cancer treated with Bacille CalmetteGuérin. BJU International 2016;118(1):44-52.

\section{GRADEpro GDT}

GRADEpro GDT: GRADEpro Guideline Development Tool [Software]. McMaster University, 2015 (developed by Evidence Prime, Inc.). Available from www.gradepro.org.

\section{Guyatt 2008}

Guyatt GH, Oxman AD, Kunz R, Vist GE, Falck-Ytter Y, Schünemann $\mathrm{HJ}$, et al. What is "quality of evidence" and why is it important to clinicians?. BMJ (Clinical Research Ed.) 2008;336(7651):995-8. [PUBMED: 18456631]

\section{Guyatt 2011a}

Guyatt GH, Oxman AD, Kunz R, Brozek J, Alonso-Coello P, Rind $D$, et al. GRADE guidelines 6 . Rating the quality of evidence - imprecision. Journal of Clinical Epidemiology 2011;64(12):1283-93. 


\section{Guyatt 2011b}

Guyatt G, Oxman AD, Akl EA, Kunz R, Vist G, Brozek J, et al. GRADE guidelines: 1. Introduction - GRADE evidence profiles and summary of findings tables. Journal of Clinical Epidemiology 2011;64(4):383-94. [DOI: 10.1016/ j.jclinepi.2010.04.026]

\section{Higgins 2002}

Higgins JPT, Thompson SG. Quantifying heterogeneity in a meta-analysis. Statistics in Medicine 2002;21(11):1539-58. [DOI: 10.1002/sim.1186]

\section{Higgins 2003}

Higgins JPT, Thompson SG, Deeks JJ, Altman DG. Measuring inconsistency in meta-analyses. BMJ (Clinical Research Ed.) 2003;327(7414):557-60. [DOI: 10.1136/bmj.327.7414.557]

\section{Higgins 2011a}

Higgins JP, Green S, editor(s). Cochrane Handbook for Systematic Reviews of Interventions Version 5.1.0 (updated March 2011). The Cochrane Collaboration, 2011. Available from handbook.cochrane.org.

\section{Higgins 2011b}

Higgins JPT, Altman DG, Sterne JAC. Chapter 8: Assessing the risk of bias in included studies. In: Higgins JPT, Green S, editor(s). Cochrane Handbook for Systematic Reviews of Interventions. Version 5.1.0 (updated March 2011). The Cochrane Collaboration, 2011. Available from handbook.cochrane.org.

\section{Higgins 2011c}

Higgins JPT, Deeks JJ, Altman DG. Chapter 16: Special topics in statistics. In: Higgins JPT, Green S, editor(s). Cochrane Handbook for Systematic Reviews of Interventions. Version 5.1.0 (updated March 2011). The Cochrane Collaboration, 2011. Available from handbook.cochrane.org.

\section{Jaeschke 1989}

Jaeschke R, Singer J, Guyatt GH. Measurement of health status. Ascertaining the minimal clinically important difference. Controlled Clinical Trials 1989;10(4):407-15.

\section{Johnston 2013}

Johnston BC, Patrick DL, Busse JW, Schünemann HJ, Agarwal A, Guyatt GH. Patient-reported outcomes in meta-analyses. Part 1 : assessing risk of bias and combining outcomes. Health and Quality of Life Outcomes 2013;11:109.

\section{Lamm 1992}

Lamm DL. Carcinoma in situ. Urologic Clinics of North America 1992;19(3):499-508. [PUBMED: 1636234]

\section{Lamm 2000}

Lamm DL, Blumenstein BA, Crissman JD, Montie JE, Gottesman JE, Lowe BA, et al. Maintenance Bacillus CalmetteGuerin immunotherapy for recurrent Ta, $\mathrm{T} 1$ and carcinoma in situ transitional cell carcinoma of the bladder: a randomized Southwest Oncology Group study. Journal of Urology 2000;163(4):1124-9. [PUBMED: 10737480]

\section{Liberati 2009}

Liberati A, Altman DG, Tetzlaff J, Mulrow C, Gøtzsche PC, loannidis JPA, et al. The PRISMA statement for reporting systematic reviews and meta-analyses of studies that evaluate health care interventions: explanation and elaboration. PLoS Medicine 2009;6(7):e1000100. [DOI: 10.1371/ journal.pmed.1000100]

\section{Maffezzini 2014}

Maffezzini M, Campodonico F, Canepa G, Manuputty EE, Tamagno S, Puntoni M. Intravesical mitomycin C combined with local microwave hyperthermia in non-muscle-invasive bladder cancer with increased European Organization for Research and Treatment of Cancer (EORTC) score risk of recurrence and progression. Cancer Chemotherapy and Pharmacology 2014;73(5):925-30. [PUBMED: 24585046]

\section{Matulewicz 2015}

Matulewicz RS, Sharma V, McGuire BB, Oberlin DT, Perry KT, Nadler RB. The effect of surgical duration of transurethral resection of bladder tumors on postoperative complications: an analysis of ACS NSQIP data. Urologic Oncology 2015;33(8):338.e19-24.

\section{Oddens 2013}

Oddens J, Brausi M, Sylvester R, Bono A, van de Beek C, van Andel G, et al. Final results of an EORTC-GU cancers group randomized study of maintenance Bacillus Calmette-Guérin in intermediate- and high-risk Ta, T1 papillary carcinoma of the urinary bladder: one-third dose versus full dose and 1 year versus 3 years of maintenance. European Urology 2013;63(3):462-72.

\section{Porten 2015}

Porten SP, Leapman MS, Greene KL. Intravesical chemotherapy in non-muscle-invasive bladder cancer. Indian Journal of Urology 2015;31(4):297-303. [PUBMED: 26604440]

\section{RevMan 2014 [Computer program]}

The Nordic Cochrane Centre, The Cochrane Collaboration. Review Manager (RevMan). Version 5.3. Copenhagen: The Nordic Cochrane Centre, The Cochrane Collaboration, 2014.

\section{Saint 2001}

Saint F, Irani J, Patard JJ, Salomon L, Hoznek A, Zammattio S, et al. Tolerability of Bacille Calmette-Guérin maintenance therapy for superficial bladder cancer. Urology 2001;57(5):883-8. [PUBMED: 11337287]

\section{Schünemann 2011}

Schünemann HJ, Oxman AD, Higgins JPT, Vist GE, Glasziou P, Guyatt GH. Chapter 11: Presenting results and 'Summary of findings' tables. In: Higgins JPT, Green S, editor(s), Cochrane Handbook for Systematic Reviews of Interventions. Version 5.1.0 (updated March 2011). The Cochrane Collaboration, 2011. Available from www.handbook.cochrane.org.

\section{Shang 2011}

Shang PF, Kwong J, Wang ZP, Tian J, Jiang L, Yang K, et al. Intravesical Bacillus Calmette-Guérin versus epirubicin for 
Ta and T1 bladder cancer. Cochrane Database of Systematic Reviews 2011, Issue 5. [DOI: 10.1002/14651858.CD006885.pub2]

\section{Shelley 2000}

Shelley M, Court JB, Kynaston H, Wilt TJ, Fish R, Mason M. Intravesical Bacillus Calmette-Guérin in Ta and T1 bladder cancer. Cochrane Database of Systematic Reviews 2000, Issue 4. [DOI: 10.1002/14651858.CD001986; PUBMED: 11034738]

\section{Shelley 2003}

Shelley M, Court JB, Kynaston H, Wilt T, Coles B, Mason M. Intravesical Bacillus Calmette-Guérin versus mitomycin $C$ for Ta and T1 bladder cancer. Cochrane Database of Systematic Reviews 2003, Issue 3. [DOI: 10.1002/14651858.CD003231; PUBMED: 12917955]

\section{Sylvester 2002}

Sylvester RJ, van der Meijden APM, Lamm DL. Intravesical Bacillus Calmette-Guerin reduces the risk of progression in patients with superficial bladder cancer: a meta-analysis of the published results of randomized clinical trials. Journal of Urology 2002;168(5):1964-70. [PUBMED: 12394686]

\section{Sylvester 2004}

Sylvester RJ, Oosterlinck W, van der Meijden APM. A single immediate postoperative instillation of chemotherapy decreases the risk of recurrence in patients with stage Ta T1 bladder cancer: a meta-analysis of published results of randomized clinical trials. Journal of Urology 2004;171(6 Pt 1):2186-90. [PUBMED: 15126782]

\section{Sylvester 2005}

Sylvester RJ, van der Meijden A, Witjes JA, Jakse G, Nonomura N, Cheng C, et al. High-grade Ta urothelial carcinoma and carcinoma in situ of the bladder. Urology 2005;66 (6 Suppl 1):90-107. [PUBMED: 16399418]

\section{Sylvester 2006}

Sylvester RJ, van der Meijden APM, Oosterlinck W, Witjes JA, Bouffioux C, Denis L, et al. Predicting recurrence and progression in individual patients with stage Ta T1 bladder cancer using EORTC risk tables: a combined analysis of 2596 patients from seven EORTC trials. European Urology 2006;49(3):466-77. [PUBMED: 16442208]

\section{CHARACTERISTICS OF STUDIES}

Characteristics of included studies [ordered by study ID]

\section{Sylvester 2016}

Sylvester RJ, Oosterlinck W, Holmang S, Sydes MR, Birtle A, Gudjonsson S, et al. Systematic review and individual patient data meta-analysis of randomized trials comparing a single immediate instillation of chemotherapy after transurethral resection with transurethral resection alone in patients with stage pTa-pT1 urothelial carcinoma of the bladder: which patients benefit from the instillation?. European Urology 2016;69(2):231-44.

\section{Van Driel 2015}

Van Driel WJ, Lok CAR, Verwaal V, Sonke GS. The role of hyperthermic intraperitoneal intraoperative chemotherapy in ovarian cancer. Current Treatment Options in Oncology 2015;16(4):14. [PUBMED: 25796375]

\section{Veeratterapillay 2016}

Veeratterapillay R, Heer R, Johnson MI, Persad R, Bach C. Highrisk non-muscle-invasive bladder cancer - therapy options during intravesical BCG shortage. Current Urology Reports 2016;17(9):68. [PUBMED: 27492610]

\section{Witjes 1998}

Witjes JA, v d Meijden AP, Collette L, Sylvester R, Debruyne FM, van Aubel A, et al. Long-term follow-up of an EORTC randomized prospective trial comparing intravesical Bacille CalmetteGuerin-RIVM and mitomycin C in superficial bladder cancer. EORTC GU Group and the Dutch South East Cooperative Urological Group. European Organisation for Research and Treatment of Cancer Genito-Urinary Tract Cancer Collaborative Group. Urology 1998;52(3):403-10.

\section{References to other published versions of this review Gudeloglu 2015}

Gudeloglu A, Kiziloz H, Neuberger MM, Kuntz GM, Dahm P. Intravesical electromotive drug administration for non-muscle invasive bladder cancer. Cochrane Database of Systematic Reviews 2015, Issue 9. [DOI: 10.1002/14651858.CD011864]

* Indicates the major publication for the study

\section{Di Stasi 2003}

\begin{tabular}{ll} 
Methods & Design: RCT, cross-over. \\
& Randomisation: blocked randomisation across $8(2 \times 2 \times 2)$ strata derived from prognostic criteria. \\
& Setting: multicentre/Italy. \\
& Dates when study was conducted: June 1994 to March 2001. \\
\hline Participants & $\begin{array}{l}\text { Inclusion criteria: people with histologically confirmed multifocal CIS of the bladder and most had } \\
\text { concurrent pT1 papillary transitional-cell carcinoma (all participants had adequate bone-marrow re- } \\
\text { serve, normal renal function, normal liver function and a Karnofsky Performance Score of 50-100). }\end{array}$
\end{tabular}


Di Stasi 2003 (Continued)

Exclusion criteria: people with a history of prior carcinoma of the bladder or upper urinary tract (or both), other malignancies within 5 years of registration and pregnancy.

Total number of participants randomly assigned: 108.

\section{Group A}

Number of participants randomly assigned: 36 .

Median age (years, interquartile range): 64.5 (not reported).

Number of participants according to gender (male/female): 26/10.

Risk classification (number of participants):

- primary/recurrent disease: all primary disease;

- stage Ta/T1: 0/32;

- grade G1/G2/G3: not reported;

- concomitant CIS: 36;

- multifocality: not reported;

- EAU risk classification (low/intermediate/high): not reported.

\section{Group B}

Number of participants randomly assigned: 36 .

Median age (years, interquartile range): 68.5 (not reported).

Number of participants according to gender (male/female): 26/10.

Risk classification (number of participants):

- primary/recurrent disease: all primary disease;

- stage $\mathrm{Ta} / \mathrm{T} 1: 0 / 33$;

- grade G1/G2/G3: not reported;

- concomitant CIS: 36;

- multifocality: not reported;

- EAU risk classification (low/intermediate/high): not reported.

\section{Group C}

Number of participants randomly assigned: 36 .

Median age (years, interquartile range): 66.5 (not reported).

Number of participants according to gender (male/female): 27/9.

Risk classification (number of participants):

- primary/recurrent disease: all primary disease;

- stage Ta/T1: 0/33;

- grade G1/G2/G3: not reported;

- concomitant CIS: 36;

- multifocality: not reported;

- EAU risk classification (low/intermediate/high): not reported.

\section{Group A}

MMC-EMDA induction after TURBT: MMC $40 \mathrm{mg}$ with excipient sodium chloride $960 \mathrm{mg}$ dissolved in 100 $\mathrm{mL}$ water instilled and retained in bladder for 30 minutes with $20 \mathrm{~mA}$ pulsed electric current $(600 \mathrm{~mA} /$ minute). 
Di Stasi 2003 (Continued)

\section{Group B}

MMC-PD induction after TURBT: MMC $40 \mathrm{mg}$ with excipient sodium chloride $960 \mathrm{mg}$ dissolved in $100 \mathrm{~mL}$ water instilled and retained in bladder for 60 minutes.

\section{Group C}

BCG induction after TURBT: intravesically with Pasteur BCG $81 \mathrm{mg}$ wet weight (mean \pm SEM: $10.2 \pm 9.0 \times$ $10^{8} \mathrm{cfu}$ ). Lyophilised BCG suspended in $50 \mathrm{~mL}$ bacteriostatic-free sodium chloride $0.9 \%$ solution. After draining bladder, suspension instilled and retained for 120 minutes.

Intervention duration: 6 intravesical treatments at weekly intervals about 3 weeks after TURBT.

\section{Adjuvant therapy for all groups}

6 intravesical treatments at weekly intervals commencing approximately 3 weeks after multiple biopsy/TURBT procedures.

- Complete response to initial 6 weekly treatments: further 10 monthly instillations.

- Cancer persisted at 3 months: second 6-week course instillations.

- Disease persisted at 6 months: cross-over to a 6-week second-line course of BCG in MMC groups and MMC-EMDA for participants in BCG group.

\begin{tabular}{ll}
\hline Outcomes & - Time to first recurrence (disease-free interval). \\
- Time to progression. \\
- Time to death due to any cause. \\
- Local and systemic adverse effects. \\
- MMC pharmacokinetics.
\end{tabular}

Median duration and interquartile range of follow-up (months): 43 (range: not reported).

Declarations of interest Financial interest or other relationship with Physion Srl, or both.

Notes Language of article: English.

\section{Risk of bias}

\begin{tabular}{lll}
\hline Bias & Authors' judgement & Support for judgement \\
\hline $\begin{array}{l}\text { Random sequence genera- } \\
\text { tion (selection bias) }\end{array}$ & Low risk & $\begin{array}{l}\text { Quote: "Randomization and data collection were performed using a central } \\
\text { computer." } \\
\text { Judgement comment: randomisation performed by central computer. }\end{array}$ \\
\hline $\begin{array}{l}\text { Allocation concealment } \\
\text { (selection bias) }\end{array}$ & Unclear risk & Judgement comment: no information given. \\
\hline $\begin{array}{l}\text { Blinding of participants } \\
\text { and personnel (perfor- } \\
\text { mance bias) } \\
\begin{array}{l}\text { Time to recurrence and } \\
\text { progression/adverse } \\
\text { events }\end{array}\end{array}$ & High risk & $\begin{array}{l}\text { Judgement comment: no blinding reported; however, continued treatment } \\
\text { was dependent on participant response so personnel blinding was unlikely. }\end{array}$ \\
\hline
\end{tabular}


Di Stasi 2003 (Continued)

Blinding of participants and personnel (perfor-

Low risk Judgement comment: blinding not reported, but unlikely to have affected outcome.

mance bias)

Disease-specific sur-

vival/time to death

\section{Blinding of outcome as- sessment (detection bias) Objective outcomes (time to death)

\author{
Blinding of outcome as- \\ sessment (detection bias) \\ Subjective outcomes \\ (time to recurrence and \\ progression/adverse \\ events/disease-specific \\ survival)
}

Low risk

come.

High risk

Quote: "weeks after multiple biopsy/TUR [transurethral resection] procedures. Patients in the 3 groups who had a complete response to the initial 6 weekly treatments underwent a further 10 monthly instillations. If cancer persisted at 3 months, a second 6-week course was given. If disease persisted at 6 months, there was a crossover to a 6 -week second line course of BCG for patients in."

Judgement comment: blinding would have been broken due to additional MMC studies to MMC-PD and MMC-EMDA arm.

$\begin{array}{ll}\begin{array}{l}\text { Incomplete outcome data } \\ \text { (attrition bias) }\end{array} & \text { Low risk } \\ \text { All outcome } & \text { across all groups at } 3 \text { months. }\end{array}$

\begin{tabular}{|c|c|c|}
\hline $\begin{array}{l}\text { Selective reporting (re- } \\
\text { porting bias) }\end{array}$ & Unclear risk & $\begin{array}{l}\text { Judgement comment: all outcomes reported well, but protocol was not pub- } \\
\text { lished. }\end{array}$ \\
\hline
\end{tabular}

\begin{tabular}{ll}
\hline Other bias & Low risk
\end{tabular} \begin{tabular}{l}
$\begin{array}{l}\text { Quote: "A total of } 53 \text { patients underwent crossover treatments, including } 40 \\
\text { with persistent disease who changed from passive MMC (25) and electromo- } \\
\text { tive MMC (15) to a 6-week course of BCG, while } 13 \text { in whom BCG failed changed } \\
\text { to a course of electromotive MMC." } \\
\text { Judgement comment: given that we only used data to a time-point prior to } \\
\text { cross-over, the results of this review are not affected by this issue. }\end{array}$ \\
\hline
\end{tabular}

\section{Di Stasi 2006}

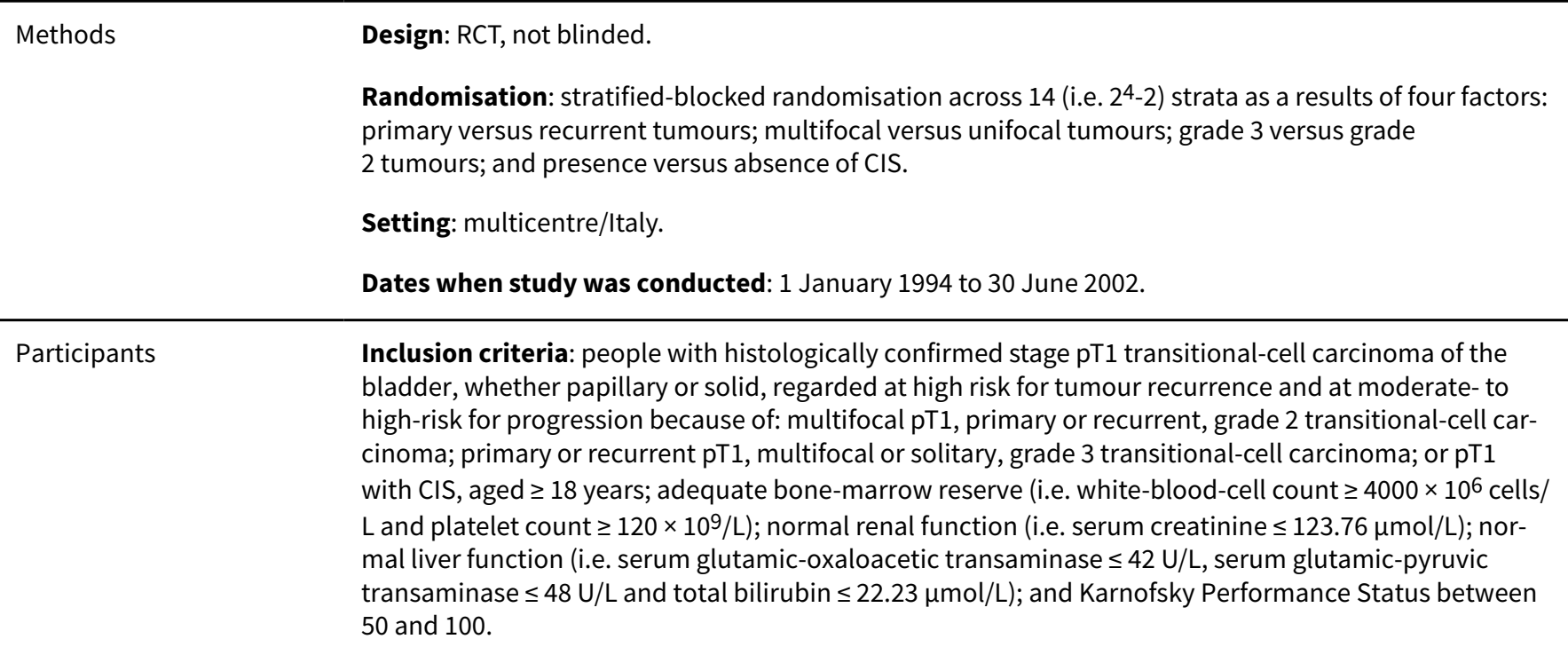


Di Stasi 2006 (Continued)

Exclusion criteria: people with previous treatment with BCG or MMC-EMDA; treatment with any other intravesical cytostatic agent within the past 6 months; concomitant urothelial tumours of the upper urinary tract; previous muscle-invasive (i.e. $\geq$ stage T2) transitional-cell carcinoma of the bladder; bladder capacity $<2$ L; untreated urinary tract infection; severe systemic infection (i.e. sepsis); urethral strictures that would prevent endoscopic procedures and repeated catheterisation; disease of upper urinary tract (e.g. vesicoureteral reflux or urinary tract stones) that would make multiple transurethral procedures a risk; previous radiotherapy to the pelvis; other concurrent chemotherapy; treatment with radiotherapy-response or biological-response modifiers; history of tuberculosis; other malignant diseases within 5 years of trial registration (except for basal-cell carcinoma); pregnancy or nursing; and psychological, familial, sociological or geographical factors that would preclude study participation.

Total number of participants randomly assigned: 212 .

\section{Group A}

Number of participants randomly assigned: 107 .

Median age (years, interquartile range): 66.0 (56.0-73.0).

Number of participants according to gender (male/female): 87/20.

Risk classification (number of participants):

- primary/recurrent disease: $61 / 46$;

- stage Ta/T1: all T1 disease;

- grade G1/G2/G3: 0/65/42;

- concomitant CIS: 29;

- multifocality: 87;

- EAU risk classification (low/intermediate/high): not reported.

\section{Group B}

Number of participants randomly assigned: 105.

Median age (years, interquartile range): 67.0 (61.0-73.0).

Number of participants according to gender (male/female): 86/19.

Risk classification (number of participants):

- primary/recurrent disease: $62 / 43$;

- stage Ta/T1: all T1 disease;

- grade G1/G2/G3: 0/64/41;

- concomitant CIS: 28;

- multifocality: 85;

- EAU risk classification (low/intermediate/high): not reported.

\section{Group A}

MMC-EMDA with sequential BCG induction and maintenance after TURBT.

- BCG infusion: BCG $81 \mathrm{mg}$ wet weight $\left(10.2 \pm 9.0 \times 10^{8} \mathrm{cfu}\right)$ Connaught substrain (ImmuCyst, Alfa Wassermann SpA, Bologna, Italy) was suspended in $50 \mathrm{~mL}$ bacteriostatic-free solution of $0.9 \%$ sodium chloride. After draining the bladder, suspension was infused intravesically for 120 minutes.

- MMC infusion: MMC 40 mg (Mitomycin, Kyowa Italiana Farmaceutici, Srl, Milan, Italy) dissolved in 100 $\mathrm{mL}$ water was infused intravesically through the Foley catheter by gravity and retained in the bladder for 30 minutes, while 40-60 mA per second to a maximum of $20 \mathrm{~mA}$ for 30 minutes pulsed electric current was given externally.

\section{Group B}

BCG induction and maintenance after TURBT: see above. 
Di Stasi 2006 (Continued)

Induction therapy: about 3 weeks after TURBT.

\section{Group A}

BCG and sequential MMC-EMDA: 3 cycles of treatment per week for 9 weeks for which 1 cycle consisted of 2 BCG infusions and 1 MMC infusion.

\section{Group B}

BCG alone: 6 intravesical treatments at weekly intervals.

Maintenance therapy (disease-free 3 months after treatment).

\section{Group A}

BCG and sequential MMC-EMDA: 1 infusion per month for 9 months: 3 cycles of MMC, MMC and BCG.

\section{Group B}

BCG alone: monthly infusion of BCG for 10 months.

$\begin{array}{ll}\text { Outcomes } & \text { Primary end point: } \\ \text { - Disease-free interval. } \\ \text { Secondary end points: } \\ \text { - Time to progression. } \\ \text { - Overall survival. } \\ \text { - Disease-specific survival. }\end{array}$

Toxic effects: local, systemic, or allergic adverse effects.

Median duration and interquartile range of follow-up (months): 88 (63-110).

\begin{tabular}{|c|c|c|}
\hline Funding sources & \multicolumn{2}{|l|}{ Not reported. } \\
\hline Declarations of interest & \multicolumn{2}{|l|}{ No conflicts of interest. } \\
\hline Notes & \multicolumn{2}{|c|}{ Language of article: English. } \\
\hline \multicolumn{3}{|l|}{ Risk of bias } \\
\hline Bias & Authors' judgement & Support for judgement \\
\hline $\begin{array}{l}\text { Random sequence genera- } \\
\text { tion (selection bias) }\end{array}$ & Low risk & Judgement comment: computer-generated random sequence. \\
\hline $\begin{array}{l}\text { Allocation concealment } \\
\text { (selection bias) }\end{array}$ & Unclear risk & Judgement comment: no information given. \\
\hline $\begin{array}{l}\text { Blinding of participants } \\
\text { and personnel (perfor- } \\
\text { mance bias) }\end{array}$ & High risk & $\begin{array}{l}\text { Quote: "This study was not blinded because of differences in treatment sched- } \\
\text { ules and drug appearance." }\end{array}$ \\
\hline $\begin{array}{l}\text { Time to recurrence and } \\
\text { progression/adverse } \\
\text { events }\end{array}$ & & Judgement comment: blinding was not done. \\
\hline
\end{tabular}

Blinding of participants Low risk Judgement comment: outcomes unlikely to be affected by lack of blinding.
and personnel (perfor-
mance bias)


Di Stasi 2006 (Continued)

Disease-specific sur-

vival/time to death

\begin{tabular}{|c|c|c|}
\hline $\begin{array}{l}\text { Blinding of outcome as- } \\
\text { sessment (detection bias) } \\
\text { Objective outcomes (time }\end{array}$ & Low risk & $\begin{array}{l}\text { Judgement comment: blinding of outcome assessor may not have affected on } \\
\text { objective outcomes. }\end{array}$ \\
\hline
\end{tabular}
to death)

Blinding of outcome as- High risk Judgement comment: outcome assessors were not blinded.
sessment (detection bias)
Subjective outcomes
(time to recurrence and
progression/adverse
events/disease-specific
survival)

Incomplete outcome data Low risk Judgement comment: all participants randomised were included in analysis.
(attrition bias)
All outcome

\begin{tabular}{lll}
\hline $\begin{array}{l}\text { Selective reporting (re- } \\
\text { porting bias) }\end{array}$ & Low risk & $\begin{array}{l}\text { Judgement comment: protocol (NCT01442519) was published and all out- } \\
\text { comes reported well. }\end{array}$ \\
\hline Other bias & Low risk & Judgement comment: not detected. \\
\hline
\end{tabular}

Di Stasi 2011

$\begin{array}{ll}\text { Methods } & \text { Design: RCT, parallel. } \\ & \begin{array}{l}\text { Randomisation: stratified-blocked randomisation across } 6(2 \times 3) \text { strata derived from prognostic crite- } \\ \text { ria. }\end{array}\end{array}$
ria.

Setting: multicentre/Italy.

Dates when study was conducted: 1 January 1994 to 31 December 2003.

Participants

Inclusion criteria: people aged $\geq 18$ years with pTa and pT1 urothelial carcinoma of the bladder, adequate bone-marrow reserve (i.e. white-blood-cell count $\geq 4000 \times 10^{6}$ cells/L; platelet count $\geq 120 \times 10^{9}$ / L), normal renal function (i.e. serum creatinine $\leq 123.76 \mu \mathrm{mol} / \mathrm{L}$ ), normal liver function (i.e. serum glutamic-oxaloacetic aminotransferase $\leq 42 \mathrm{U} / \mathrm{L}$, serum glutamic-pyruvic aminotransferase $\leq 48 \mathrm{U} / \mathrm{L}$ and total bilirubin $\leq 22 \mu \mathrm{mol} / \mathrm{L}$ ), and Eastern Cooperative Oncology Group performance status between 0 and 2.

Exclusion criteria: people with non-urothelial carcinomas of the bladder; previous bladder cancer; previous intravesical treatment with chemotherapeutic and immunotherapeutic drugs; known allergy to mitomycin; previous or concomitant urinary tract CIS, urothelial carcinoma of the upper urinary tract and urethra, or both; bladder capacity $<200 \mathrm{~mL}$; untreated urinary tract infection; severe systemic infection (i.e. sepsis); treatment with immunosuppressive drugs; urethral strictures that would prevent endoscopic procedures and catheterisation; previous radiotherapy to the pelvis; other concurrent chemotherapy, radiotherapy, and treatment with biological response modifiers; other malignant diseases within 5 years of trial registration (except for adequately treated basal-cell or squamous-cell skin cancer, in situ cervical cancer); pregnancy; and any factors that would preclude study participation.

Total number of participants randomly assigned: 374 (352: 11 with concomitant CIS and 11 with muscle invasive disease (stage pT2) were excluded on restaging TURBT.

\section{Group A}

Number of participants randomly assigned: 124 (117 in analysis). 
Median age (years, interquartile range): 67.0 (63.0-74.0).

Number of participants according to gender (male/female): 92/25.

Risk classification (number of participants):

- primary/recurrent disease: all primary disease;

- stage Ta/T1:63/54;

- grade G1/G2/G3: 22/62/33;

- concomitant CIS: not reported;

- multifocality: 81;

- EAU risk classification (low/intermediate/high): 11/73/33.

\section{Group B}

Number of participants randomly assigned: 126 (119 in analysis).

Median age (years, interquartile range): 67.0 (61.0-72.0).

Number of participants according to gender (male/female): 92/27.

Risk classification (number of participants):

- primary/recurrent disease: all primary disease;

- stage Ta/T1: 64/55;

- grade G1/G2/G3: 23/64/32;

- concomitant CIS: not reported;

- multifocality: 84;

- EAU risk classification (low/intermediate/high): 10/77/32.

\section{Group C}

Number of participants randomly assigned: 124 (116 in analysis).

Median age (years, interquartile range): 66.5 (60.0-73.0).

Number of participants according to gender (male/female): 92/24.

Risk classification (number of participants):

- primary/recurrent disease: all primary disease;

- stage Ta/T1:63/53;

- grade G1/G2/G3: 21/63/32;

- concomitant CIS: not reported;

- multifocality: 80;

- EAU risk classification (low/intermediate/high): 9/75/32.

\section{Group A}

Single-dose, MMC-EMDA before TURBT: about 30 minutes before spinal or general anaesthesia TURBT participants received mitomycin $40 \mathrm{mg}$ dissolved in $100 \mathrm{~mL}$ sterile water infused intravesically through the Foley catheter by gravity and retained in the bladder for 30 minutes, while $20 \mathrm{~mA}$ pulsed electric current for 30 minutes was given externally. The mitomycin solution was drained and TURBT was done.

\section{Group B}

Single-dose, MMC-PD immediately after TURBT: participants received mitomycin $40 \mathrm{mg}$ dissolved in 50 $\mathrm{mL}$ sterile water within 6 hours of TURBT. After bladder draining, the mitomycin solution was infused intravesically through a Foley catheter, retained in the bladder for 60 minutes with catheter clamping, and then drained.

\section{Group C}


Di Stasi 2011 (Continued)

TURBT alone.

\section{Adjuvant therapy}

\section{Induction therapy}

- Low-risk NMIBC: no adjuvant therapy.

- Intermediate-risk NMIBC: initial intravesical treatment of MMC-PD $40 \mathrm{mg}$ dissolved in $50 \mathrm{~mL}$ sterile water and retained in the bladder for 60 minutes, once a week for 6 weeks.

- High-risk NMIBC cancer: initial intravesical treatment of BCG $81 \mathrm{mg}$ Connaught substrain (ImmuCyst, Alfa Wassermann SpA, Bologna, Italy) dissolved in $50 \mathrm{~mL}$ bacteriostatic-free solution of $0.9 \%$ sodium chloride and retained in the bladder for 120 minutes once per week for 6 weeks.

Maintenance therapy (disease free at 3 months after induction treatment).

Monthly intravesical instillation for 10 months, with the same dose and methods of infusion as initial assigned treatment. Total of 16 instillations were given over 12 months.

Outcomes $\quad$ Primary end points:
- Recurrence rate.
- Disease-free interval.
Secondary end points:
- Time to progression.
- Overall survival.
- Disease-specific survival.

Safety: local, systemic, or allergic symptoms and adverse effects.

Median duration and interquartile range of follow-up (months): 86 (57-125).

\begin{tabular}{|c|c|c|}
\hline Funding sources & \multicolumn{2}{|l|}{ None. } \\
\hline Declarations of interest & \multicolumn{2}{|l|}{ No conflict of interest. } \\
\hline Notes & \multicolumn{2}{|c|}{ Language of article: English. } \\
\hline \multicolumn{3}{|l|}{ Risk of bias } \\
\hline Bias & Authors' judgement & Support for judgement \\
\hline $\begin{array}{l}\text { Random sequence genera- } \\
\text { tion (selection bias) }\end{array}$ & Low risk & $\begin{array}{l}\text { Quote: "We randomly assigned patients to one of our three treatment groups } \\
\text { by means of stratified-blocked randomisation across six (two by three) strata } \\
\text { derived from two prognostic criteria: unifocal versus multifocal tumours, and } \\
\text { grade } 1 \text { versus grade } 2 \text { versus grade } 3 \text { urothelial carcinoma. This method en- } \\
\text { sured prognostic parity among our three treatment groups." } \\
\text { Judgement comment: computer-generated sequence. }\end{array}$ \\
\hline $\begin{array}{l}\text { Allocation concealment } \\
\text { (selection bias) }\end{array}$ & Low risk & $\begin{array}{l}\text { Quote: "We concealed assignment by varying the blocking number. Variation } \\
\text { of the block number prevented the clinician from guessing what the next treat- } \\
\text { ment will be; therefore, varying the block sizes at random makes it difficult (al- } \\
\text { though not impossible) to break the treatment code." } \\
\text { Judgement comment: appropriate allocation concealment. }\end{array}$ \\
\hline $\begin{array}{l}\text { Blinding of participants } \\
\text { and personnel (perfor- } \\
\text { mance bias) }\end{array}$ & High risk & $\begin{array}{l}\text { Quote: "Patients and the physicians giving the interventions were aware of as- } \\
\text { signment." }\end{array}$ \\
\hline
\end{tabular}


Di Stasi 2011 (Continued) Time to recurrence and progression/adverse events
Judgement comment: lack of blinding may have affected these outcomes.

\begin{tabular}{|c|c|c|}
\hline $\begin{array}{l}\text { Blinding of participants } \\
\text { and personnel (perfor- } \\
\text { mance bias) } \\
\text { Disease-specific sur- } \\
\text { vival/time to death }\end{array}$ & Low risk & $\begin{array}{l}\text { Quote: "Patients and physicians giving the interventions were aware of assign- } \\
\text { ment." } \\
\text { Judgement comment: not blinded but unlikely to be affected. }\end{array}$ \\
\hline $\begin{array}{l}\text { Blinding of outcome as- } \\
\text { sessment (detection bias) } \\
\text { Objective outcomes (time } \\
\text { to death) }\end{array}$ & Low risk & $\begin{array}{l}\text { Quote: "Assignment was masked from the outcome assessors and data ana- } \\
\text { lysts." } \\
\text { Judgement comment: outcome assessors were blinded. }\end{array}$ \\
\hline $\begin{array}{l}\text { Blinding of outcome as- } \\
\text { sessment (detection bias) } \\
\text { Subjective outcomes } \\
\text { (time to recurrence and } \\
\text { progression/adverse } \\
\text { events/disease-specific } \\
\text { survival) }\end{array}$ & Low risk & $\begin{array}{l}\text { Quote: "assignment was masked from the outcome assessors and data ana- } \\
\text { lysts." } \\
\text { Judgement comment: outcome assessors were blinded. }\end{array}$ \\
\hline $\begin{array}{l}\text { Incomplete outcome data } \\
\text { (attrition bias) } \\
\text { All outcome }\end{array}$ & Low risk & $\begin{array}{l}\text { Judgement comment: } 117 / 124(94.3 \%), 119 / 126(94.4 \%) \text {, and } 116 / 124(93.5 \%) \\
\text { participants randomised in Group A, B and C were included in analysis, respec- } \\
\text { tively. }\end{array}$ \\
\hline $\begin{array}{l}\text { Selective reporting (re- } \\
\text { porting bias) }\end{array}$ & Low risk & $\begin{array}{l}\text { Judgement comment: protocol (NCT01149174) was published and all out- } \\
\text { comes appeared reported. }\end{array}$ \\
\hline Other bias & Low risk & Judgement comment: no other sources of bias detected. \\
\hline
\end{tabular}

BCG: Bacillus Calmette-Guerin; cfu: colony-forming unit; CIS: carcinoma in situ; EAU: European Association of Urology; MMC-EMDA: electromotive drug administration of mitomycin C; MMC-PD: passive diffusion of mitomycin C; NMIBC: non-muscle invasive bladder cancer; RCT: randomised controlled trial; SEM: standard error of the mean; TURBT: transurethral resection of bladder tumour.

Characteristics of excluded studies [ordered by study ID]

\begin{tabular}{ll}
\hline Study & Reason for exclusion \\
\hline Brausi 1998 & Wrong study design (non-randomised trial). \\
\hline Grossman 2006 & Wrong study design (commentary). \\
\hline
\end{tabular}

\section{Characteristics of studies awaiting assessment [ordered by study ID]}

NCT01920269

\begin{tabular}{ll}
\hline Methods & Randomised parallel open-label trial. \\
\hline Participants & Inclusion criteria \\
& - Histologically confirmed primary stage $\mathrm{pTa}$-pT 1 urothelial bladder cancer. \\
& - Adequate bone-marrow reserve (i.e. white-blood-cell count $\geq 4000 \times 10^{6}$ cells $/ \mathrm{L} ;$ platelet count $\geq$ \\
& $\left.120 \times 10^{9} / \mathrm{L}\right)$.
\end{tabular}


- Normal renal function (i.e. serum creatinine $\leq 123.76 \mu \mathrm{mol} / \mathrm{L}$ ).

- Normal liver function (i.e. serum glutamic-oxaloacetic aminotransferase $\leq 42 \mathrm{U} / \mathrm{L}$, serum glutamic-pyruvic aminotransferase $\leq 48 \mathrm{U} / \mathrm{L}$ and total bilirubin $\leq 22 \mu \mathrm{mol} / \mathrm{L}$ ).

- Eastern Cooperative Oncology Group performance status between 0 and 2 .

\section{Exclusion criteria}

- Non-urothelial carcinomas of the bladder.

- Previous or concomitant grade G3 urothelial or carcinoma in situ of the bladder, or both.

- Urothelial carcinoma of the upper urinary tract and urethra, or both.

- Previous intravesical treatment with chemotherapeutic and immunotherapeutic drugs.

- Known allergy to mitomycin.

- Bladder capacity $<200 \mathrm{~mL}$.

- Untreated urinary tract.

- Infection; severe systemic infection (i.e. sepsis).

- Treatment with immunosuppressive drugs.

- Urethral strictures that would prevent endoscopic procedures and catheterisation.

- Previous radiotherapy to the pelvis.

- Other concurrent chemotherapy, radiotherapy and treatment with biological response modifiers.

- Other malignant diseases within 5 years of trial registration (except for adequately treated basalcell or squamous-cell skin cancer, in situ cervical cancer).

- Pregnancy.

- Any factors that would preclude study participation.

\section{Group A}

Transurethral resection alone: participants underwent urinary cytology, random cold-cup biopsies of the bladder and prostatic urethra, and complete transurethral resection of all bladder tumour visible on endoscopy, ensuring muscle is included in resected samples.

\section{Group B}

Intravesical MMC-PD after TURBT: mitomycin $40 \mathrm{mg}$ dissolved in $50 \mathrm{~mL}$ sterile water is infused intravesically through a Foley catheter, retained in the bladder for 60 minutes with catheter clamping, and then drained. Participants who had a complete response to the initial 6 weekly treatments underwent a further 10 monthly instillations, with the same dose and methods of infusion as initial assigned treatment.

\section{Group C}

Intravesical electromotive mitomycin after TURBT: mitomycin $40 \mathrm{mg}$ dissolved in $100 \mathrm{~mL}$ water is instilled and retained in the bladder for 30 minutes with $20 \mathrm{~mA}$ pulsed electric current, and then drained. Participants who had a complete response to the initial 6 weekly treatments underwent a further 10 monthly instillations with the same dose and methods of infusion as initial assigned treatment.

Response to treatment will be assessed with cystoscopy, biopsy and urinary cytology at 3-month intervals for 2 years, 6-month intervals for 3 years and yearly thereafter.

Outcomes

\section{Primary outcome}

Disease-free interval (time frame: 120 months).

Time from randomisation to first cystoscopy noting recurrence as recorded by pathological assessment of transurethral-resection samples or biopsy samples.

\section{Secondary outcome}

Time to progression (time frame: 120 months). 
Time from randomisation until the onset of muscle invasive disease as recorded by pathological assessment of transurethral-resection samples or biopsy samples.

Overall survival (time frame: 120 months).

Time from randomisation until death from any cause.

Disease-specific survival (time frame: 120 months).

Time from randomisation until death from bladder cancer.

Notes ClinicalTrials.gov Identifier: NCT01920269.

This study has been completed, but the results have not published.

EMDA: electromotive drug administration; MMC-PD: passive diffusion of mitomycin C; TURBT: transurethral resection of bladder tumour.

DATA AND ANALYSES

Comparison 1. Postoperative MMC-EMDA induction versus postoperative BCG induction (short term)

\begin{tabular}{llllll}
\hline Outcome or subgroup title & No. of studies & $\begin{array}{l}\text { No. of partici- } \\
\text { pants }\end{array}$ & Statistical method & Effect size \\
\hline 1 Time to recurrence & 1 & 72 & Risk Ratio (M-H, Random, 95\% Cl) & $1.06[0.64,1.76]$ \\
\hline 2 Time to progression & 1 & 72 & Risk Ratio (M-H, Random, 95\% Cl) & $0.0[0.0,0.0]$ \\
\hline 3 Serious adverse events & 1 & 72 & Risk Ratio (M-H, Random, 95\% Cl) & $0.75[0.18,3.11]$ \\
\hline 4 Disease-specific survival & 1 & 72 & Risk Ratio (M-H, Random, 95\% Cl) & $0.0[0.0,0.0]$ \\
\hline 5 Time to death & 1 & 72 & Risk Ratio (M-H, Random, 95\% Cl) & $0.0[0.0,0.0]$ \\
\hline
\end{tabular}

Analysis 1.1. Comparison 1 Postoperative MMC-EMDA induction versus postoperative BCG induction (short term), Outcome 1 Time to recurrence.

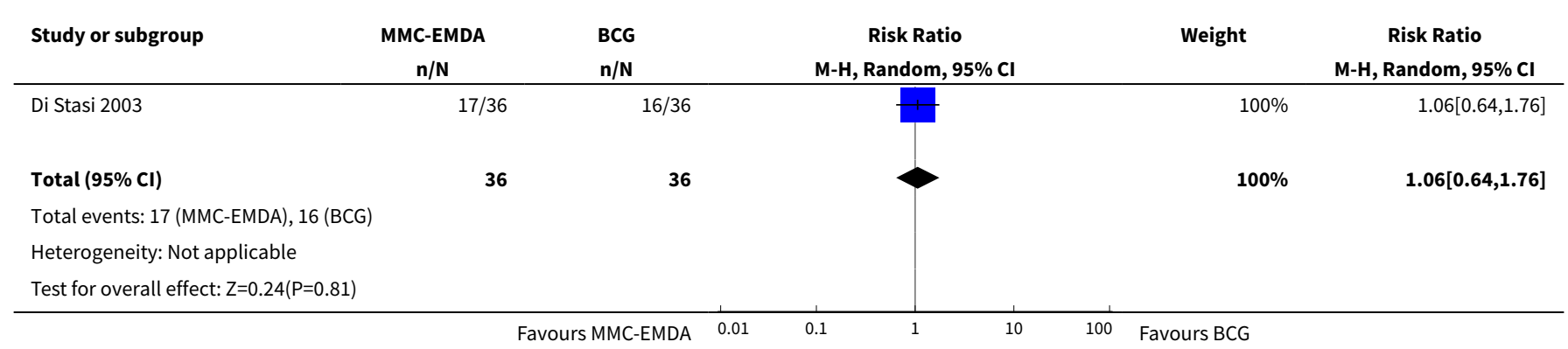


Analysis 1.2. Comparison 1 Postoperative MMC-EMDA induction versus postoperative BCG induction (short term), Outcome 2 Time to progression.

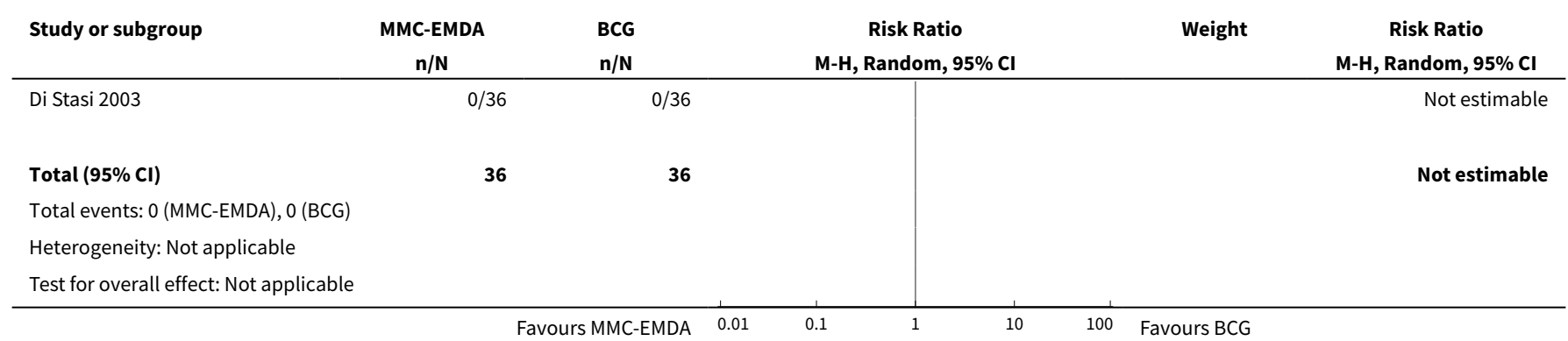

Analysis 1.3. Comparison 1 Postoperative MMC-EMDA induction versus postoperative BCG induction (short term), Outcome 3 Serious adverse events.

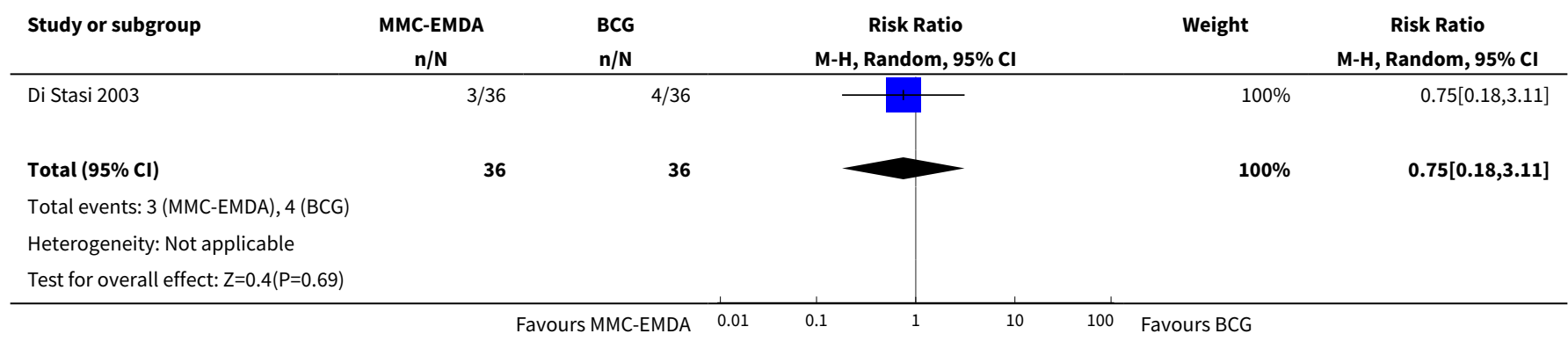

Analysis 1.4. Comparison 1 Postoperative MMC-EMDA induction versus postoperative BCG induction (short term), Outcome 4 Disease-specific survival.

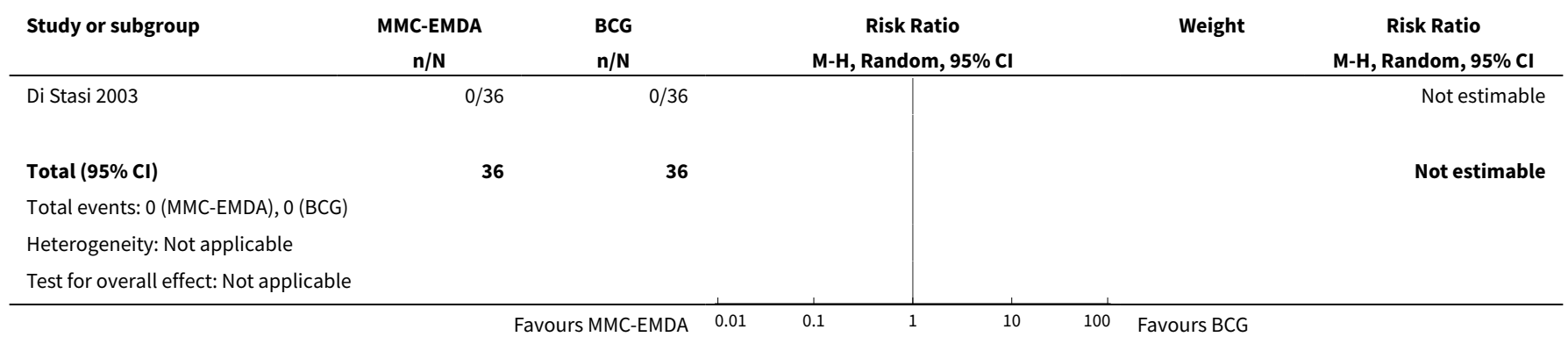

Analysis 1.5. Comparison 1 Postoperative MMC-EMDA induction versus postoperative BCG induction (short term), Outcome 5 Time to death.

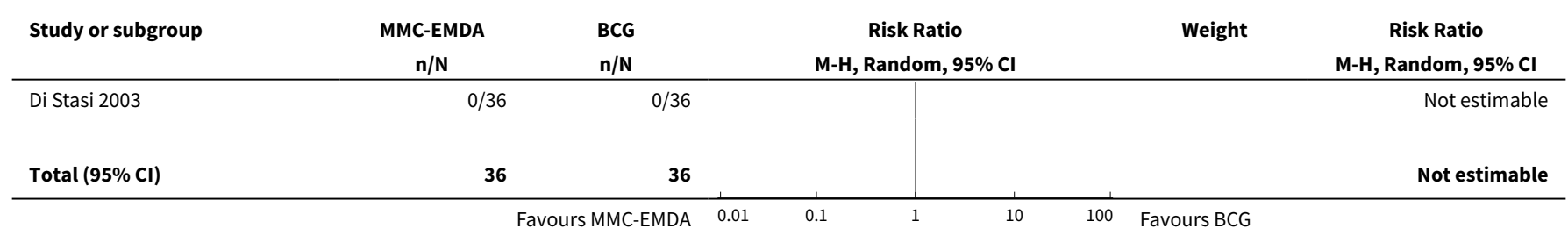




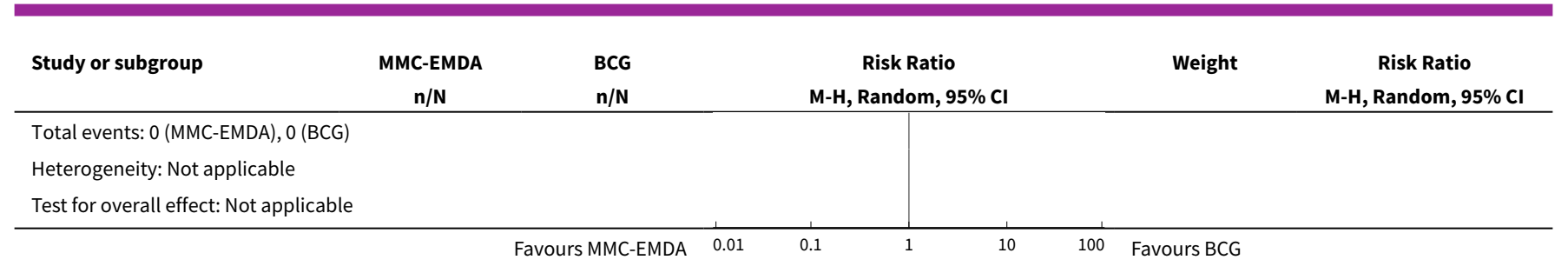

Comparison 2. Postoperative MMC-EMDA induction versus MMC-PD induction (short term)

\begin{tabular}{llllll}
\hline Outcome or subgroup title & No. of studies & $\begin{array}{l}\text { No. of partici- } \\
\text { pants }\end{array}$ & Statistical method & Effect size \\
\hline 1 Time to recurrence & 1 & 72 & Risk Ratio (M-H, Random, 95\% Cl) & $0.65[0.44,0.98]$ \\
\hline 2 Time to progression & 1 & 72 & Risk Ratio (M-H, Random, 95\% Cl) & $0.0[0.0,0.0]$ \\
\hline 3 Serious adverse events & 1 & 72 & Risk Ratio (M-H, Random, 95\% Cl) & $1.5[0.27,8.45]$ \\
\hline 4 Disease-specific survival & 1 & 72 & Risk Ratio (M-H, Random, 95\% Cl) & $0.0[0.0,0.0]$ \\
\hline 5 Time to death & 1 & 72 & Risk Ratio (M-H, Random, 95\% Cl) & $0.0[0.0,0.0]$ &
\end{tabular}

Analysis 2.1. Comparison 2 Postoperative MMC-EMDA induction versus MMC-PD induction (short term), Outcome 1 Time to recurrence.

\begin{tabular}{|c|c|c|c|c|c|}
\hline Study or subgroup & $\begin{array}{c}\text { MMC-EMDA } \\
\mathbf{n} / \mathbf{N} \\
\end{array}$ & $\begin{array}{c}\text { MMC-PD } \\
\mathbf{n} / \mathbf{N}\end{array}$ & $\begin{array}{c}\text { Risk Ratio } \\
\text { M-H, Random, } 95 \% \text { CI }\end{array}$ & Weight & $\begin{array}{c}\text { Risk Ratio } \\
\text { M-H, Random, } 95 \% \mathrm{CI}\end{array}$ \\
\hline Di Stasi 2003 & $17 / 36$ & $26 / 36$ & & $100 \%$ & $0.65[0.44,0.98]$ \\
\hline Total $(95 \% \mathrm{Cl})$ & 36 & 36 & & $100 \%$ & $0.65[0.44,0.98]$ \\
\hline \multicolumn{6}{|c|}{ Total events: 17 (MMC-EMDA), 26 (MMC-PD) } \\
\hline \multicolumn{6}{|c|}{ Heterogeneity: Not applicable } \\
\hline \multicolumn{6}{|c|}{ Test for overall effect: $Z=2.08(P=0.04)$} \\
\hline
\end{tabular}

Analysis 2.2. Comparison 2 Postoperative MMC-EMDA induction versus MMC-PD induction (short term), Outcome 2 Time to progression.

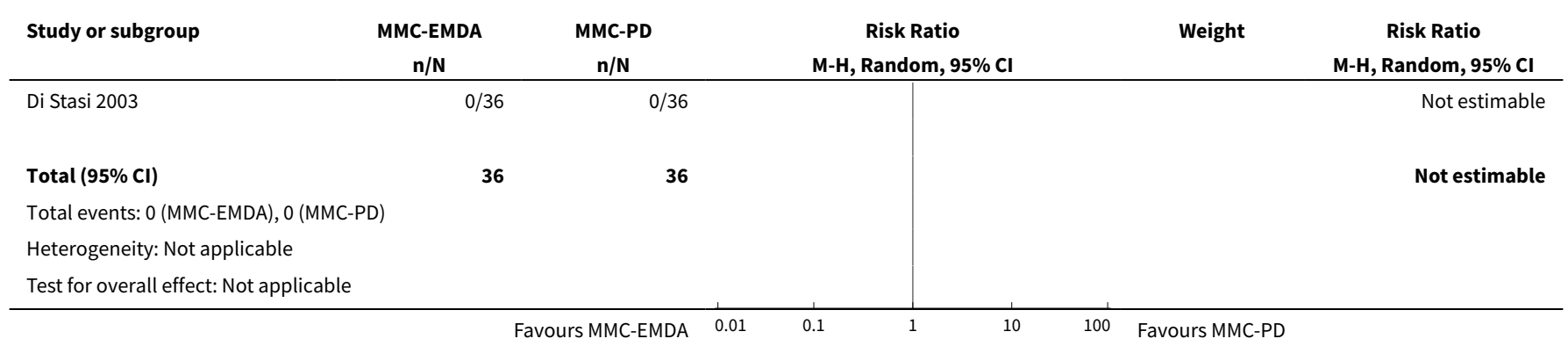


Analysis 2.3. Comparison 2 Postoperative MMC-EMDA induction versus MMC-PD induction (short term), Outcome 3 Serious adverse events.

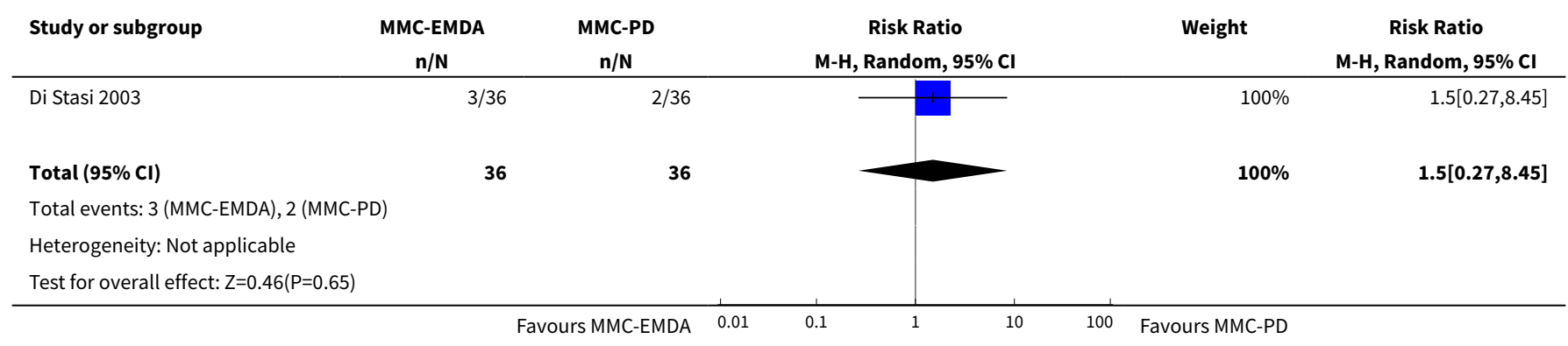

Analysis 2.4. Comparison 2 Postoperative MMC-EMDA induction versus MMC-PD induction (short term), Outcome 4 Disease-specific survival.

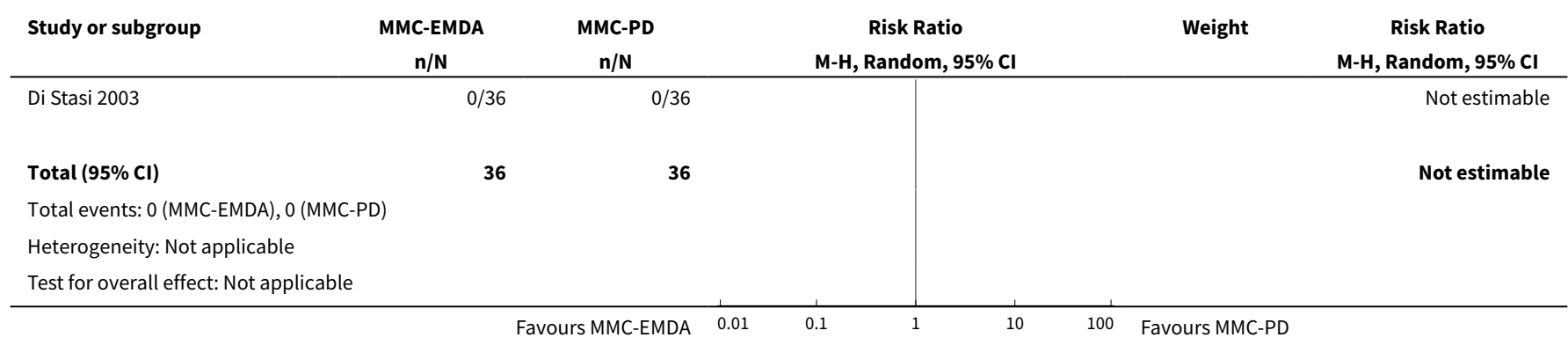

Analysis 2.5. Comparison 2 Postoperative MMC-EMDA induction versus MMC-PD induction (short term), Outcome 5 Time to death.

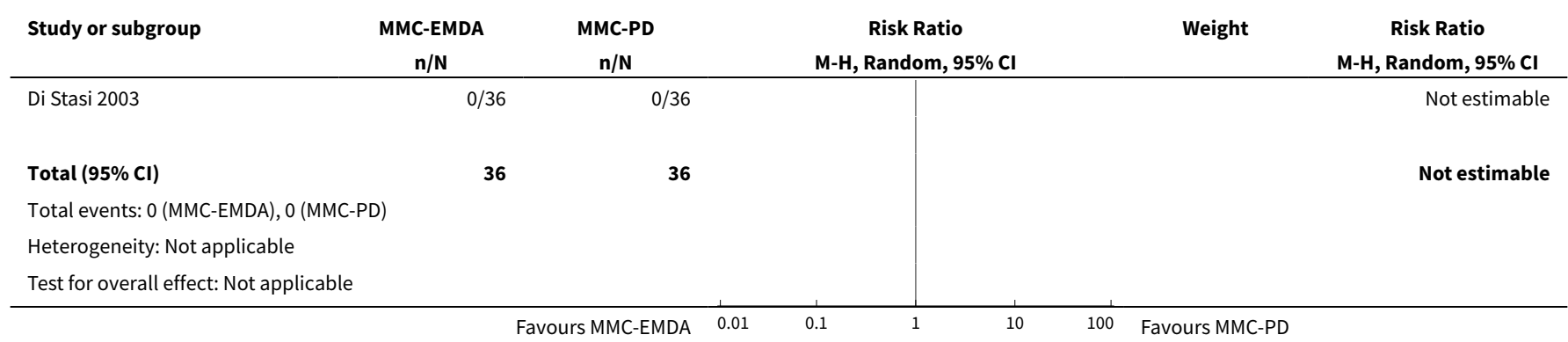

Comparison 3. Postoperative MMC-EMDA with sequential BCG induction and maintenance versus postoperative BCG induction and maintenance (long term)

\begin{tabular}{|c|c|c|c|c|}
\hline Outcome or subgroup title & No. of studies & $\begin{array}{l}\text { No. of partici- } \\
\text { pants }\end{array}$ & Statistical method & Effect size \\
\hline 1 Time to recurrence & 1 & 212 & Hazard Ratio (Random, 95\% Cl) & $0.51[0.34,0.77]$ \\
\hline
\end{tabular}




\begin{tabular}{lllll}
\hline Outcome or subgroup title & No. of studies & $\begin{array}{l}\text { No. of partici- } \\
\text { pants }\end{array}$ & Statistical method & Effect size \\
\hline 2 Time to progression & 1 & 212 & Hazard Ratio (Random, 95\% Cl) & $0.36[0.17,0.75]$ \\
\hline 3 Serious adverse events & 1 & 212 & Risk Ratio (M-H, Random, 95\% Cl) & $1.02[0.21,4.94]$ \\
\hline 4 Disease-specific survival & 1 & 212 & Hazard Ratio (Random, 95\% Cl) & $0.31[0.12,0.80]$ \\
\hline 5 Time to death & 1 & 212 & Hazard Ratio (Random, 95\% Cl) & $0.59[0.35,1.00]$ \\
\hline
\end{tabular}

Analysis 3.1. Comparison 3 Postoperative MMC-EMDA with sequential BCG induction and maintenance versus postoperative BCG induction and maintenance (long term), Outcome 1 Time to recurrence.

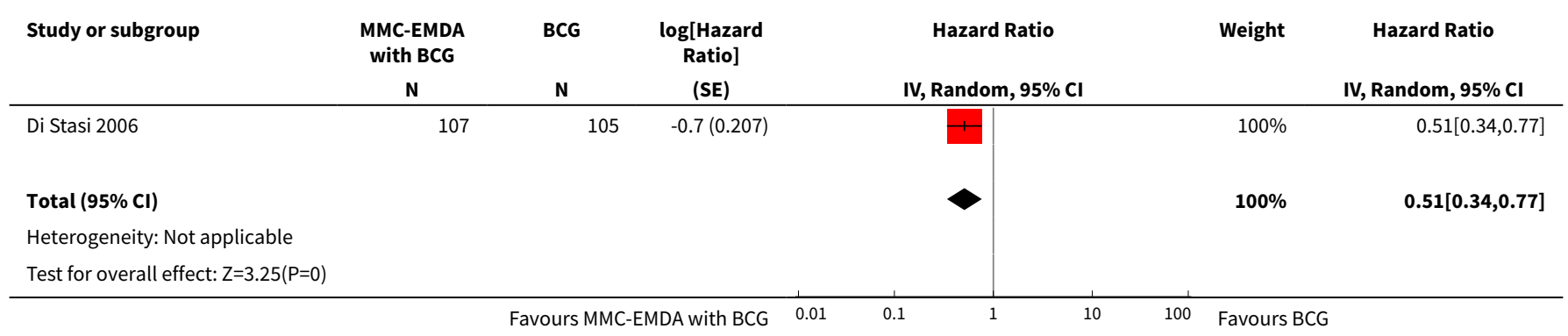

\section{Analysis 3.2. Comparison 3 Postoperative MMC-EMDA with sequential BCG induction and maintenance versus postoperative BCG induction and maintenance (long term), Outcome 2 Time to progression.}



Analysis 3.3. Comparison 3 Postoperative MMC-EMDA with sequential BCG induction and maintenance versus postoperative BCG induction and maintenance (long term), Outcome 3 Serious adverse events.






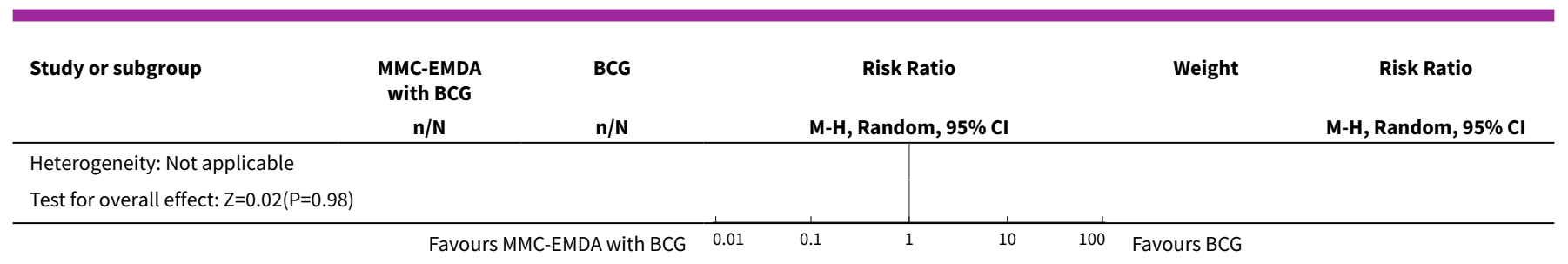

Analysis 3.4. Comparison 3 Postoperative MMC-EMDA with sequential BCG induction and maintenance versus postoperative BCG induction and maintenance (long term), Outcome 4 Disease-specific survival.

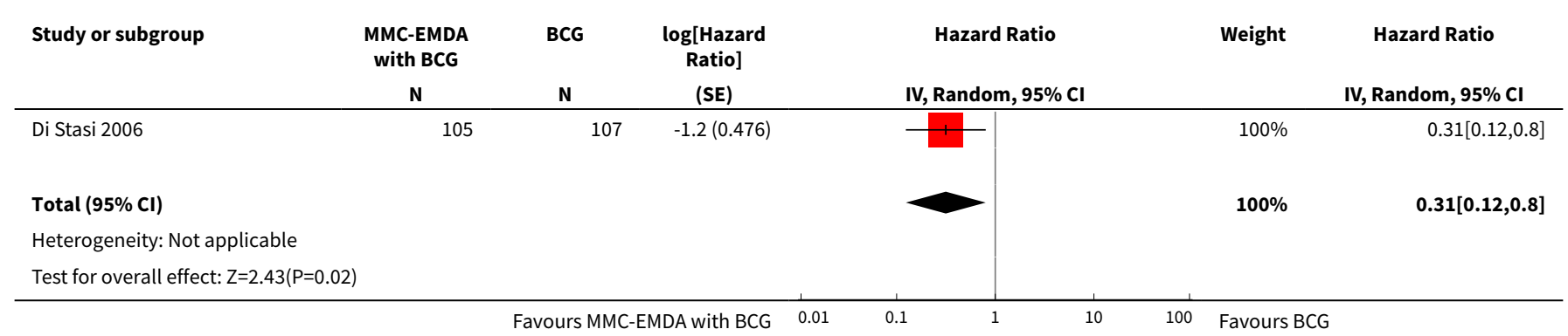

Analysis 3.5. Comparison 3 Postoperative MMC-EMDA with sequential BCG induction and maintenance versus postoperative BCG induction and maintenance (long term), Outcome 5 Time to death.

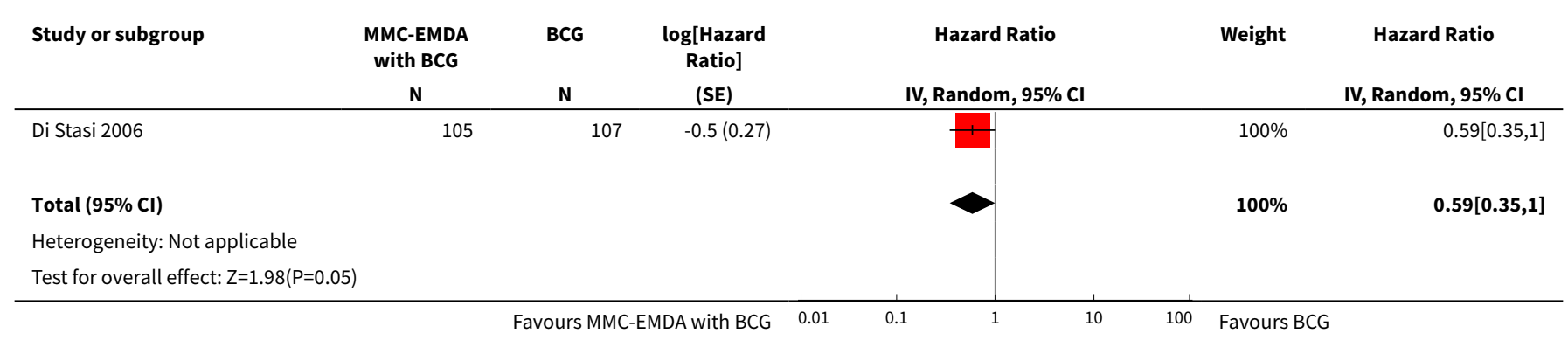

\section{Comparison 4. Single-dose, preoperative MMC-EMDA versus single-dose, postoperative MMC-PD (long term)}

\begin{tabular}{lllll}
\hline $\begin{array}{l}\text { Outcome or subgroup ti- } \\
\text { tle }\end{array}$ & No. of studies & $\begin{array}{l}\text { No. of partici- } \\
\text { pants }\end{array}$ & Statistical method & Effect size \\
\hline 1 Time to recurrence & 1 & 236 & Hazard Ratio (Random, 95\% Cl) & $0.47[0.32,0.69]$ \\
\hline 2 Time to progression & 1 & 236 & Hazard Ratio (Random, 95\% Cl) & $0.81[0.00,259.93]$ \\
\hline 3 Serious adverse events & 1 & 236 & Risk Ratio (M-H, Random, 95\% Cl) & $0.79[0.30,2.05]$ \\
\hline 4 Disease-specific survival & 1 & 236 & Hazard Ratio (Random, 95\% Cl) & $0.99[0.74,1.32]$ \\
\hline 5 Time to death & 1 & 236 & Hazard Ratio (Random, 95\% Cl) & $0.89[0.62,1.28]$ \\
\hline 6 Minor adverse events & 1 & 236 & Risk Ratio (M-H, Random, 95\% Cl) & $0.55[0.42,0.72]$ \\
\hline \hline
\end{tabular}


Analysis 4.1. Comparison 4 Single-dose, preoperative MMC-EMDA versus singledose, postoperative MMC-PD (long term), Outcome 1 Time to recurrence.

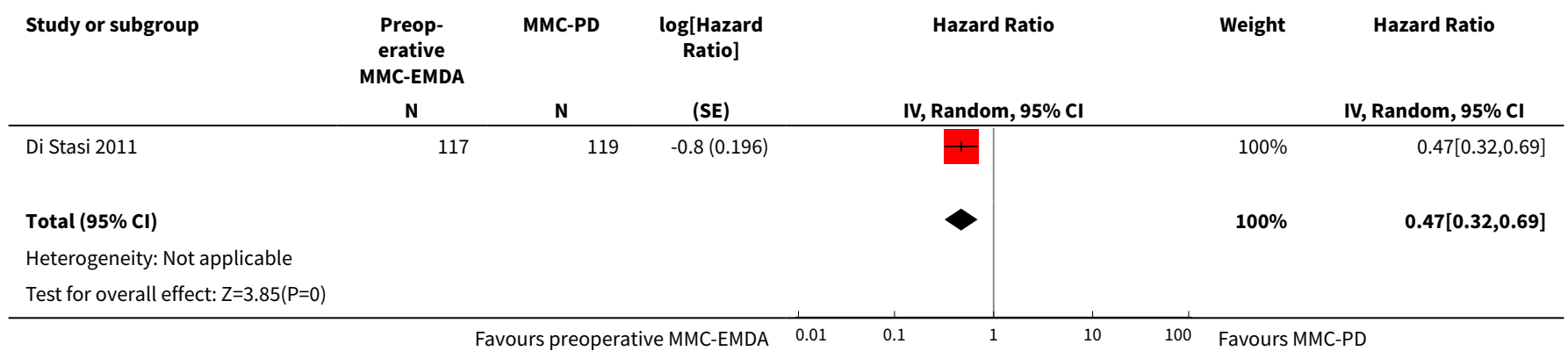

Analysis 4.2. Comparison 4 Single-dose, preoperative MMC-EMDA versus singledose, postoperative MMC-PD (long term), Outcome 2 Time to progression.

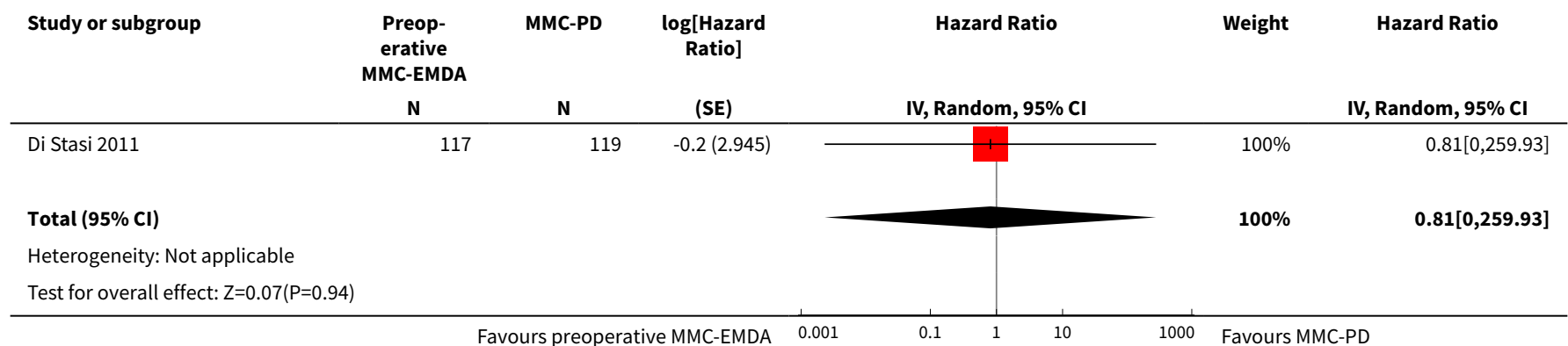

Analysis 4.3. Comparison 4 Single-dose, preoperative MMC-EMDA versus singledose, postoperative MMC-PD (long term), Outcome 3 Serious adverse events.

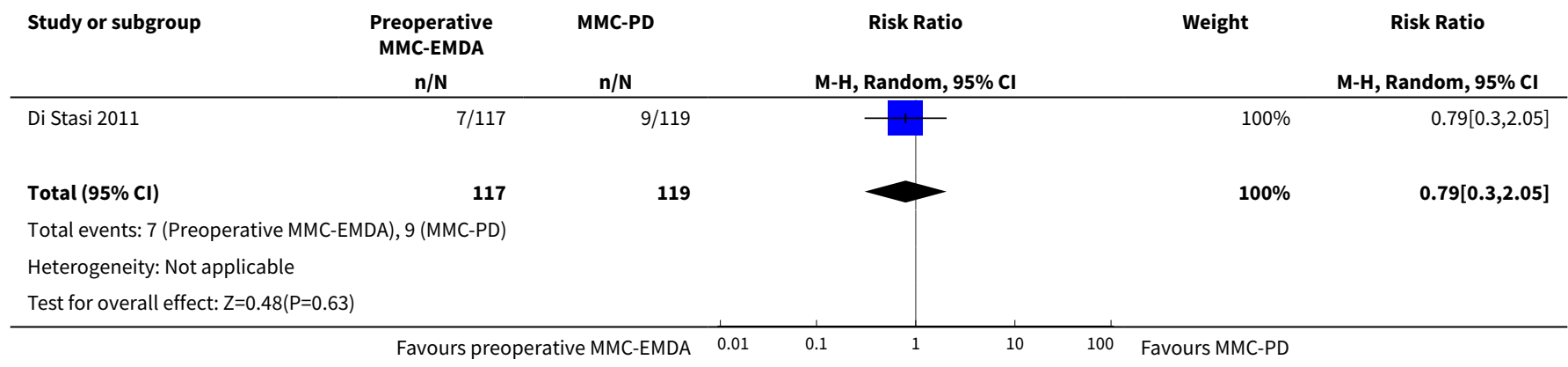


Analysis 4.4. Comparison 4 Single-dose, preoperative MMC-EMDA versus singledose, postoperative MMC-PD (long term), Outcome 4 Disease-specific survival.

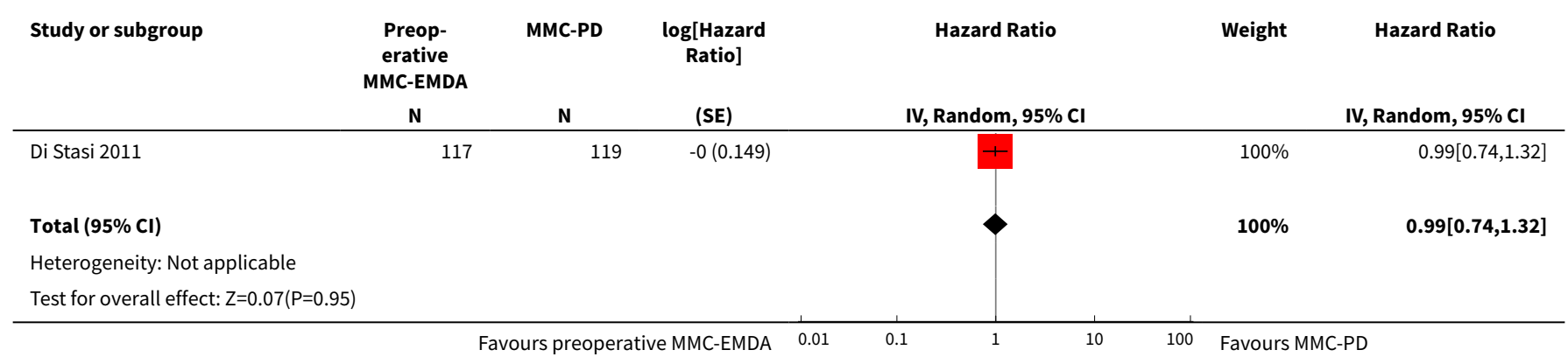

Analysis 4.5. Comparison 4 Single-dose, preoperative MMC-EMDA versus single-dose, postoperative MMC-PD (long term), Outcome 5 Time to death.

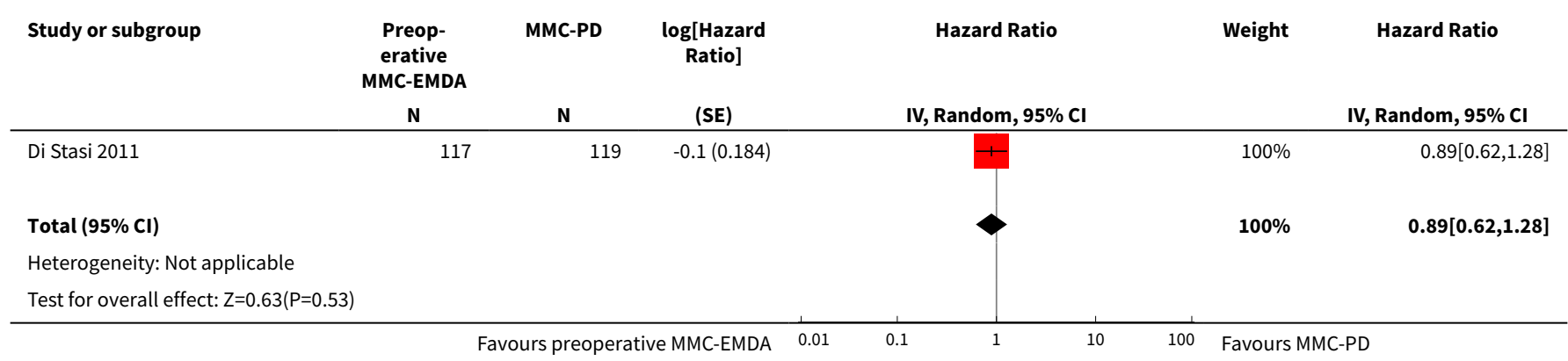

Analysis 4.6. Comparison 4 Single-dose, preoperative MMC-EMDA versus singledose, postoperative MMC-PD (long term), Outcome 6 Minor adverse events.

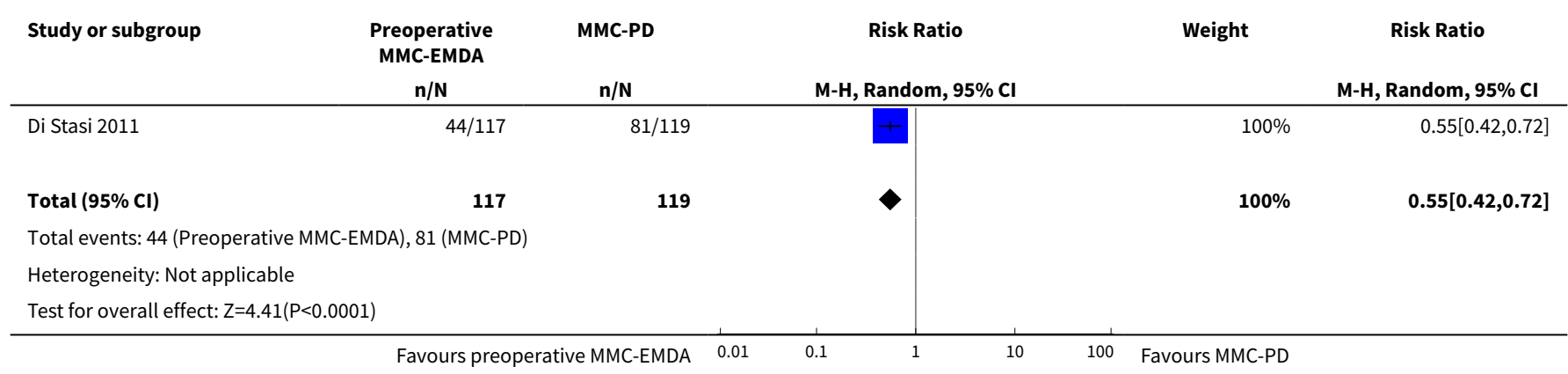

Comparison 5. Single-dose, preoperative MMC-EMDA versus TURBT alone (long term)

\begin{tabular}{lllll}
\hline $\begin{array}{l}\text { Outcome or subgroup ti- } \\
\text { tle }\end{array}$ & No. of studies & $\begin{array}{l}\text { No. of partici- } \\
\text { pants }\end{array}$ & Statistical method & Effect size \\
\hline 1 Time to recurrence & 1 & 233 & Hazard Ratio (Random, 95\% Cl) & $0.40[0.28,0.57]$ \\
\hline
\end{tabular}




\begin{tabular}{lllll}
\hline $\begin{array}{l}\text { Outcome or subgroup ti- } \\
\text { tle }\end{array}$ & No. of studies & $\begin{array}{l}\text { No. of partici- } \\
\text { pants }\end{array}$ & Statistical method & Effect size \\
\hline 2 Time to progression & 1 & 233 & Hazard Ratio (Random, 95\% Cl) & $0.74[0.00,247.93]$ \\
\hline 3 Serious adverse events & 1 & 233 & Risk Ratio (M-H, Random, 95\% Cl) & $1.74[0.52,5.77]$ \\
\hline 4 Disease-specific survival & 1 & 233 & Hazard Ratio (Random, 95\% Cl) & $1.06[0.80,1.40]$ \\
\hline 5 Time to death & 1 & 233 & Hazard Ratio (Random, 95\% Cl) & $1.07[0.73,1.57]$ \\
\hline 6 Minor adverse events & 1 & 233 & Risk Ratio (M-H, Random, 95\% Cl) & $1.68[1.11,2.53]$ \\
\hline
\end{tabular}

Analysis 5.1. Comparison 5 Single-dose, preoperative MMC-EMDA versus TURBT alone (long term), Outcome 1 Time to recurrence.

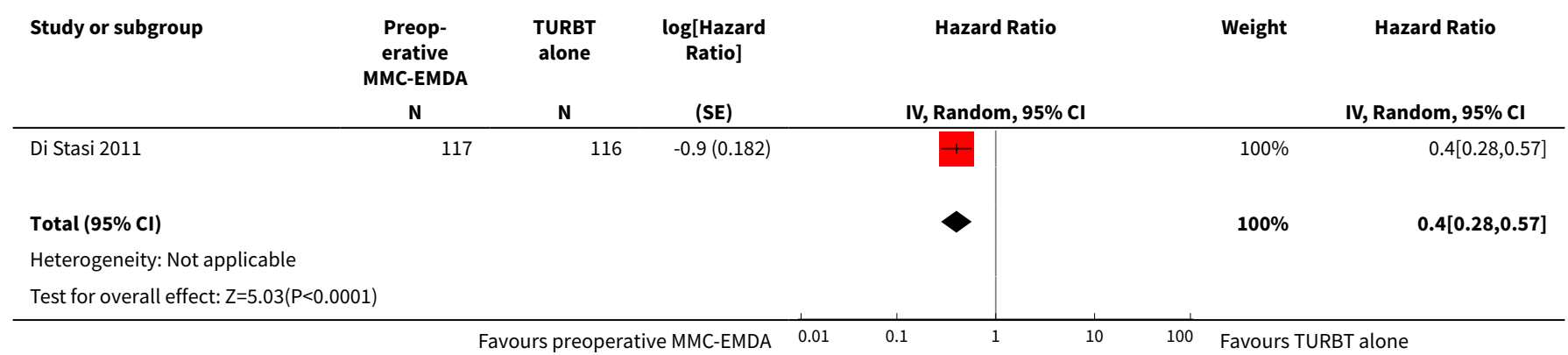

Analysis 5.2. Comparison 5 Single-dose, preoperative MMC-EMDA versus TURBT alone (long term), Outcome 2 Time to progression.

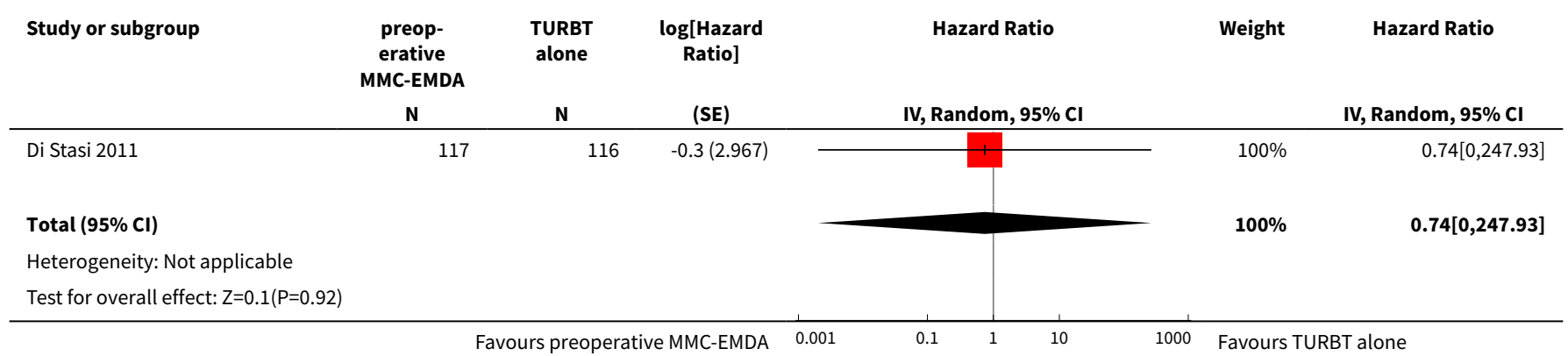

Analysis 5.3. Comparison 5 Single-dose, preoperative MMC-EMDA versus TURBT alone (long term), Outcome 3 Serious adverse events.

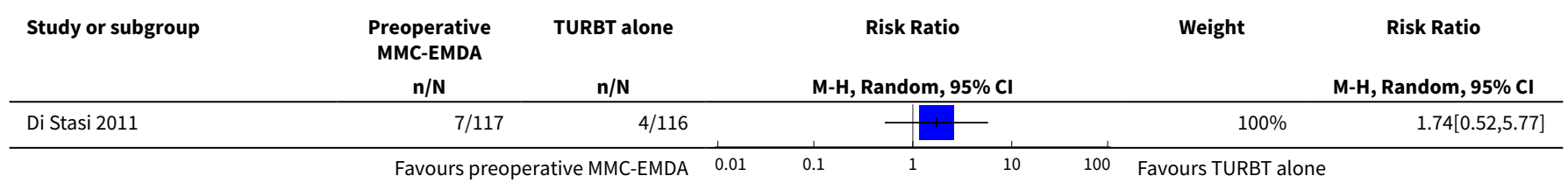




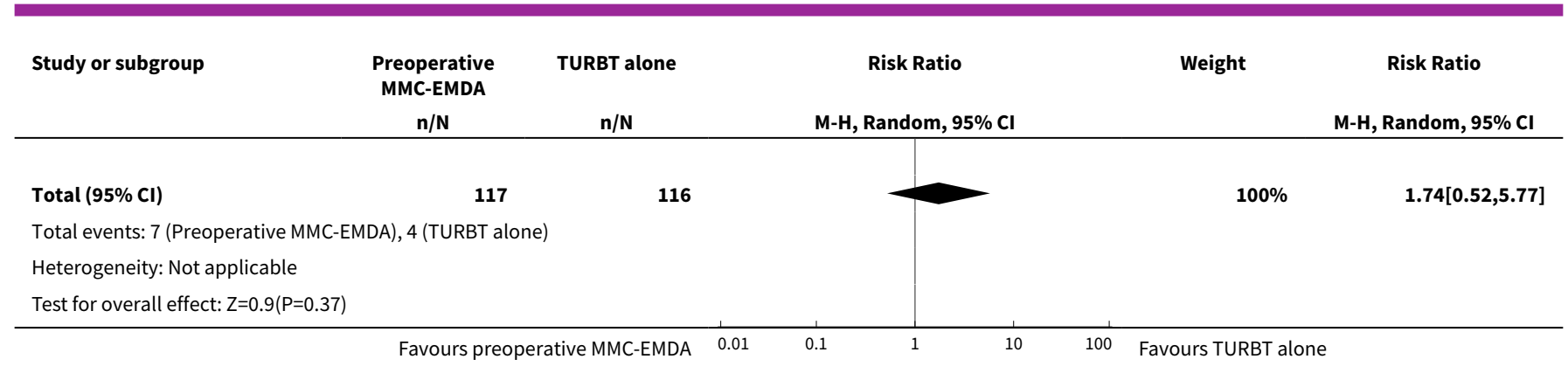

Analysis 5.4. Comparison 5 Single-dose, preoperative MMC-EMDA versus TURBT alone (long term), Outcome 4 Disease-specific survival.

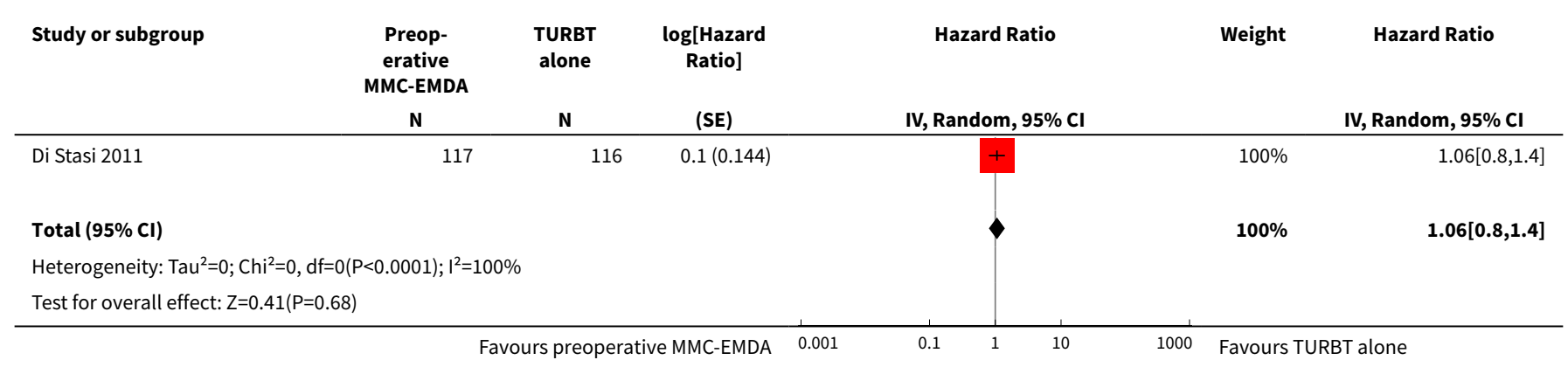

Analysis 5.5. Comparison 5 Single-dose, preoperative MMC-

EMDA versus TURBT alone (long term), Outcome 5 Time to death.

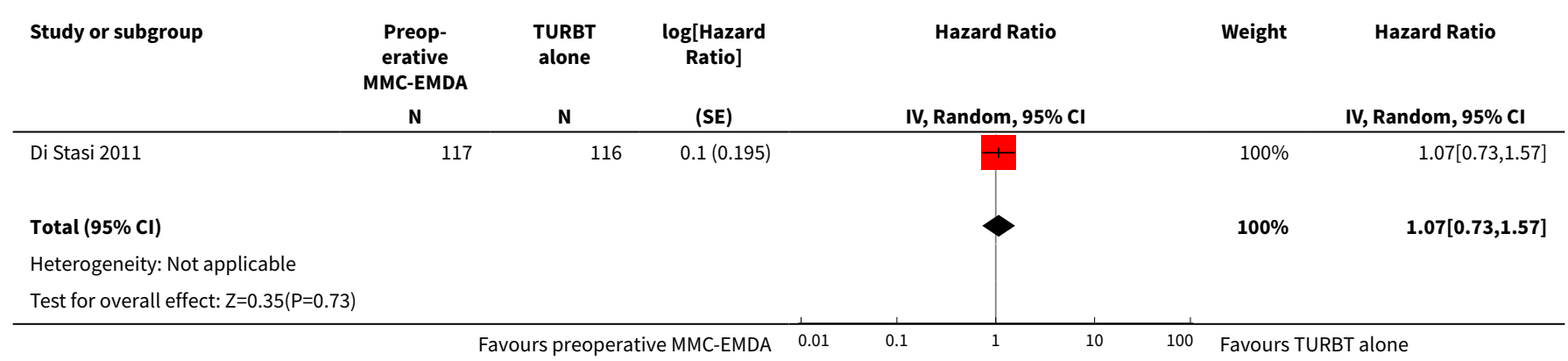

Analysis 5.6. Comparison 5 Single-dose, preoperative MMC-EMDA versus TURBT alone (long term), Outcome 6 Minor adverse events.

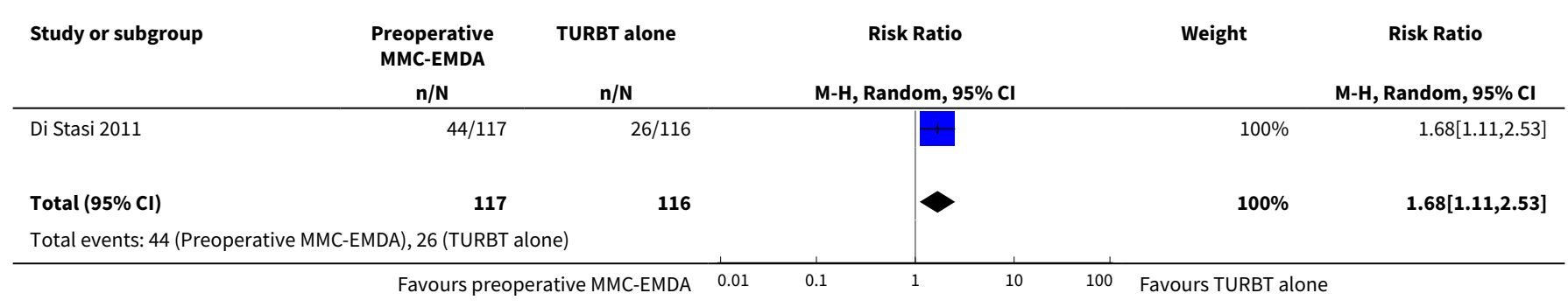




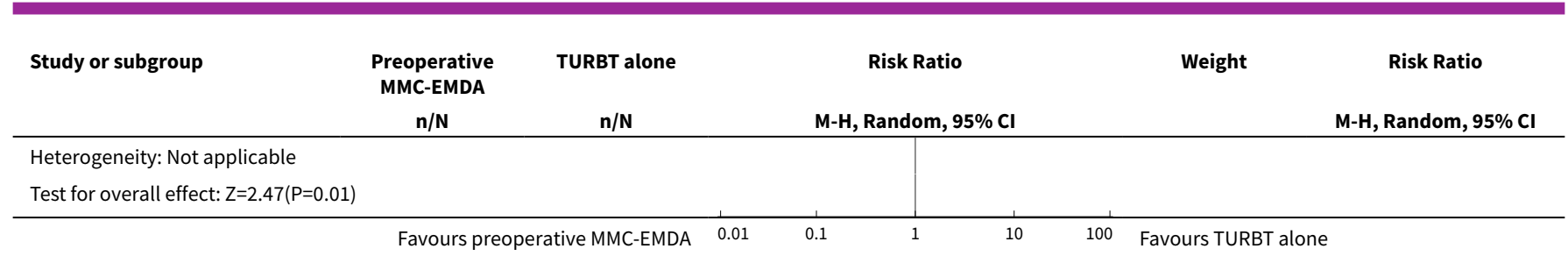




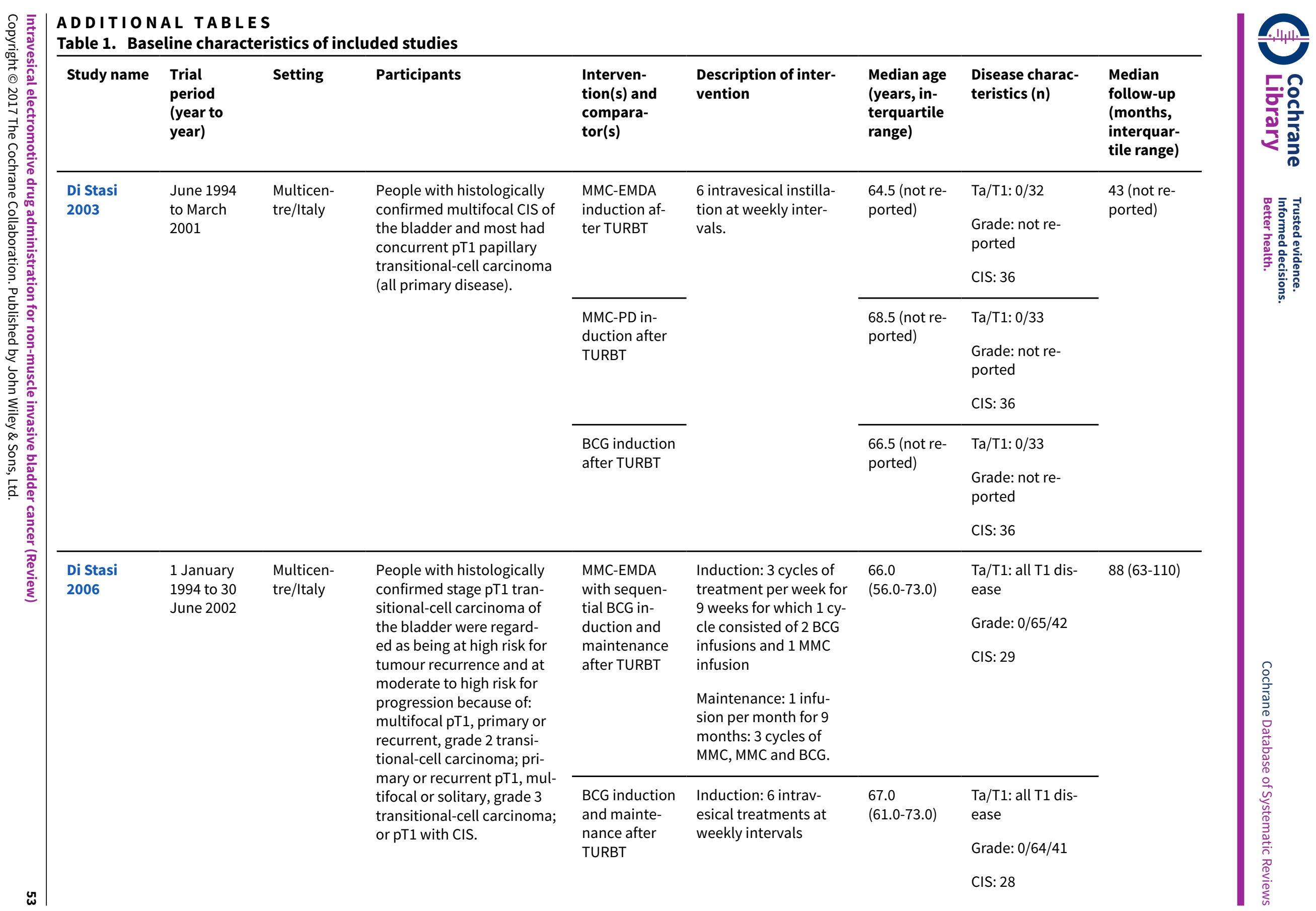




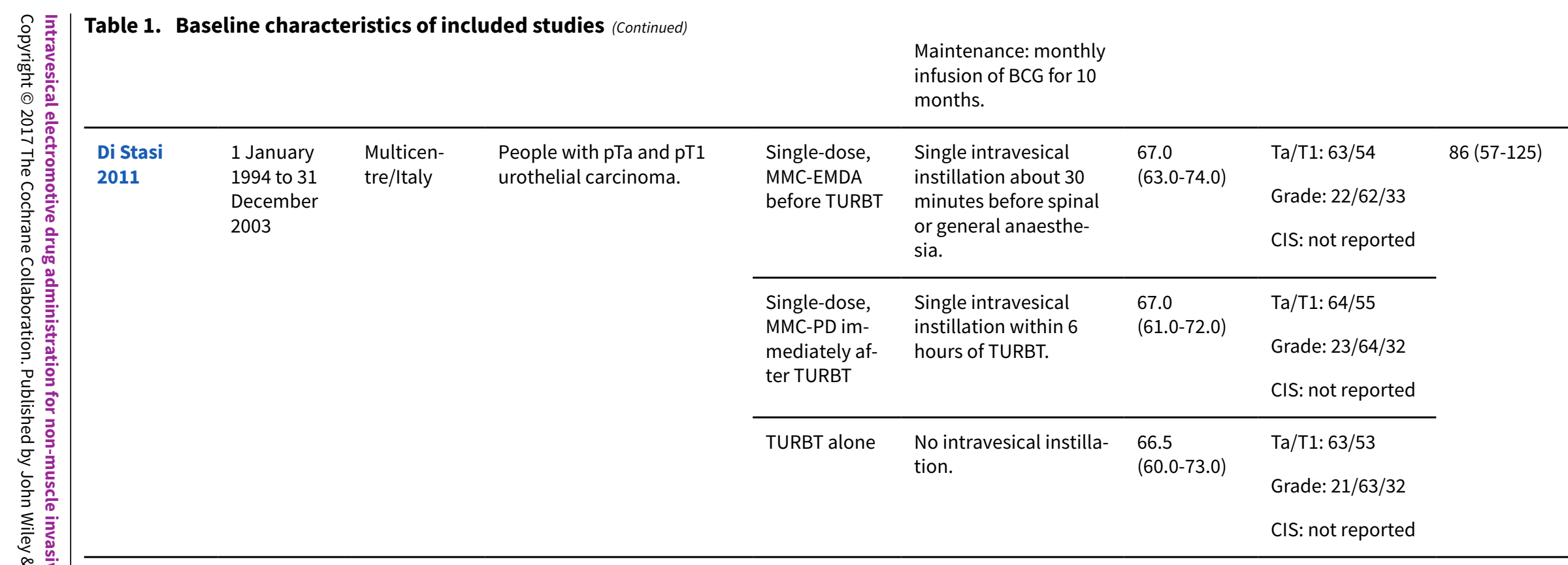

BCG: Bacillus Calmette-Guérin; CIS: carcinoma in situ; MMC-EMDA: electromotive drug administration of mitomycin C; MMC-PD: passive diffusion of mitomycin C; TURBT: transurethral resection of bladder tumour. 
Table 2. Participants' disposition of included studies

\begin{tabular}{|c|c|c|c|c|c|}
\hline Study name & Intervention(s) and comparator(s) & $\begin{array}{l}\text { Screened/eli- } \\
\text { gible }(\mathbf{n})\end{array}$ & $\begin{array}{l}\text { Randomised } \\
\text { (n) }\end{array}$ & $\begin{array}{l}\text { Treatment com- } \\
\text { pletion }(\mathrm{n}(\%))\end{array}$ & $\begin{array}{l}\text { Analysed ( } \mathbf{n} \\
(\%))\end{array}$ \\
\hline \multirow[t]{4}{*}{ Di Stasi 2003} & MMC-EMDA induction after TURBT & \multirow{3}{*}{$\begin{array}{l}\text { Not report- } \\
\text { ed } 1117\end{array}$} & 36 & $36(100)$ & $36(100)$ \\
\hline & MMC-PD induction after TURBT & & 36 & $36(100)$ & $36(100)$ \\
\hline & BCG induction after TURBT & & 36 & $36(100)$ & $36(100)$ \\
\hline & Total & & 108 & $108(100)$ & $108(100)$ \\
\hline \multirow[t]{3}{*}{ Di Stasi 2006} & $\begin{array}{l}\text { MMC-EMDA with sequential BCG induc- } \\
\text { tion and maintenance after TURBT }\end{array}$ & $241 / 212$ & 107 & $96(89)$ & $107(100)$ \\
\hline & $\begin{array}{l}\text { BCG induction and maintenance after } \\
\text { TURBT }\end{array}$ & & 105 & $94(89)$ & $105(100)$ \\
\hline & Total & & 212 & $190(89)$ & $212(100)$ \\
\hline \multirow[t]{4}{*}{ Di Stasi 2011} & Single-dose, MMC-EMDA before TURBT & $398 / 374$ & 124 & $117(94)$ & $117(94)$ \\
\hline & $\begin{array}{l}\text { Single-dose, MMC-PD immediately after } \\
\text { TURBT }\end{array}$ & & 126 & $119(94)$ & $119(94)$ \\
\hline & TURBT alone & & 124 & $116(93)$ & $116(93)$ \\
\hline & Total & & 374 & $352(94)$ & $352(94)$ \\
\hline Grand total & & & 694 & $650(93)$ & $672(96)$ \\
\hline
\end{tabular}

BCG: Bacillus Calmette-Guérin; MMC-EMDA: electromotive drug administration of mitomycin C; MMC-PD: passive diffusion of mitomycin C; $\mathrm{n}$ : number of participants; TURBT: transurethral resection of bladder tumour.

\section{A P PE N DICES}

\section{Appendix 1. CENTRAL search strategy}

1. electromotive mitomycin

2. EMDA

3. mitomycin

4. \#1 or \#2 or \#3

5. urinary bladder neoplasms

6. non-invasive bladder cancer

7. non-invasive bladder neoplasms

8. \#5 or \#6 or \#7

9. \#4 and \#8

\section{Appendix 2. MEDLINE search strategy}

1. randomized controlled trial (pt) 
2. controlled trial (pt)

3. randomized (tiab)

4. placebo (tiab)

5. drug therapy (sh)

6. randomly (tiab)

7. trial (tiab)

8. groups (tiab)

\section{1 OR 2 OR 3 OR 4 OR 5 OR 6 OR 7 OR 8}

10. bcg vaccine

11. gemcitabine

12. epirubicin

13. thiotepa

14. doxorubicin

15. 10 OR 11 OR 12 OR 13 OR 14

16. 9 AND 15

\section{EMDA}

18. Electromotive mitomycin

19. Electromotive mitomycin administration

\section{17 OR 18 OR 19}

21. urinary bladder neoplasms

22. non-invasive bladder neoplasms

23. non-invasive bladder cancer

24. 21 OR 22 OR 23

25. 16 AND 20 AND 24

\section{Appendix 3. EMBASE search strategy}

1. "intravesical drug administration"/

2. drug administration/

3. drug diffusion/

4. or/1-3

5. exp electric current/

6. exp electricity/

7. (electromotive or electro-motive or electric $\left.{ }^{\star}\right)$.tw.

8. or/5-7

9. 4 and 8

10. (intravesical adj3 (electric* or electro*)).mp. 
11. (electromotive drug administration or electro-motive drug administration or EMDA).mp.

12. 9 or 10 or 11

13. exp bladder tumor/

14. (bladder\$ adj3 (cancer\$ or carcinoma\$ or neoplas\$ or tumo? $\$$ )).mp.

15. 13 or 14

16. 12 and 15

17. Crossover Procedure/

18. double-blind procedure/

19. randomized controlled trial/

20. single-blind procedure/

21. (random\$ or factorial\$ or crossover\$ or cross over\$ or placebo $\$$ or assign $\$$ or allocat\$ or volunteer\$).mp.

22. ((doubl\$ or singl\$) adj blind\$).mp.

23. or $/ 17-22$

24. 16 and 23

\section{Appendix 4. ClinicalTrials.gov}

bladder cancer OR bladder neoplasms AND Electromotive mitomycin OR mitomycin OR EMDA

\section{Appendix 5. World Health Organization International Clinical Trials Registry Platform Search Portal}

bladder cancer OR bladder neoplasms AND Electromotive mitomycin OR mitomycin OR EMDA

\section{CONTRIBUTIONS OF AUTHORS}

$\mathrm{JHJ}$ : study selection, extracting data, assessing risk of bias, performing data analysis, interpretation of data and drafting review.

AG: drafting the protocol and review, searching for trials, study selection and extracting data.

HK: searching for trials and study selection.

GMK: creating search strategies and search for trials.

AM: assessing risk of bias, providing general advice on the review, critical content review and final approval.

BK: providing critical content review and final approval.

PD: assessing risk of bias, interpretation of data, methodological/clinical advice on the review and final approval.

\section{DECLARATIONSOF INTEREST}

JHJ: none known.

AG: none known.

HK: none known.

GMK: none known.

AM: none known.

BK: none known.

PD: none known. 


\section{SOURCES OF SUPPORT}

\section{Internal sources}

- Minneapolis VA Health Care System, USA.

- University of Minnesota Department of Urology, USA.

\section{External sources}

- No sources of support supplied

\section{DIFFERENCES BETWEEN PROTOCOL AND REVIEW}

- Types of interventions: we added TURBT without intravesical instillation as a comparator.

- Types of outcome measures: we renamed primary and secondary outcomes and added details in the 'Methods' section to describe the measurement of all outcomes.

- Selection of studies, data extraction and management, assessment of risk of bias in included studies, dealing with missing data, assessment of heterogeneity, data synthesis, summary of findings table for each comparison: we updated these sections to use the current standard template language of Cochrane Urology.

- Data extraction and management: we added a section 'Dealing with duplicate and companion publications.'

- Assessment of risk of bias in included studies: we redefined subjective and objective outcomes according to current methodological expectations by Cochrane Urology.

- We rated the QoE for all outcomes (not only those included in the SoF)

\section{INDEX TERMS}

\section{Medical Subject Headings (MeSH)}

Administration, Intravesical; Antibiotics, Antineoplastic [ ${ }^{*}$ administration \& dosage]; BCG Vaccine [administration \& dosage]; Carcinoma in Situ [ ${ }^{\star}$ drug therapy] [mortality] [pathology]; Carcinoma, Transitional Cell [ ${ }^{\star}$ drug therapy] [mortality] [pathology]; Disease Progression; Electrochemotherapy [adverse effects] [*methods]; Mitomycin [ ${ }^{*}$ administration \& dosage]; Neoplasm Recurrence, Local; Randomized Controlled Trials as Topic; Time Factors; Urinary Bladder Neoplasms [^drug therapy] [mortality] [pathology]

\section{MeSH check words}

Humans 